\title{
THE "CREATIVE WORKSPACE": A COMPARATIVE ANALYSIS OF STAKEHOLDER PERCEPTIONS
}

\author{
A Thesis \\ presented to \\ the Faculty of California Polytechnic State University, \\ San Luis Obispo
}

In Partial Fulfillment

of the Requirements for the Degree

Master of Science in Architecture

by

Augustina Radziunaite

July 2016 
(c) 2016

Augustina Radziunaite

ALL RIGHTS RESERVED 


\section{COMMITTEE MEMBERSHIP}

TITLE: $\quad$ The "Creative Workspace": A Comparative Analysis

of Stakeholder Perceptions

AUTHOR: $\quad$ Augustina Radziunaite

DATE SUBMITTED: July 2016

COMMITTEE CHAIR: Umut Toker, Ph.D.

Associate Professor of College of Architecture and Environmental Design

COMMITTEE MEMBER: Doug Jackson, M.Arch.

Associate Professor of College of Architecture and Environmental Design

COMMITTEE MEMBER: Dale Clifford, M.S.

Assistant Professor of College of Architecture and Environmental Design 


\section{ABSTRACT \\ The "Creative Workspace": A Comparative Analysis \\ of Stakeholder Perceptions}

Augustina Radziunaite

The rise of information technologies and creative industries formed a new class of "creative knowledge workers" with special needs for a workspace design. The recent tendency of playful and bold workspace designs for creative industries was labeled by some researchers as a "creative workspace," but a body of knowledge about design strategies supporting "creative knowledge workers"' performance is still limited.

This master's thesis research attempts to define "creative workspace" design phenomenon based on the three main stakeholder groups' perceptions. The research analyzes existing literature and conducts in-depth interviews with designers and users to collect the data and compare the findings. Based on the findings, research proposes an interactive exploratory design game helping to easier communicated spatial ideas related to the "creative workspace" design.

Keywords: "creative workspace," perceptions, comparative analysis, exploratory design game 


\section{ACKNOWLEDGMENTS}

First of all, I would like to thank my thesis committee chair Prof. Umut Toker for the academic support in developing a research and writing the thesis. It has been a true pleasure and honor to work under his supervision.

Also, I would like to thank the rest of my committee: Prof. Doug Jackson and Prof. Dale Clifford for making it possible to fulfill thesis requirements and helping in the development of the design part.

Additionally, I would like to express my thanks to the faculty and staff of the Architecture department, CAED workshop managers and dFab staff for their thorough help in troubleshooting every possible issue related to the research or design parts.

Furthermore, I want to thank to all of my interviewees that made my research possible and were very detailed in their answers. Not only did it add an extra layer to my study, but also taught me a lot of interesting things about the industry.

Special thanks go to my visa sponsors and Fulbright scholarship providers Institute of International Education (IIE) - that made this academic journey possible. Especially, I want to express my gratitude to my visa coordinator Ms. Laurie Stevens.

Last but not least, I would like to thank my family and friends for the moral support, loose leave tea, chocolate bars, hugs, skype calls and other necessary distractions that helped me to maintain my focus. 


\section{TABLE OF CONTENTS}

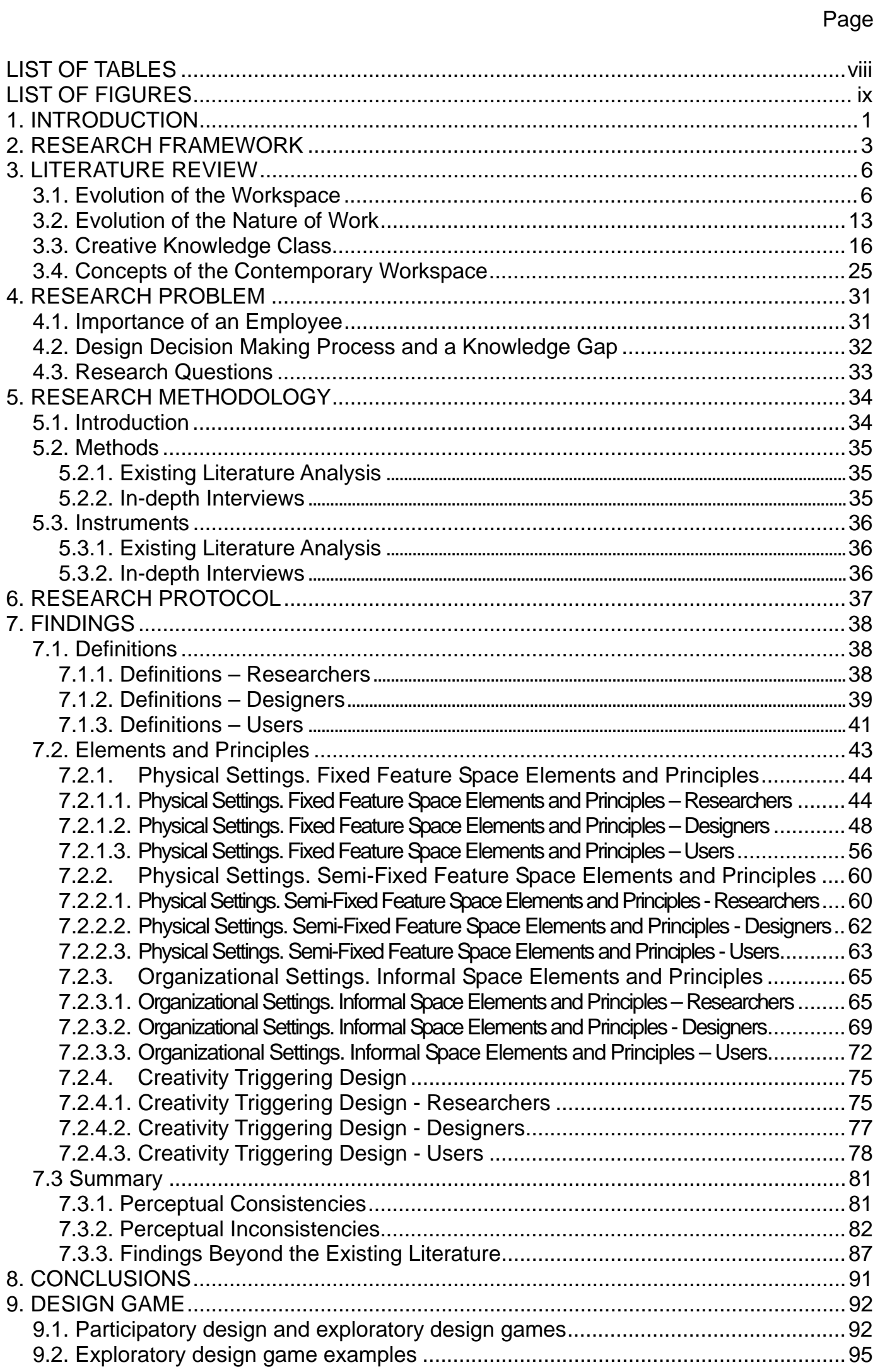


9.2.1. Concept Design Game ....................................................................................................95

9.2.2. Nurses' and patients' participatory workshops ..............................................................95

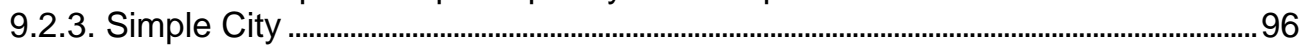

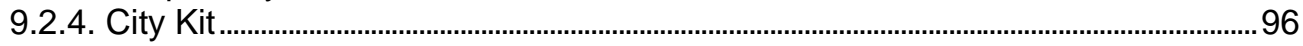

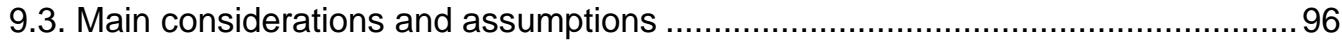

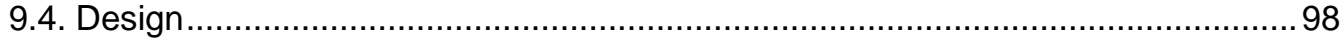

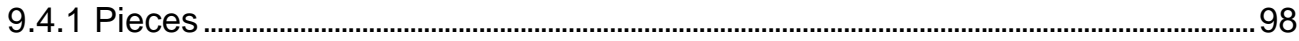

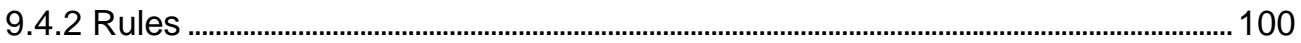

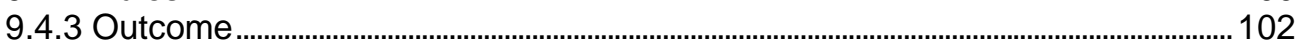

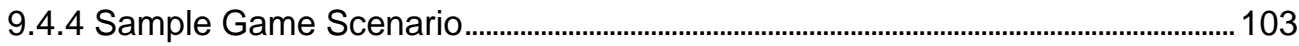

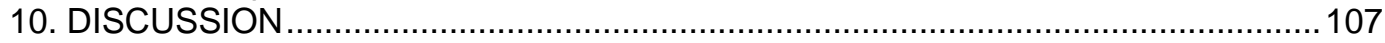

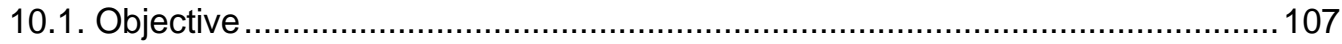

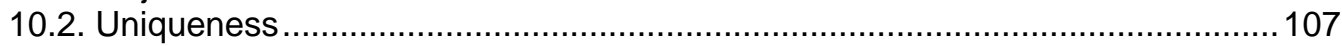

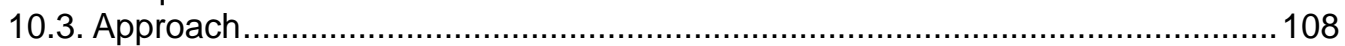

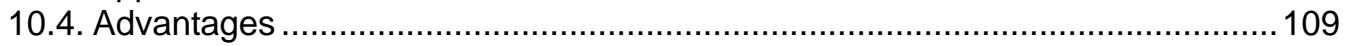

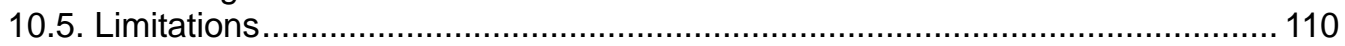

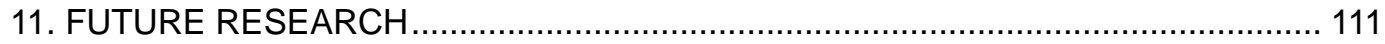

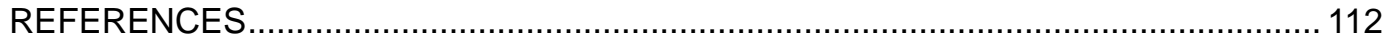




\section{LIST OF TABLES}

Table

Page

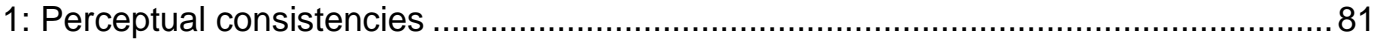

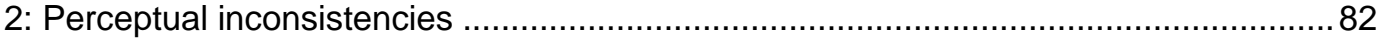

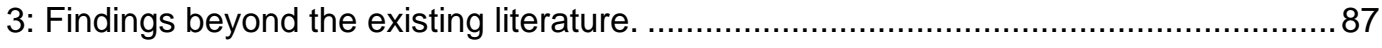




\section{LIST OF FIGURES}

Figure

Page

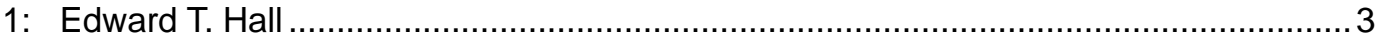

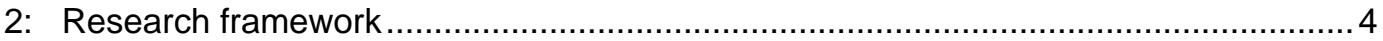

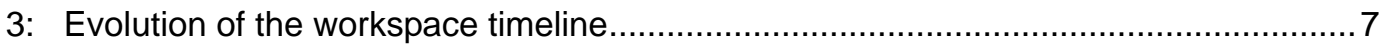

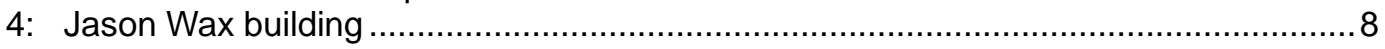

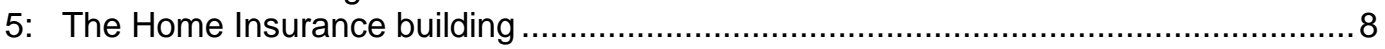

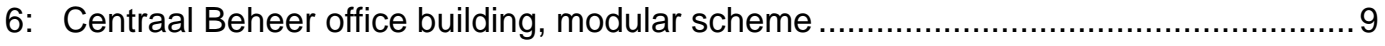

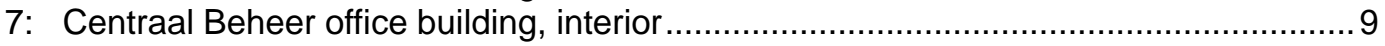

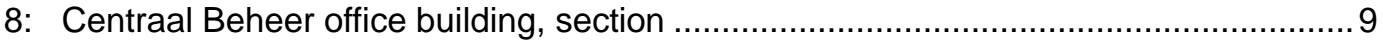

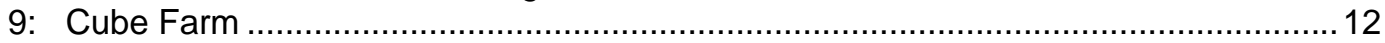

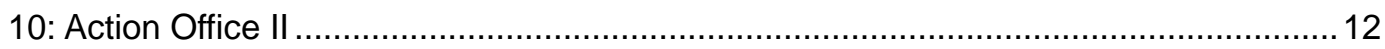

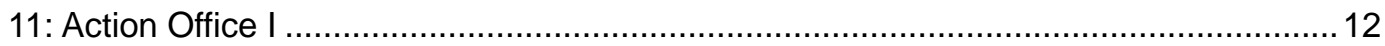

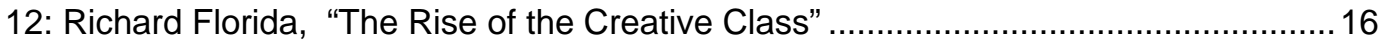

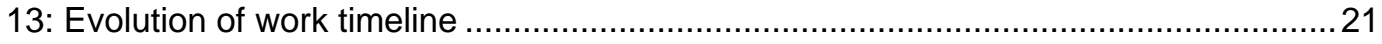

14: Modelling the cultural and creative industries; United Nations Creative Economy Report...23

15: Top innovator countries in high-income group; The Global Innovation Index 2015 ....23

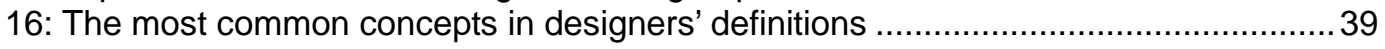

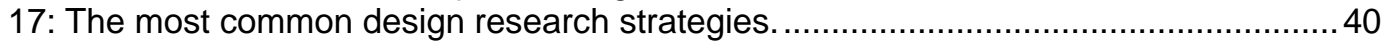

18: The most common concepts in users' definitions. .................................................. 41

19: "Creative workspace" user definitions ............................................................. 42

20: "Creative workspace" definitions in relation to identified activities.............................4 43

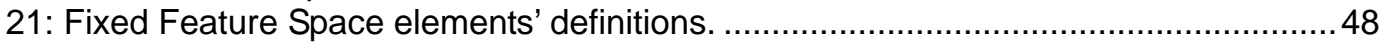

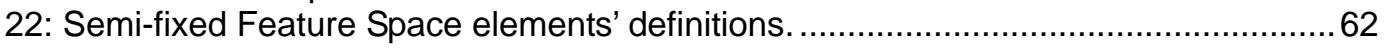

23: A range of different spaces for different levels of collaboration ................................6 65

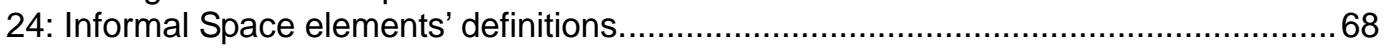

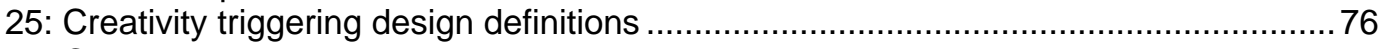

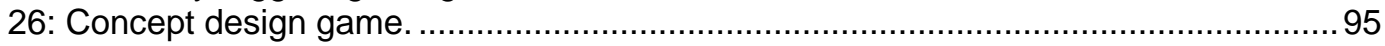

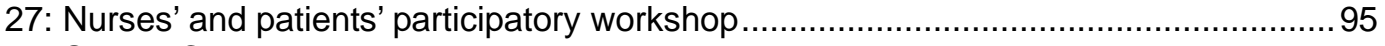

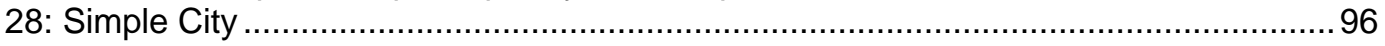

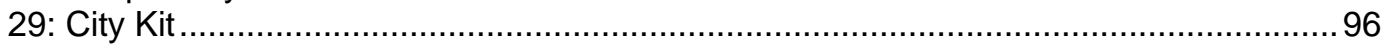

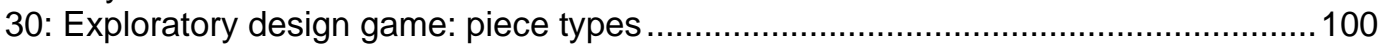

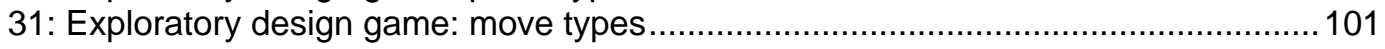

32: Sample game scenario. Player 1. Move 1.................................................... 103

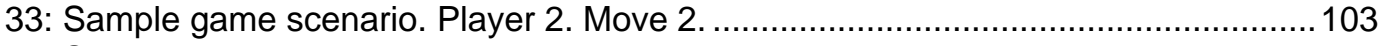

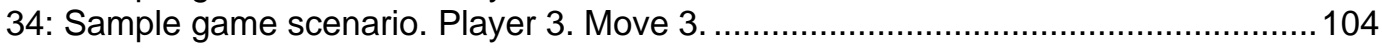

35: Sample game scenario. Player 4. Move 4 …................................................ 104

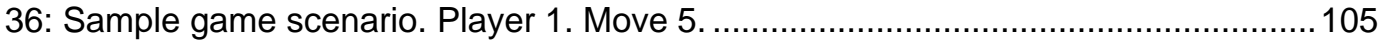

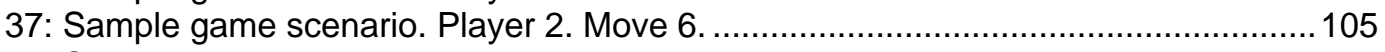

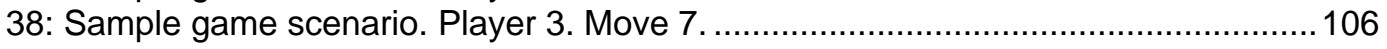




\section{INTRODUCTION}

In the last two centuries the way we work has evolved. The shift from the industrial age, with an emphasis on production of goods, to the service-based economy in the 1930s was followed by the formation of a "knowledge economy" with an emphasis on information process in 1960s and growing importance of "creative industries," with the production of new and original data in the late 1990s. The changing nature of work resulted in changing requirements for the workforce, and hence changing needs for the workspace.

The rise of information technologies in the 1980s and the formation of "creative industries" - a separate economic segment dedicated to creative production - has caused the formation of a completely new social group, which R.Florida referred to as the "creative class" (Florida, 2012). Other sources attributed creative work function to "knowledge workers" (Megill, 2005; Duffy, Laing, Crisp, 1993; Dul et al. 2011) or started using a blended term "creative knowledge workers" (Nadler, 2014). Florida (2012) was analyzing the factors that positively contributed to creative work patterns or innovation. He was also interested in creative workers' migration patterns and what physical setting features are attractive and influential for such migration.

Since the year 2000, IT companies have been trying to push for a more creative, innovative office design and to find the "next big thing" to adapt to changing markets and labor competition (Cagnol, R. 2013). The term "creative workspace" became a buzz word, attracting key young talents to the main technology and other "creative knowledge industry" related companies. It has also become a stereotype of playful and unique work environments, disguising the main function and purpose of the space, making users believe that the only reason they are there is to play. Slides connecting different floors, ping pong tables, free food, recreational facilities and any amenities an employee might need or find entertaining are incorporated in "creative workspace" design. All this effort immerses the user by blurring division between work and life. 
Despite all of these economic, academic and design trends, the term "creative workspace" has not been broadly discussed or even described in the existing academic sources. The literature that the researcher found in relation to "creative workspace" topic elaborate on the changes in the nature of work, analyze the evolution of the workforce, pinpoint "creative knowledge workers" needs and discusses general workspace design tendencies, but does not indicate and explore a new spatial construct.

This research thesis attempts to define the "creative workspace" and to identify its specific spatial characteristics by comparing perceptions of three main stakeholder groups: Researchers, Designers and Users. The data is gathered from existing literature and in-depth interviews with "creative workspace" Designers and Users. Collected data is then coded and sorted in a selected spatial framework for an ease of comparison in processing the results.

The research findings reveal certain perceptual inconsistencies between the different stakeholders and knowledge gaps in the existing literature. In response, the research presents an exploratory design game proposal to improve communication between all three stakeholder groups and enable more accurate and efficient "creative workspace" design solutions. 


\section{RESEARCH FRAMEWORK}

A workspace is a complicated environment to analyze. It is composed of tangible elements and physical environments of architectural surfaces, structural frames, movable divisions, furniture and technological appliances. It also holds less tangible visual and phonic elements in space and outside of it that might either stimulate the imagination,

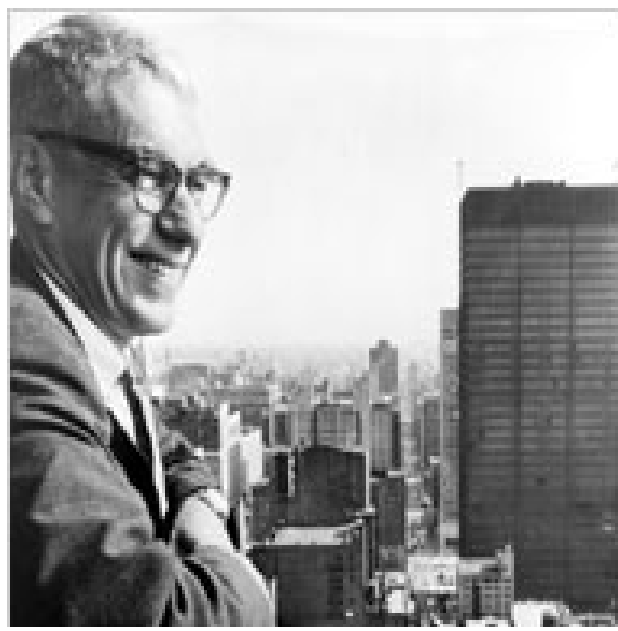

Figure 1: Edward T. Hall distract or, on the contrary, help one to concentrate. Finally, the workspace is shaped by inter-human relationships, the level of demographic diversity, hierarchical or organizational structures and different work modes.

Following Edward T. Hall's (Hall, E., 1966) conceptual framework, a physical setting can be analyzed on three levels: Fixed Feature Space, Semi-fixed Feature Space and Informal Space. Fixed Feature Space is formed by spatial arrangements perceived as immovable, and implies certain social and functional patterns. As the author states, it is "the mold into which a great deal of behavior is cast." In the context of the workspace it may include, but is not limited to: geographic location, structural, engineering and architectural design, building materiality, functional layout and floor zoning. 


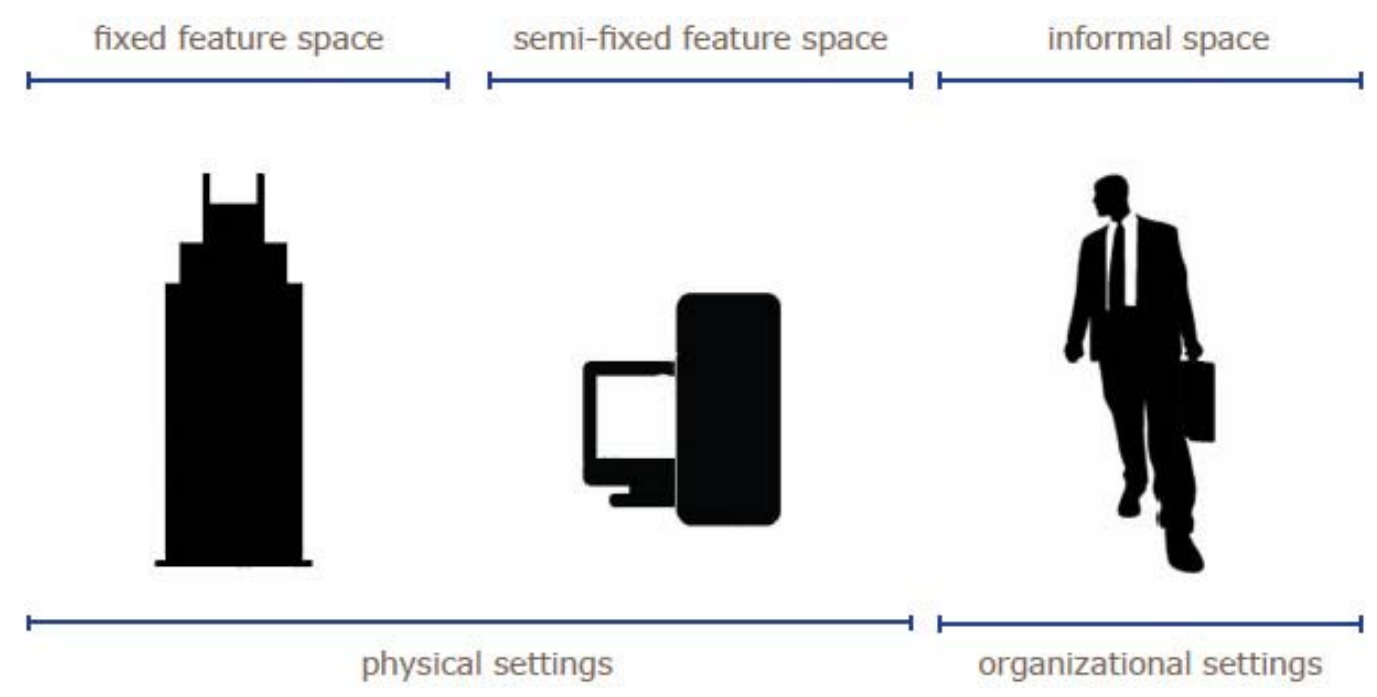

Figure 2: Research framework

Semi-fixed Feature Space is defined by movable parts of physical arrangement that influence human interactions and functions on a smaller scale. The intentional placement of certain elements such as furniture, movable partitions, technological appliances, light and sound fixtures creates "a variety of spaces, and people can be involved or not, as the occasion and mood demand" (Hall, E., 1966).

The last level of analysis - Informal Space - is related to inter-human relationships, social norms, demographic diversity, hierarchy, organizational systems and acceptable physical distances. It has a lot to do with business etiquette as well as every company's internal values. Controlling Informal Space is important because it has a direct impact on different work, modes and thus to the professional achievements.

These three types of spaces form internalized as well as externalized patterns that influence every workers' perception and performance. The first two levels of the framework refer to a physical environment that users experience with their senses, visual often being the main one. Therefore, Fixed Feature Space and Semi-Fixed Feature Space elements were grouped under the "Physical Settings" name. On the other hand, Informal Space elements represent an intangible side of a workplace and work process patterns and were subdivided as a part of "Organizational Settings." Despite the differing 
nature of all three levels of analysis, the elements within the different categories are interrelated and codependent.

The objective of this research is to study to what extent Fixed Feature Space and Semi-Fixed Feature Space elements positively contribute to the intangible outcomes of Informal Space, taking into account workers comfort, performance, health and specific professional needs related to creative performance. 


\section{LITERATURE REVIEW}

\subsection{EVOLUTION OF THE WORKSPACE}

The elements of workspace physical setting have mainly evolved during the last two centuries. The shift from the production of goods to the service industry was a critical point in workspace evolution. New types of complex business activities required more sophisticated settings and managerial systems to enhance employees' performance. Fixed Feature and Semi-fixed Feature Space elements greatly contributed to the interface of the current work space.

The routes of workspace design lie in early thirteenth century when the intellectual production that was previously attributed primarily to the religious world began to be a significant part of science and commerce. Traders, engineers and artists began to utilize the worktable to perform their work tasks (Cagnol, R. 2013).

Essential changes in workspace design started in the very beginning of the 20th century. "Scientific management" principles developed by Frederic Winslow Taylor led to the industrial Fordism model adopted by non-industrial businesses (On the Job: Design and the American Office, 2000, Cagnol, R., 2013). Initially Fordism was pioneered by Ford Motor Company and hence named after Henry Ford. This new work model for industrial settings promoted the concept of breaking down labor processes into detailed tasks to improve efficiency. This new way of work had a huge influence on architectural as well as interior design. Fordism became a dominant industrial model for fast growing market 


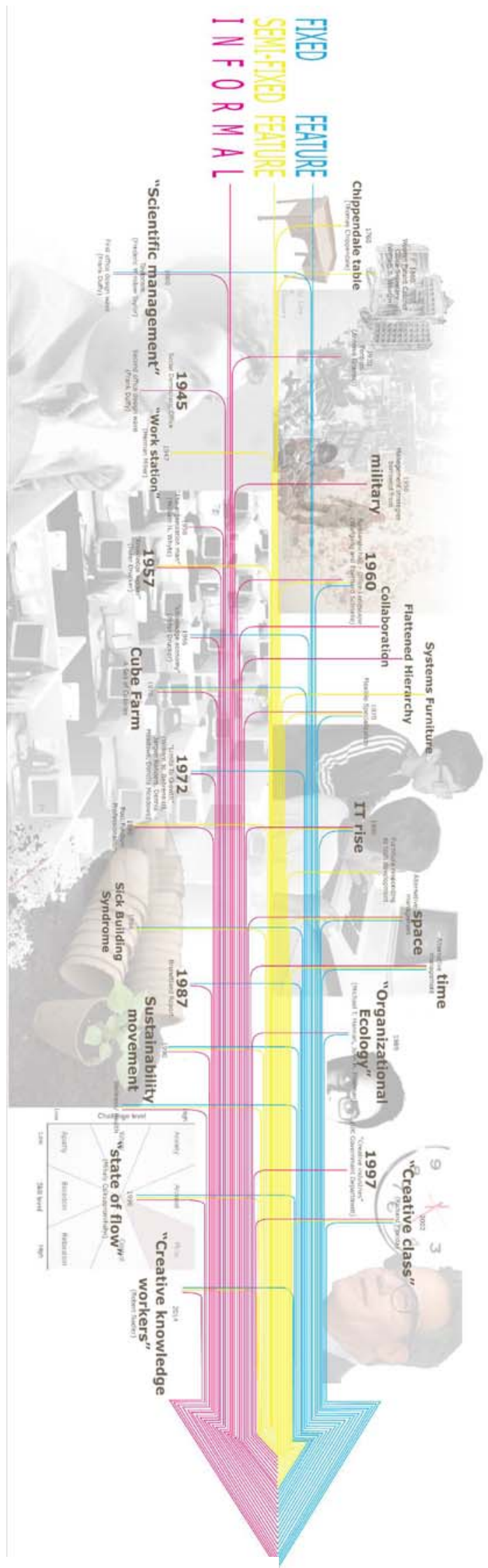

Figure 3: Evolution of the workspace timeline 
economies. At the same time, the shift from goods production to services started rapidly changing business concepts, resulting in the formation of a new "white collar" class, and also placed a demand for new infrastructure and workspace arrangements (Myerson, Bichard, Erlich, 2010; On the Job: Design and the American Office, 2000). Moreover, it had spatial implications, suggesting that spaces should be designed for efficient production by focusing on economical movement rather than on intangible qualities.

These changes were best reflected in The Home Insurance Building built in Chicago in 1885, which happened to be the first tall building to use structural steel or, in other words, the first skyscraper in the world. It was then followed by the Larkin Administration Building, designed in 1904 by Frank Lloyd Wright which was able to welcome more than 1800 workers. These buildings showcased design innovations such as air conditioning, furniture absorbing noise and custom furnishings such as a rolling chair (Cagnol, R. 2013).

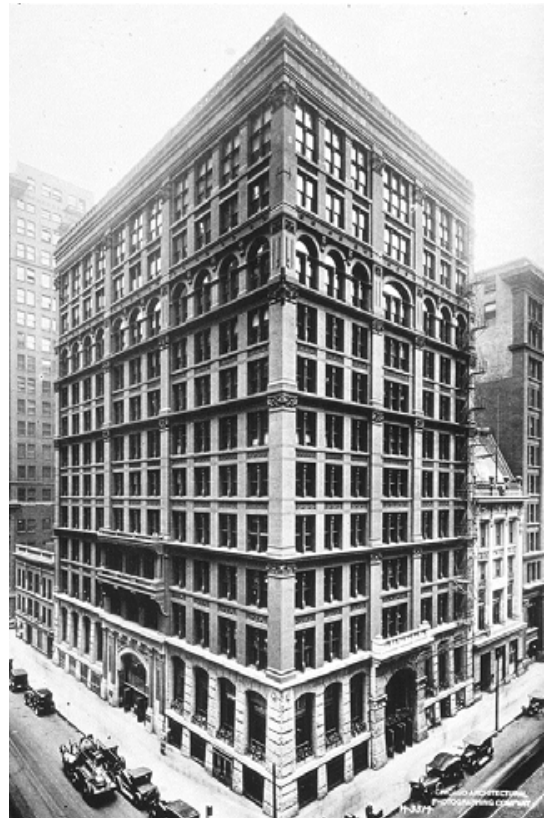

Figure 5: The Home Insurance building

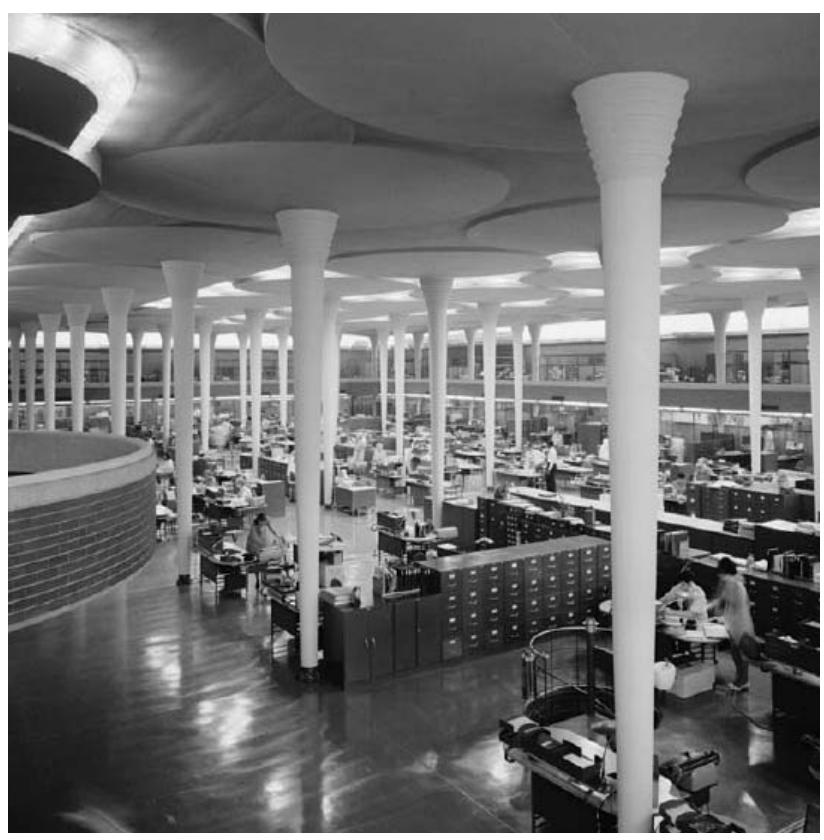

Figure 4: Jason Wax building 
In the 1930s expressing identity became another important concern for the companies. Following this need, Frank Lloyd Wright in 1939 designed the Johnson Wax building, that represented popular design tendencies of the time. It resulted in employees becoming proud of their business and thus improving their productivity. The architecture also reflected the strong organizational hierarchy (Cagnol, R. 2013).

The next big change happened in the post-war period during the mid-1950s. Modern architecture had a much lighter aesthetic expression. Steel structures made out of leftover military resources were a physical statement of a strict hierarchical organization transition into work environment (On the Job: Design and the American Office, 2000).

In the subsequent decades a new spatial tendency arose in Europe. In 1960 Wolfgang and Eberhard Schnelle developed a new concept for workspace design called "burolandschaft" or "office landscaping." The initial intention was to promote teamwork and collaboration with new arrangements designed to fit patterns of communication, informal layouts, environmental psychology, staff satisfaction and performance, open space, flexible furniture, rising equity and diminishing hierarchy. Herman Hertzberger created the Centraal Beheer insurance company building in 1974. The space intended that the occupants "would have the feeling of being part of a working community without being lost in the crowd." The space was flexible and consisted of small workspaces connected to one another. These clusters were built repeatedly throughout the space to accommodate groups of ten people, who were encouraged to decorate their workspace themselves, including adding their own furniture. (Cagnol, R. 2013).

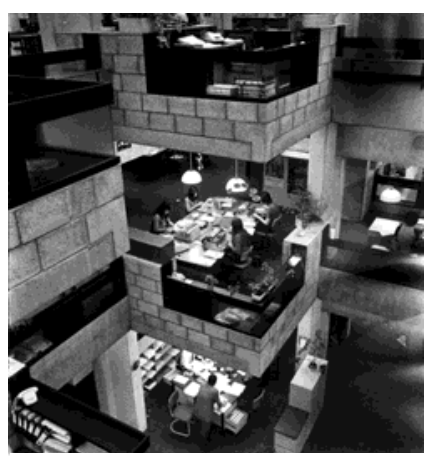

Figure 7: Centraal Beheer office building, interior

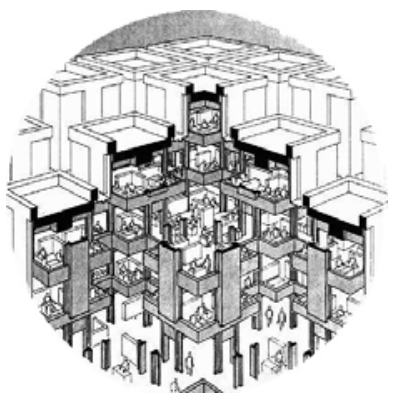

Figure 8: Centraal Beheer office building, section

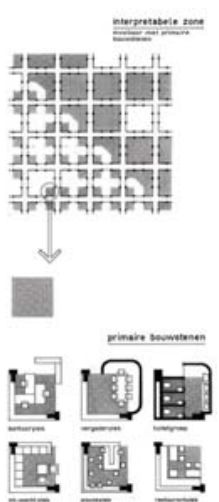

Figure 6: Centraal Beheer office building, modular scheme 
Having less partitions also improved the use of space, and that was the main advantage that American businessmen noticed in this new system. In the US, office landscaping was adjusted to a new space division often times called "cube farms" or "cubicle seas." Instead of open spaces encouraging collaboration, office layout more and more resembled military organizations (Duffy, Laing, Crisp, 1993; On the Job: Design and the American Office, 2000).

In the late 1980s to 1990 s the rise of technologies started the post-industrial era. The internet was a great engine for many start-ups that would grow overnight from small teams to organizations of 300 employees that would need a huge space to develop its projects. Unpredictable markets and patterns required teamwork for productivity and flexible spaces to adjust to changing needs (Myerson, Bichard, Erlich, 2010; On the Job: Design and the American Office, 2000).

Another important feature resulting from the introduction of the internet to the workplace was a freedom to perform work tasks without the attachment to geographical location. Many new work modes and concepts such as "free address" and "group address," "just-in-time space," "caves," "commons," "hives," "clubs," "hot desking," "hotelling," "new officing" "flextime," and "telecommuting" were introduced and applied due to increased mobility and fluidity (Florida, R., 2012, On the Job: Design and the American Office, 2000, Brill et.al., 2001, Myerson, Bichard, Erlich, 2010). Not all of the experiments proved to result in greater efficiency, but the set of work organization concepts was definitely broadened.

Lastly, the rise of IT partially caused the formation of a completely new social group, which R.Florida refers to as the "creative class"(Florida, R., 2012). He indicates that this particular cluster of workers needs creative thinking besides their skills to perform the tasks. Moreover, he states that these people would most likely be professionally related to a certain economic segment he calls "creative industries." Florida was analyzing the factors that positively contributed to creative work patterns or 
innovation. He was also interested in creative workers' migration patterns and what physical setting features are attractive and influential for such migration. Since the year 2000, IT companies have been trying to push for a more creative, innovative office design and to find the "next big thing" to adopt to changing markets and labor competition (Cagnol, R. 2013).

Semi-fixed Feature Space, which is primarily defined by furniture, technological appliances and flexible zoning options, has also gone through extensive changes, as reflected in contemporary workspace. These changes influenced work efficiency, data collection and storage as well as communication within and outside of the office. Being more flexible than Fixed Feature Space elements, Semi-Fixed Feature Space elements impacted the workspace instantly and dynamically.

The evolution of basic furniture elements such as a desk, made a tangible impact on work efficiency and process. The Chippendale style table, introduced in 1762 , emphasized individual work style and was elegantly small. The Wooton Patent Cabinet Office Secretary, created in 1880 , was initially designed to provide instant data storage and management but ended up being a clumsy piece of furniture that isolated the worker and reduced efficiency due to its complexity. Finally, more practical "work station" approach was developed by Herman Miller in 1947. Its simplicity provided easier supervision of employees as well as allowed for communication and collaboration to happen.

In the 1970s Henry Dreyfuss and Niels published two texts on the importance of ergonomics in space design: "Human Scale" and "Measure of a Man." "Human Scale" incorporated the latest scientific research in the fields of medicine and psychology. This inspired architects and designers to focus more on the needs of the workers (Cagnol, R. 2013).

Other elements shaping the workspace were being questioned during the office landscaping period. Furniture became more flexible in order to reflect changing organizational hierarchy patterns. Interior layouts with movable partitions also allowed multiple setting options, which were easy to reorganize according to the need. 
In 1968 Robert Probst, a designer at Herman Miller, developed a revolutionary office furniture design called Action Office. The intention was to make an employee move more, and to have flexibility in the workspace. The project was received well by the public, but the executive manager did not intend for expensive high quality designs to take up a lot of office space. Trying to simplify and condense the initial design R.Probst offered Action Office II with three angular vertical divisions that could be adjusted to individual needs. This option seemed to be more economically feasible and was copied by rival furniture design companies. Continuous simplifications and ignorance towards the height of partitions led to the unintentional development of the cubicles, that were very well received by developers wanting to host more employees within visually autonomous environments (Saval, N.,2014).

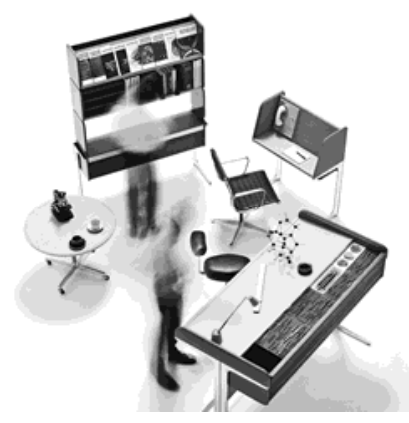

Figure 11: Action Office I

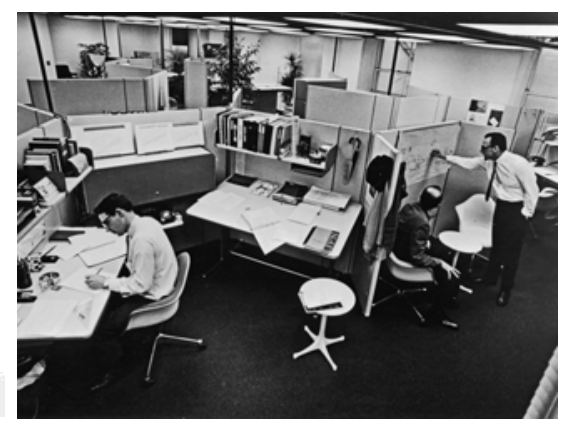

Figure 10: Action Office II

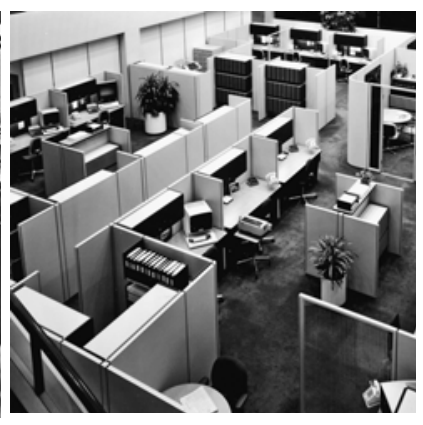

Figure 9: Cube Farm

"Modern architecture with its sealed and mechanically conditioned building has created unhealthy work environments" (On the Job: Design and the American Office, 2000). This has been noticed in the 1990s alongside with natural lighting issues and general sustainability movement (Duffy, Laing, Crisp, 1993; On the Job: Design and the American Office, 2000).. The worker is now perceived as more than just a tool to perform tasks, but rather as an individual that needs to be taken care of. Hence, providing healthy work conditions became the employer's ethical responsibility (On the Job: Design and the American Office, 2000).

Technological advancement has also had a crucial impact on workspace design. Not only has it transformed aspects of the furniture (special storage for punch cards, 
sliding desk parts for the keyboard or paperless office concept) and engineering solutions (pre-wired partitions and internet connection plugs) but it has also reduced the physical distances with communication channels, changed the concept of data, work and the worker as well as revolutionized organizational structures.

To sum up, current physical workspace design was primarily influenced by open plan development and functional zoning, the rise of information technology and environmental concerns related to both: building shell, materiality and skin as well as indoor environment in relation to its impact on users' health and performance.

\subsection{EVOLUTION OF THE NATURE OF WORK}

The last type of spatial arrangement from the selected framework is called "Informal Space." It relates to intangible aspects of a physical setting and is tightly connected to human capital, its behavior and management. In workspace it would represent the work process as well as social features related to it. As mentioned previously, Informal Space is codependent with the elements of Fixed Feature Space and Semi-Fixed Features Space elements that create a physical setting.

A very important shift in Informal Space happened with Fordism and "scientific management." Tasks were broken down into oversimplified functions and responsibility levels were redistributed among the remaining workers. Employers' focus shifted from those who perform to those who manage. Efficiency increased, but there were new issues to consider related to the new model of work. Taylor recognized the worker as "an integral and significant part of the work process and mandated layouts and conditions supporting productivity" (On the Job: Design and the American Office, 2000), however, performing the very same task over and over again tended to be monotonous and nonmotivating. In addition, a newly formulated concept of the "overqualified" worker sometimes appeared contradictory to the basic education system. 
Efficiency was a big concern and scientists conducted research to measure and improve it. But due to the subjectivity of experiences and unique individual perspectives of comparable settings it was not easy to capture such data objectively. For instance, after World War 2 military hierarchical organizational structure was applied to the workspace and efficiency levels were high. But it may not have been a result of a better workspace design or staff management: people adjusted to harsher war conditions and were performing better under psychological pressure and resource shortages (On the Job: Design and the American Office, 2000). The influence of Bauhaus school on office design was also important as the followers of Taylorism spread the idea that "the office is a machine for working in" (Myerson, Bichard, Erlich, 2010).

Office landscaping was introduced in the 1960 s to flatten hierarchical structure, increase space use efficiency and encourage collaboration. It had very different expressions in Europe and US, but in both cases the intention was to change employees' placement in the workspace while encouraging professional interaction.

Early post-industrial workers' images were greatly formed by William $\mathrm{H}$. Whyte's “The Organization Man" (Whyte, 1956). An office employee was pictured as a dutiful part of a system, whose skills were shaped by training rather than by self-initiative or curiosity and who primarily identified himself with an organization rather than the tasks he performed. Whyte precisely described the bureaucratic apparatus and pointed out its malfunctions. This design stage was also described by Duffy as a "social democratic office"- a second wave of office design (Taylorism being the first), with strongly expressed white-collar unions, efficiency related concerns and the rise of the service economy (Myerson, Bichard, Erlich, 2010).

The later stage of Informal Space development was centered on the quality of work. Industrial psychology transformed technical work managers to human relations experts. At the same time, specialization over certain tasks resulted in a Post Fordism organizational concept. Professionalization led towards a new type of "craft worker" who 
could perform complex specialized tasks, needed little to no supervision and was encouraged to take individual responsibility and initiative. Post Fordism approaches were related to "flexible labor processes and markets, programmable automated production, <...> geographical mobility" (Duffy, Laing, Crisp, 1993) and participation over a hierarchy.

Another distinct Post Fordism attribute was information technologies. Rising in the 1980s it changed the perception of space, time and human interaction. "The electronic service has been particularly important in providing the technology for calculating, communicating, and processing" (Duffy, Laing, Crisp, 1993), which facilitated new operations, where knowledge itself became a "big business."

As technological devices became more and more multifunctional and mobile, employees became less attached to a particular geographic location or time for work to be done. New space-time concepts mentioned previously resulted in new work modes and professional interactions. Not all of these modes turned out to be most productive, but together they started a discussion about existing managerial issues and possible solutions.

In opposition to the rise of technologies, the growing level of a global environmental awareness was also introduced into business. The Club of Rome Report (Limits to Growth) in 1972 as well as the Bruntland Report in 1987 (Duffy, Laing, Crisp, 1993)) were the historical milestones for sustainability movements. As a result the concept of environmentally friendly workspace became acceptable due to its relation to economic profitability, company's image and employees' health.

The long term building pay back concept was always around, but an emphasis on sustainable design concepts helped to develop certain strategy sets to achieve tangible outcomes. Conscious site selection, total resource efficiency and the mindset to choose a more environmentally sound option have been proven to reduce long term costs. Currently there is a wide variety of sustainable building rating systems on both national and international levels that ensure the application of quantifiable green tools in office design processes. 
Indoor Environment Quality (IEQ) or absence as evident in Sick Building Syndrome (SBS, the term coined in 1986) (European Concerted Action, 1989) are the terms used to measure the effects buildings have on people spending an extended amount of time inside. Building policies and regulations set a baseline of requirements for HVAC, daylight, acoustic and occupant controls, but sustainable initiatives (ie LEED) push these requirements even further and thus influence a more positive impact on the users.

Also, organizations expressing a pro-environmental position positively contribute to their public image, which is one of the most valuable assets that $s$ company can possess. The number of environmentally concerned people exert "their influence on workplace design, as voters, activists, consumers, employees and shareholders"(Duffy, Laing, Crisp, 1993). Therefore, adapting sustainable strategies means not only a wider circle of customers, but also happier and prouder employees.

\subsection{Creative Knowledge Class}

Rapid technological development has greatly contributed to the appearance of new industrial concepts. Ideas about "information society" and "knowledge economy" have been circulating since the 1960s. In order to present initial knowledge related to socioeconomic issues Jochen Steinbicker (Steinbicker, 2001) compares three main scholars within the field. Peter Drucker, Daniel Bell and Manuel Castells were among the first ones to

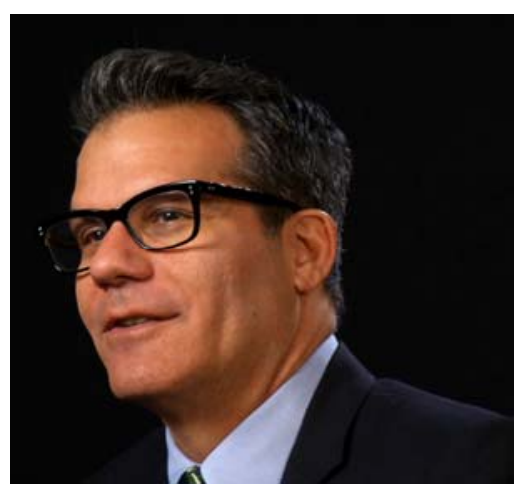

Figure 12: Richard Florida, "The Rise of the Creative Class" undermine the importance of information and knowledge, but their visions slightly differed.

An Austrian-born American Peter Drucker who in the 1960s together with Fritz Machlup simultaneously but independently coined the term "knowledge worker" was greatly concerned about the expansion of education and its restructuring power over the existing social frame. He also claimed that knowledge was "the main resource for the 
economy in information society." Also, Drucker suggested that even though knowledge workers were self-defining, but they were still not fully independent, as the power over their productivity stayed in employer's hands.

Daniel Bell, an American sociologist, writer and professor, famous for his contribution to the discussion of post-industrialism, was imagining "meritocratic class" with codified theoretical knowledge and stressed the importance of an industrial shift from production of goods to service sector dominance. Bell also realized the importance of management for this new structure, emphasized bureaucratization and a "third infrastructure," which referred to information technologies. The codified information concept also resembled Robert Reich's ideas about "symbolic analysts," members, whose economic function was to manipulate ideas and symbols (Florida, 2012).

Manual Castells, a Spanish sociologist was mainly talking about modern social and technological networks and their influence on socioeconomic structures. He was also emphasizing the importance of identity (Castells, 2004) as authenticity also encompasses economic value. Similar to Bell Castells discusses "micro coordination" through mobile communication as a managerial tool (Mobile Communication and Society, 2007). Castells described the essence of a knowledge work as "the action of knowledge upon knowledge itself as a main source of productivity" (Castells, 1996, p.17).

Steinbicker's (Steinbicker, 2001) comparison concludes with the extraction of seven shared elements among the three authors' theoretical works. First and foremost, all authors agree about the importance of knowledge and innovation in a context of new information society. Both of these elements are being expected from a potential employee. Second, information technologies play a major role in the knowledge management process and therefore is also an essential asset to master for knowledge workers. However, "the use of information technology is not in itself a sufficient criterion for classifying work as informational" (Pyöriä, 2005). Third, the previous hierarchy based vertical social frame has flattened to a more horizontal and flexible system. Fourth, all the 
authors agree on the importance of knowledge workers due to their ability to operate information. Cognitive skills or in other words training "to deal with abstract ideas" (Cuvillier, 1974, pp 292-3) are a distinctive feature of information economy's employee. Formal education is described as a methodological training for a lifelong learning rather than a package of a finite amount of information. Fifth, the information society is defined by its members' stratification due to the differing levels of access to the information. The higher level of access a person has the more independent and valuable in the work that person can be. Author predicts that "closing digital divide" (Mobile Communication and Society, 2007) will be an important equity issue. Sixth, authors agree that information flow triggers political and social globalization. Seventh, social divides due to the differing informational access will result in conflicting situations.

"Knowledge work is the work of those who think for a living" (Megill, 2005). "Knowledge work" or "knowledge-intensive sector" most commonly refers to the industries where information is not only processed, but also produced (Duffy, Laing, Crisp, 1993). Knowledge workers "think creatively and experimentally rather than organizationally," "are suspicious of formal hierarchy" (Myerson, Bichard, Erlich, 2010) and "creativity is at the heart of knowledge work" (Megill, 2004).The initial list of knowledge workers created by Drucker and Machlup consisted of "doctors, lawyers, academics, accountants and scientists" (Myerson, Bichard, Erlich, 2010). Later on, Drucker suggested, that employees who combine manual and white-collar work throughout the day should be called "knowledge technologists" and added to the list "computer technicians, software designers, analysts in clinical labs, paralegals and so on" (Myerson, Bichard, Erlich, 2010).

Knowledge work can also be defined by classifying jobs into three areas: transformational, transactional and tacit (Myerson, Bichard, Erlich, 2010). The first group is related to physical transformation i.e. manufacturing. The second one is related to data processing following a rigid set of rules. Tacit tasks, involve more ambiguity and are therefore primarily related to knowledge economy. According to Myerson et al "70 percent of jobs in the US since 1998 can be described as based in knowledge work." 
As the use of information and communications technology (ICT) dramatically increase knowledge workers' mobility it is important to emphasize the global migration related to this new type of industry. Saskia Sassen described this process as "A new geography of centrality and marginality" (Sassen, 2007). Castells was fascinated about the endless communication possibilities and the way it may change physical environments (Mobile Communication and Society, 2007).

Knowledge workers are often differentiated according to their age or generation. Calabrese in his article about the "Evolution of twenty-first century workers" (Calabrese, 2010) mentions Traditionalists, Baby Boomers, Generations X and Millennials. Traditionalists are born before 1946, mostly have blue collar family roots and are currently in a senior position. Baby Boomers were defined as born between 1946 and 1964. This generation has high goals, motivation and level of education, but also faced 2007 recession and increasing complexity of the work related to ICT development. Generation X was born between 1965 and 1981, they are more adept to increasingly changing work environments and demands, but are more skeptical and less positive than Baby Boomers. The Millenials were defined as a workforce born between 1980 and 2000 and best suited for a contemporary work environment. Brought up in a collaborative spirit, they have high expectations from their jobs and themselves, are innovative and caught up with technological advancement.

There is a common misconception about knowledge workers as singularly young employees. It is mainly related to the assumed elders' disability to master rapidly changing informational technologies. However, older knowledge workers have continuously proven to be able to adapt novel work modes and tools. This ability is connected to an important self-sufficiency characteristic. "Being an expert is not a stable characteristic - a knowledge worker needs to learn and develop expertise continuously" (Myerson, Bichard, Erlich, 2010). 
Besides the generational differences knowledge workers also differ in the work modes they prefer the most. Royal College of Art design researcher, Catherine Greene, in her Study "Space through: designing for knowledge workers" (Greene, Myerson, 2011) describes four types of creative knowledge workers depending on their motion patterns: Anchor, Connector, Gatherer and Navigator. The Anchor workers tend to spend most of their work day by the table, which they perceive as their property or even 'an extension of home' and they are very valuable information providers as others can rely on them to be at the particular place. The Connector employees move around the building and are usually very social figures managing projects and distributing information. Gatherer workers spends half of their time dealing the business outside of the office, and the rest of it efficiently sharing gathered information, documentation and connections with trusted coworkers back in the office. Navigators spend the bigger portion of their effective time outside of the office and are very mobile.

The term "cultural industries" was first used by the UK Labour Party in 1997. Later on the term was changed to "creative industries" and described by the UK Government Department for Culture, Media and Sport (DCMS) as "those industries which have their origin in individual creativity, skill and talent and which have a potential for wealth and job creation through the generation and exploitation of intellectual property" (DCMS, 2001). The concept got further attention after US regional economist Richard Florida has published "The Rise of the Creative Class" (2002), in which he argues that this new type of workers create "new economic and social order" (Florida, 2012).

Florida presents new ideas that expand on the previous knowledge work concept. He explains the essential differences between the regular and the creative worker by stating that their main function is to "create meaningful new forms" and that "along with problem solving their work might entail problem finding" (Florida, 2012). He distinguishes two segments within the creative class. A Super Creative Core consisting of scientists, university professors, poets, novelists, artists, entertainer, actors, designers, and architects as well as the thought leadership of modern society: nonfiction writers, 
editors, cultural figures, think-tank researchers, analysts, and other opinion makers. The members of this segment are supposed to "produce transferable, widely usable new forms." The second segment - Creative Professionals - encompasses a wide range of knowledge-intensive industries: high tech, financial services, the legal and health care professions, and business management. These creative class workers "engage in creative problem solving drawing on complex bodies of knowledge to solve specific problems" (Florida, 2012). From this segmentation and descriptions, it can been understood that the creative class is a part of the knowledge workers, specifically the ones that besides possessing and producing the knowledge must have a creative element to deliver a final original product.

Similarly, Daniel H. Pink in his book "A Whole New Mind" (Pink, 2005) talks about the threshold between the "information age" and "concept age." As Florida, he talks about the importance of creativity, employing the "right side of the brain" over the left one and producing original content. Although, Pink sees the change in the characteristics of the worker as a new stage rather than evolution of "knowledge worker," his descriptions share similarities with the ones provided by Florida.

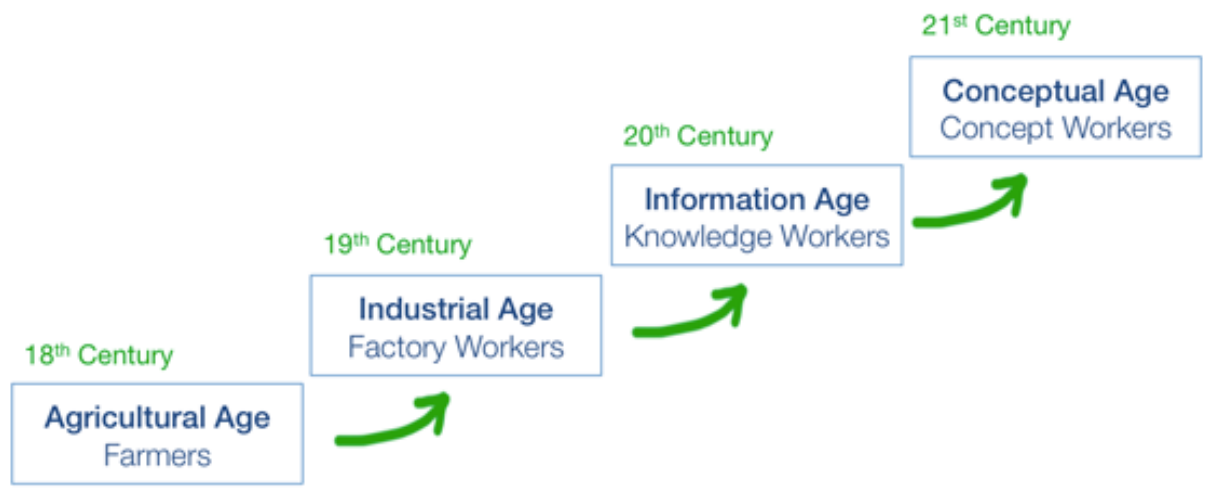

Figure 13: Evolution of work timeline

Florida dedicates a big portion of his writings for the specific creative class's environmental needs. Contrary to common belief that an employee should follow the job, he argues that creative class members are so valuable that the employer should be 
concerned to attract them. The spatial theories about the merge of talent, tolerance and technology (three T's) or the importance of attractive work environment over the living one, drew bold speculations about possible changes in creative and knowledge industries market.

Deborah Leslie agrees with the importance of cultural transformations in the economically significant industries and expands on Florida's spatial concerns by wondering "how arguments concerning tolerance, diversity and innovation can be operationalized" (Leslie, 2005). Sharon Zukin echoes the importance of creativity in an economic context describing "cultural consumption" and the entertainment industry as "a driving force of technology" (Zukin, 1995), which is also tightly related to knowledge work.

Nadler refers to a portion of high-skilled knowledge workers with expressed creativity characteristics as to "creative knowledge workers." The linkage between knowledge and creative workers is very important as it describes a particular group of employees that process a valuable information into an original product applying their unique creative abilities. "Creative industries and creative knowledge workers are now described as fulfilling a bridging function between arts, philosophy, science and business" (Nadler, 2014).

Dul et al (Dul et al. 2011) presents "knowledge workers" and "creative class" as equal definition for the participants of knowledge based economy. However, he emphasizes the importance of creativity to perform the tasks and that it is a part of one's "personal characteristics." Acknowledging that knowledge can be gained with training, the author explores possibilities to enhance creativity with physical environment or human resources management.

From an economic point of view "knowledge industries" and "knowledge economy" has been discussed and attempted to measure in quantifiable tools since 1962 (Nadler, R., 2014). A good way to weight the gravity of an economic sector is by seeing a share in the national GDP. Fritz Machlup's research 
indicated the rise of knowledge sector share in US GDP from $11 \%$ in 1900 to $32 \%$ in 1959. Another American scientist Mark Porat continued on Machlup's work by dividing the whole economy into four sectors - extraction, producing industries, service activities and information services - and measuring a 46\% information services sector share in 1970 US GDP (Nadler, R., 2014).

A Japanese author, Tadao Umesao similarly divides economy into four sectors and believes in industrialization of a mind. Yujiro Hayami discussed a possible measure of financial profit from a growing knowledge related sector with "an increased demand in emotional goods oriented to fashion, lifestyle and quality" (Nadler, R., 2014), as this would uniformly indicate total economic growth.

Another measure for increased importance of knowledge work is an eightfold on average since the 1980s increase in CEO's salaries and diminished power of workers' unions (Martin, Moldoveanu, 2003). It shows reshaped power patterns and the need of new employees' skills as well as ever increasing importance of management.

Continuous attempts to measure an economic share of knowledge sector persisted and became official and institutionalized. For example, The Organisation for Economic Co-operation and Development (OECD) data indicates that in 2006 $43 \%$ of national income in both Germany and the US was derived from knowledge

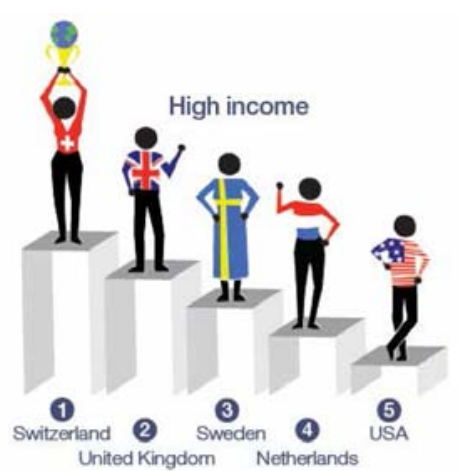

Figure 15: Top innovator countries in highincome group; The Global Innovation Index 2015

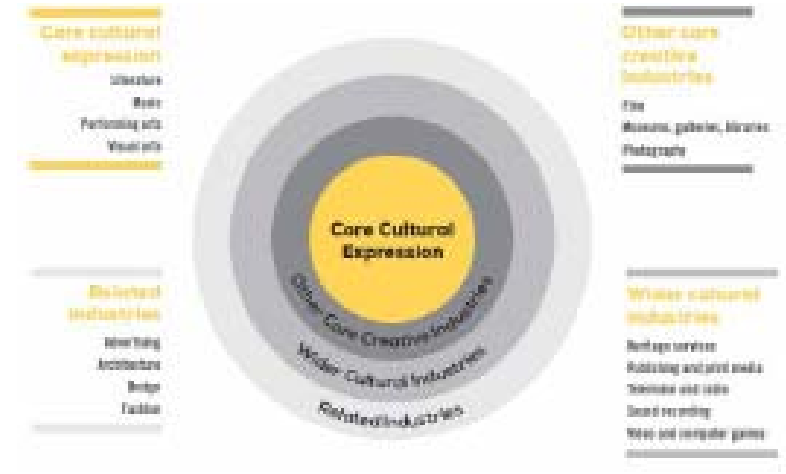

Figure 14: Modelling the cultural and creative industries; United Nations Creative Economy Report 
based industries (Myerson, Bichard, Erlich, 2010). Moreover, it also measured the growing investment in Knowledge Based Capital (KBC) as well as higher value added in comparison to tangible capital measures (OECD, 2013, a). A growing importance of information processing sector can also be proven by an increasing percentage of knowledge workers within a country (OECD, 2013, b, European Commission, 2014 a). Some countries such as the UK even separate knowledge or creative industries sectors on national statistics (DCMS, 2001) to notice and support areas of a great financial potential.

Economic value of an employee also comes from their productivity. The problem is that compared to manual workforce, knowledge work is very complicated to asses and measure (Myerson, Bichard, Erlich, 2010). Nonetheless, there are concepts on how to improve the productivity even if it cannot be measured. Davenport, for instance, states that the three main factors to improve knowledge workers' performances are "management and organization, workplace design and information technology"(Davenport, Thomas, Cantrell, 2002).

The knowledge and creativity sectors are also directly related to education, scientific advancement and innovation. Knowledge workers are exceptional for "undertaking tasks that require formal education, rather than a traditional apprenticeship" (Myerson, Bichard, Erlich, 2010). Labour Force Survey shows that creative industries have the highest proportion of employees with tertiary education (ISCED levels $5 \& 6$ ), ranging up to $57 \%$ as compared to $26 \%$ in the total EU economy (European Commission, 2010). High skilled labor, that is mostly employed in knowledge-intensive sector also added a significant value to global value chains (European Commission, 2014 a). The level of innovation also positively characterizes knowledge and creative work sector with share of innovative enterprises (Eurostat, 2015), innovation indexes (Cornell University, INSEAD, and WIPO, 2014, Coy, 2015), amount of annual patents (OECD, 2007) or research and development $(R \& D)$ sector's growth (European Commission, 2014 a, The World Bank, 2014, OECD, 2015). 
The extended use of ICT is a trademark of knowledge and creative industry sectors, as big amounts of information have to be processed. An ever increasing investment and use of these technologies (OECD, 2007, Nadler, R., 2014, European Commission, 2010, European Commission, 2014 b) also confirms the importance and financial gravity of knowledge-intensive organizations.

\subsection{CONCEPTS OF THE CONTEMPORARY WORKSPACE}

Vast literature indicated that the changes in work patterns, hierarchical structures and marketable employees' skills all contributed to the need of a novel workspace. There is a wide discussion on how environments for creative knowledge workers should be designed, what strategies of organizational management be chosen or whose opinions on the matter counts the most. All of those concepts create a context for designers and managers to better understand a fast changing situation and the most current needs.

To begin with, office work is not a singular clearly defined activity, but rather a range of actions performed within a certain physical setting: the office building (Duffy, Laing, Crisp, 1993). The fact that different industries have similar types of workspace with varying characteristics makes it difficult for a designer to figure out particular requirements for each case. Even narrowing down to creative knowledge workers as a potential clientele, architects might have to provide suitable physical setting for activities varying from advertising, video games, and entertainment or business incubators to ICT, think-tanks and sciences.

It is also important to evaluate that the office workers are not the only ones using the

office space. Rasmus defined a term "blended workforce" (Rasmus, Salkowitz, 2008) which means that a much bigger group of people than just office employees is considered as a part of a company's processes and office users: contractor, contingent staff, freelancers, outsourced employees, out-tasked employees, consultants and other classes of workers (Rasmus, 2010). Knowledge work is client/customer centered (Megill, 2005) and the office building (or a space) makes a big influence on company's image, expressing its core values and work models. 
F.D.Becker in his book "Workspace. Creating Environment in Organizations" (Becker, F.D., 1981) analyzes organizational and behavior patterns at work and how they influence physical settings. He coins a term 'organisational ecology', which describes a symbiotic relationship between the social unit of organization and the physical structure of the work environment within which it exists. Brill (Brill et.al., 2001) talks about two possible workspace design schemes: either the physical environment impacts key workers' behavior, which in turn impacts business success or anticipated business success dictates required behaviors and then the environment is designed to support those behaviors. The second approach is considered to be more strategic and efficient.

Becker also rightly notices that the situation involving humans and their personal perceptions create a lot of ambiguity. Since every person has a different view on the same physical environment due to numerous factors, the environment itself cannot always be strictly defined. The author talks about different strategies and elements that may encourage desired or undesired behavior, but at the same time acknowledges their suggestive nature and implication restrictions due to the social and cultural limitations or lack of personal resources. Brill (Brill a. al, 2001) performed big scale long term (from 6 to 15 years) researches to find out workspace influence on employee's performance using rigorous and objective measurements, achieved from structured questionnaires. His research showed that workplace has the most influence on job satisfaction, individual performance and team performance.

Becker elaborates on how human resources management through designed environment can be broken into segments that have the most influence on shaping of that environment. Author describes how physical layout creates visual order that indirectly guides employees' daily attitudes. He also explains how different time segmentation and spatial use patterns create various densities of actions and people within the workspace. Then he moves on with the way personal characteristics tend to reflect in physical environment representing professional status, hierarchy level or even loyalty to the company. Finally, Becker discusses the social context and how that shapes collegial 
relationships. By the time this book was written, the emphasis on collaboration at work was not that strong, but the fact that employees' interaction should be encouraged with workspace design was already understood.

The importance of collaboration is emphasized by most of the authors (Becker, F.D., 1981; Duffy, Laing, Crisp, 1993; Myerson, Bichard, Erlich, 2010; Megill, 2005, Dul, Ceylan, Jaspers, 2011, Groves, 2011). A balance between open and closed spaces should facilitate "work as a social activity" (Myerson, Bichard, Erlich, 2010). Information sharing is essential for knowledge work, so there must be a platform to easier exchange data. The concept of collaboration is not limited to team work on certain projects or brainstorming in half formal meetings. The convenient access to the information existing within the company also includes properly managed archive and access to the work data among not necessarily directly involved co-workers, because the knowledge made "in the course of doing knowledge work becomes someone else's information that they need to do their work" (Megill, 2005). In addition, "productive collaboration" is seen as a process that generates "new information or insights" rather than coordinate, cooperate or communicate the existing ones (Groves, 2011). Moreover, The generation of Milenials that forms a big portion of creative knowledge force was brought up in team-oriented group learning environment (Rasmus, 2010).

Collaboration in a contemporary workspace is so important that in some cases the whole building layout is focused on encouraging this matter. It is labeled as a "collaborative," "co-working" or just "shared" facilities (Lynch, 2016) and includes business incubators or established organizations that choose to share the workspace due to convenience and financial reasons. "WeWork, Nextspace, or Impact HUB, have already begun developing and marketing their own identities as creative centers filled with up-and-coming-businesses, and some have begun to cater their services to a particular field" (Lynch, 2016). 
The opportunity of choice is another important feature of the workspace for knowledge workers and their productivity (Duffy, Laing, Crisp, 1993; Myerson, Bichard, Erlich, 2010). Ability to control the environment even with minimal measures has a significant impact on employees' positive attitude towards the workspace and the work.

A big portion of knowledge workers consists of women, whose professional qualifications help them avoid discrimination and elders who possess a big body of knowledge due to their long career and extended experiences. However the need of elder workers are very often neglected orienting design solutions solely towards the Millenials generation in their 20s to 30s (Myerson, Bichard, Erlich, 2010). Despite powerful movements of 'inclusive deign', 'design for all' or 'universal design' in the past 30 years, people over 50 years old are still not seen as active economic contributors and therefore, from the financial perspective their needs matter less. However, as the gerontologist Bernard Isaacs once remarked: "Design for the young and you exclude the old. Design for the old and you include everyone" (Myerson, Bichard, Erlich, 2010).

A changing nature of work dictated novel management tendencies. Calabrese (Calabrese, 2010) develops a four pillar model based on A.Stankosky's late 1990s concept of a Leadership-Organization-Technology-Learning. Garrity talks about 'learnership' and ads a fifth pillar of lifelong learning which leads to self-sufficiency of a worker (Calabrese, 2010, Brill et. Al., 2001). There are also international organizations (i.e. The KNOW Network) uniting knowledge industry representatives, that aim to improve current knowledge management strategies through networking and systemic reports.

The rise of information technologies create endless opportunities for flexibility and connectivity in work. Frank Duffy (Duffy, Laing, Crisp, 1993) even described it as a "networked office" and calls 'the third wave of office design'. The release from 
obligation to be in the office physically to perform tasks, creates a whole new set of options for the organization to manage its real estate assets in a more efficient way.

As ICT integration within the workspace become crucial for workers and work, it is also true that the use of technological innovations reach even further. Building intelligence that helps to control HVAC, light and water systems are essential tools to ensure the comfort of creative knowledge workers (Duffy, Laing, Crisp, 1993).

Location selection for a contemporary office is tied not only to regular business reasons (proximity to the client and profitability), but also to environmental factors, that may reduce operational costs (exploiting existing infrastructures, minimized commuting, intensified use of central premises, office space itself, and energy efficiency measures) (Duffy, Laing, Crisp, 1993).

Myerson and Ross in 2006 studied 43 office design cases from around the world. The observation showed four novel office buildings zoning trends, which were directly related to the increased workers' mobility. The first one was called 'Academy' due to the new corporate headquarters' layout similarities to university campuses. Academy style offices with brainstorm and chill-out zones, smoothly encouraged work as a social activity.

A second trend, called 'Guild', detected workers' intention to cluster with their professional peers rather than with fellow employees. Such a kind of clustering within the office encourages sharing and perfecting particular skills just like in medieval craft guilds.

A third type of trend encouraging workers' interaction with clients and customers was called 'Agora', after a Greek name for the open trading space. The intended interaction is being achieved with more permeable relationship with the city and marketplace - "either by enabling public thoroughfares through office buildings, providing public facilities such as art galleries or creating workspace within mixed use developments, retail schemes or landmark civic buildings" (Myerson, Ross, 2006). 
Lastly, the fourth type of trend described the blend of living and working spaces. The rise of 'live-work' units in urban areas, more flexible living space design, which includes work zone and a more domestic style to workspace to accommodate the culture of long work hours - all these factors were assigned to the 'Lodge' trend. However, work from home is still constricted by employee's position in organizational hierarchy, the need for face-to-face meetings and inadequate facilities for particular tasks. It also may have a negative impact on employee's personal life as work-life and life-life lines blur.

Sam Jacobs (Jacobs, 2013) classifies possible design approaches for creative industries in three categories: office as a form of installation art, serving as an inspirational example, interior design driven by organizational management and consultancy, where spatial schemes are though logically and in support of different work modes and contra-intuitive design that seems to be so out of place that it is supposed to be stimulating creativity.

A contemporary workspace is also greatly shaped by environmentally sound design concepts. The efforts to preserve or restore natural conditions are driven by few factors. The understanding about limited resources impact public opinion of possible customers or employees and thus it becomes and important issue from business perspective. Therefore, including sustainable strategies in a company's image program is beneficial. Moreover, government is taking legislative measures to regulate negative environmental processes, which are mandatory. 


\section{RESEARCH PROBLEM}

\subsection{IMPORTANCE OF AN EMPLOYEE}

Increased recognition of the employees' value as an "intellectual capital" (Brill et. al, 2001) encourages employers to take serious measures for their work environment quality. The importance of the issue becomes especially obvious, when different organizational costs are being compared. The construction and maintenance of the office building only contribute to a minor part of total expenses. "Over the 25-year life of a typical office scheme, for example, 85 per cent of all costs goes on paying the occupants" (Myerson, Bichard, Erlich, 2010). Brill et. al. (2001) gives similar ratios over different periods of time where employees' salaries vary from 82 to $92 \%$ of all costs.

In this context, the need to tailor the environment more closely to individual user needs becomes especially important. As workspace helps improve performance and therefore the output from initial investment in the employees designers, managers and business owners should all make sure that every measure to facilitate productive work has been incorporated in office design.

The workplace is responsible for 24 per cent of total job satisfaction and this can affect staff performance by 5 percent for individuals and 11 percent for teams (Myerson, Bichard, Erlich, 2010). Workspace can also support concentration, impromptu access to interact with colleagues, meetings and undistracted group works, informal information exchange, technological tools and thermal as well as light quality (Brill et. al, 2001).

The growing importance of knowledge economy and hence the need of creative knowledge work force places even more specific requirements on workspace design. The built environment becomes an important asset of the organization not only to complete the work with current resources but also to attract and retain the most competent and relevant work force. As discussed in the section 1.5. "Creative Knowledge Class," Creative knowledge workers possess a lot of universally applicable and easily 
transferable skills. Moreover, they have high standards for the work they do as well as the place they work at. Therefore, it is increasingly challenging for the organizations to ensure stable labor and they have to pull all of their resources to achieve it.

\subsection{Design Decision Making Process and a Knowledge GaP}

Workspace design is usually developed by designers or architects consulting clients and their managerial representatives as well as building codes and local regulations. It is complicated to manage discussion with all of the end users due to high volumes of information. The most common practice of investigating users' position toward the newly designed workspace is a postoccupancy evaluation, but that is an assessment of final design with little to no room for adjustments.

As Brill rightly noted, an efficient design process should start with expected business results identification, strategies development and certain settings that support those particular strategies design. However, it is not always easy to identify strategies as creative knowledge work is ambiguously defined, measured and managed. Many companies, unable to clearly identify the needs of their knowledge workforce, bribe key knowledge workers and then try to blindly mimic their work environment (Myerson, Bichard, Erlich, 2010).

Such a mechanical approach to the cause shows the lack of trustworthy information and the need to reach out to the user. Becker was discussing the differences between the perceived and actual need for certain features in design process. "Designed environment is an environment of possibilities. The created environment, or what Gans (1972) has referred to as the 'effective' environment, is a set of possibilities to which individual users have attended. In almost any designed environment some possibilities will not be attended to, while other possibilities the designer did not imagine will be attended to" (Becker, 1981). 
A more systemic approach to analyze future employees' needs should result in a set of preferred workspace attributes, which are not only suggested by designers or managers, but also approved by end users. The intent of this research is to produce such set of design guidelines as a checklist to inform "creative workspace" design.

\subsection{RESEARCH QUESTIONS}

The focus of this study is on "creative workspace" design. This research is investigating the key concepts and definitions related to this topic as they are perceived by different stakeholders: academics, designers and users.

Specifically, the study addresses the following research question:

- What are academics', designers' and users' assumptions about elements and/or principles of the "creative workspace" design? 


\section{RESEARCH METHODOLOGY}

\subsection{INTRODUCTION}

This study uses in-depth interviews with a selected sample of stakeholders. The main scope of the research is related to individual perceptions towards the particular matter which is subjective. This means that qualitative methodology would help in capturing specific details, authentic definitions and other in-depth information. Moreover, open ended questions may result in additional relevant information which the researcher may have not been aware of and may not have asked for in particular.

The research is focused on the comparison of academics, designers and users perceptions towards "creative workspace" design concept. In order to compare these positions, data will be collected through in-depth interviews with selected sample from designers and users category. To identify academics' positions similar set of questions will be used as a guideline to evaluate existing literature beyond literature review framework.

The authors to represent academics' position are selected based on their recently published work related to "creative workspace," knowledge work and contemporary workspace design. The texts are analyzed following the same questions used for in-depth interviews. The data can be taken from the books, scholarly articles, professional journals, press articles, websites and thesis/dissertations. This way of extracting and coding the information will make it easier to compare results with the ones extracted from the interviews.

For the in-depth interviews office design and company's profile are used as a base criteria to select the users and the designers. The industries that represent creative knowledge work sector in this research were narrowed down to software 
engineering, social network platform, advertisement, design segment in governmental institution and technology related business startup cluster. Based on the company's profile and the office design that was either freshly executed or still under development certain workspaces were selected. The interviews were conducted either with the designers who were in charge of the design of those spaces or the users who are currently working there.

\subsection{METHODS}

\subsubsection{EXISTING LITERATURE ANALYSIS}

In addition to the literature review that captured general workspace evolution and trends, research examined existing body of knowledge in the relationship to the research questions. The scope was to formulate academics' position towards this emerging topic and get a better understanding about existing definitions and concepts related to "creative workspace." The data coded following interview structure was easy to compare to the data extracted from the in-depth interviews with "creative workspace" designers and users.

\subsubsection{IN-DEPTH INTERVIEWS}

To get rich qualitative information on "creative workspace" designers and users, the research utilized in-depth in person and telephone interviews. A set of open ended questions helped to capture authentic testimonies and compare different stakeholders' positions.

The interviews took from 15 to 25 minutes depending on the interviewee's responses. Each conversation was recorded, then transcribed and coded to track the patterns in the answers. 


\subsection{INSTRUMENTS}

\subsubsection{EXISTING LITERATURE ANALYSIS}

To analyze the existing body of knowledge a set of open ended questions based on the research questions were developed. These questions were used as a guideline to extract data about "creative workspace" design representing academics' position.

The data was coded and to certain extent simplified to make the comparison between the positions of different stakeholders (academics, designers and users) easier.

\subsubsection{IN-DEPTH INTERVIEWS}

The research developed open ended question sets based of the research questions. The questions to "creative workspace" designers and users slightly differ to better capture diverse perceptions and positions. Depending on the situation and interviewee's availability the interviews were conducted either in person or via phone. Interviews would take between 15 to 25 minutes depending on how explicit in their answer interviewees were.

All the interviews were recorded and transcribed. Once the data was in the written form it was coded and to a certain extent simplified to make it easier to process and compare information gathered from different sources (academics, designers and users). 


\section{RESEARCH PROTOCOL}

Research started in April 2015 and was completed in February 2016. The work begun with literature review and research problem identification. Literature review informed a research questions and helped identify research methodology. Three different sets of open ended interview questions (slightly varying for each group of stakeholders: academics, designers and users) were developed.

The next research phase consisted of identifying potential interviewees and reaching out to them. It is worth noting that the chosen segment of "creative knowledge workers" is not always easy to reach out to. Different mediums were used to get in touch: contact information from company's website, social media or personal connections.

Once the connections were made, interviews were conducted either in person or via phone depending on interviewees' availability. In person interviews would often times be conducted in "creative workspace," which added a wider perspective for the researcher.

At the same time, an existing body of knowledge was examined and coded based on the same interview framework. Information was categorized and sorted to make it easier to compare data coming from different sources.

Lastly, information obtained from all of the three sources was compared to understand the consistencies and inconsistencies between perceptions of the three groups of stakeholders. The conclusions are discussed in "research findings" and informed a conceptual "creative workspace" design. 


\section{$\underline{\text { 7. FINDINGS }}$}

The research findings primarily concentrated on "creative workspace" perceptions from the three key stakeholders groups: researchers, designers and users. To identify and compare the results, through coding process the findings firstly describe definitions and common concepts related to "creative workspace," its user and creativity or innovation.

After discussing the definitions, spatial and managerial ideas derived from the literature review and interviews were sorted into three categories from the research framework (Fixed Feature Space, Semi-Fixed Feature Space and Informal Space) and additional category of creative performance related elements that may fall into more than one of those three categories.

\subsection{DEFINITIONS}

\subsection{DEFINITIONS - RESEARCHERS}

From the literature review the research has identified that the definition of "creative workspace" is more common on articles or very recent publications. However, ideas of supporting innovation and creativity (versus productivity) through open plan design and encouraged collaboration are common in general descriptions of a contemporary workspace. Although the importance of "creative industries" gain economic measures there still is a certain disconnect between that specific kind of work and workspace design requirements.

As discussed in the literature review section 1.5. "Creative knowledge class," the ideas of "creative workspace" user are tightly connected to "information society" and "knowledge economy." These individuals are referred to as "knowledge workers," "symbolic analysts," "creative class" or "creative knowledge workers." Their unique characteristics are described in the literature as the ability to master information technology, operate within the flattened organizational hierarchy and be in the need of "micro coordination." It is also seen as an ability to deal with abstract, ambiguous ideas, self-manage lifelong learning, possess high levels of mobility, consists of diverse age groups and adaptability levels, engage in 
varying work modes and most importantly "create meaningful new forms."

\subsection{DEFINITIONS - DESIGNERS}

The most common concepts in designers' definitions of "creative workspace" were related to openness, supportive environment, adaptability, collaboration and promotion of creativity or inspiration. Besides these initial definitions the concepts that showed up in more than a half of in-depth interviews with the designers were related to connectivity of different spatial elements, flexibility, zoning of the workspace, especially spatial arrangements helping to control the focus and instigating spontaneous interactions and innovation. The interviews also showed the importance of geographical location and views, control of daylight, air and acoustics through the design, considering incorporation of natural

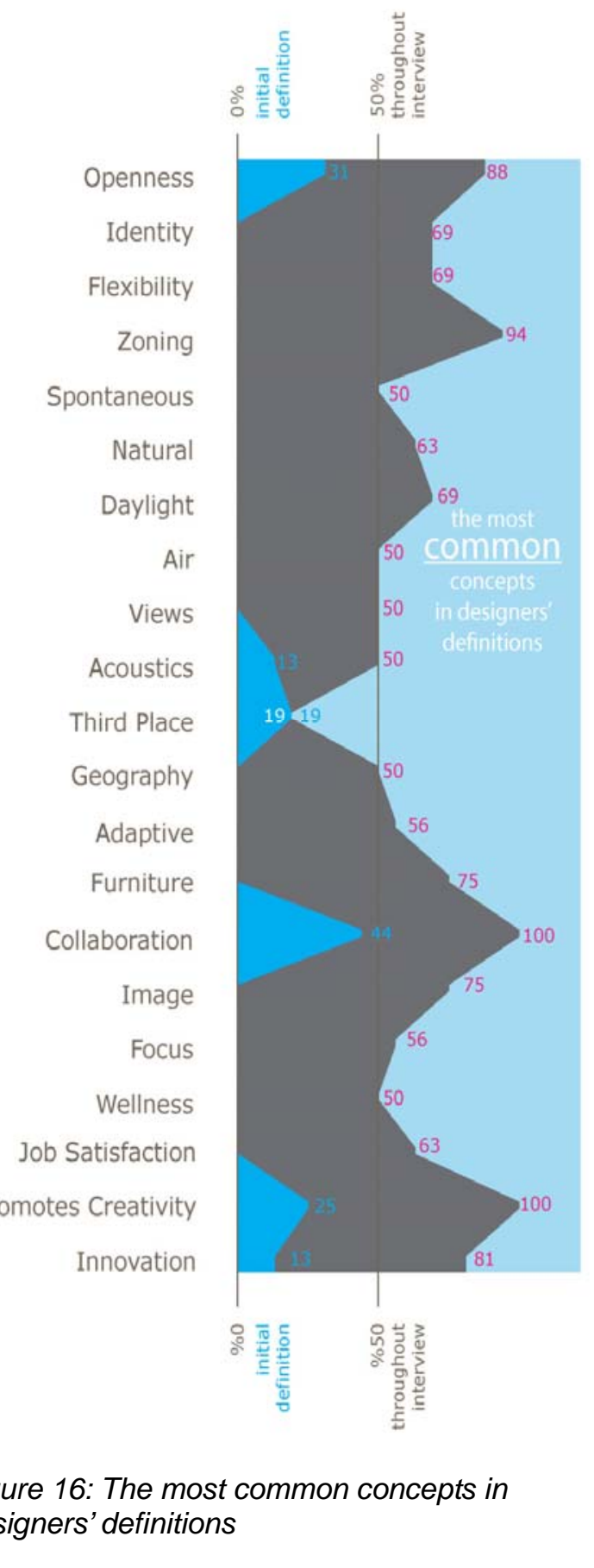
elements, mostly customized designers' definitions

furniture. The identity or emotional quality of the space as well as its impact on company's image and employees' job satisfaction was also very important. These key elements may 
have been described in a slightly varying fashion by different interviewees, but are consistently present in their responses and definitions. Such consistency may showcase certain patterns in "creative workspace" design practice.

In describing the user of the "creative workspace" designers mainly talked about the importance of being able to work independently as well as collaborate in the often times interdisciplinary and diverse teams. The other crucial aspect for the "creative workspace" user according to the designers is the need to transition through different work modes in order to complete complex tasks.

The terms "creativity" and "innovation" in many cases were named as too abstract and intangible to be defined or measured. However, among the interviewees there were certain attempts to frame it in the relation to "creative workspace." Creativity or the outcome of creative work was defined as "something different than what has always been put in place" or a stimulus that "inspires an individual to work and think differently."

To better understand the initial stage of design and resources that Designers take into consideration, the Interviewees were also asked about the type of research they perform in order to design "creative workspace". The main research strategies

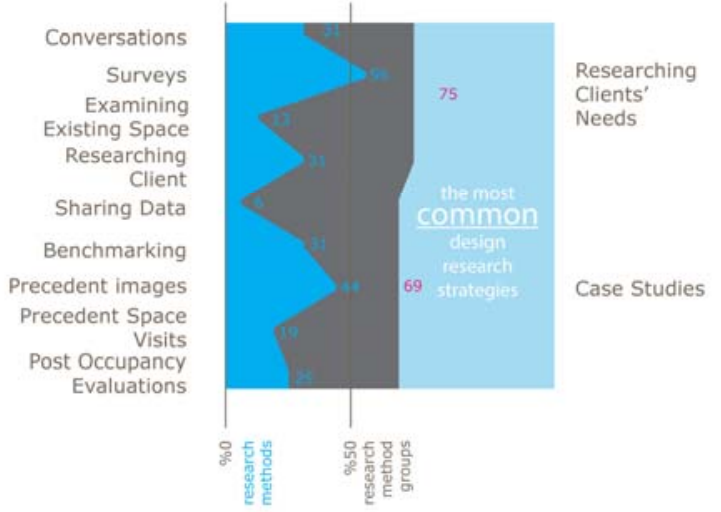

Figure 17: The most common design research employed by the interviewees were strategies.

Researching the Needs of the future tenants through conversation with clients, survey of the staff, examining the existing workspace and/or performing an extensive research on the client. Another major way of making more informed decisions in "creative workspace" design discussed by the Designers was the Case 
Studies that covered sharing data with other companies, benchmarking studies, precedent images for discussion with the client and within design team, precedent spaces visits and/or previously designed "creative workspace" post-occupancy evaluations.

\subsection{DEFINITIONS - USERS}

The most common concepts in users' definitions of "creative workspace" were related to openness, daylight and glare control, supportive environments, collaboration, flexibility, adaptability, furniture, promotion of creativity and playfulness. Besides these initial definitions the concepts that showed up in more than a half of in-depth interviews with the users were related to zoning of the workspace, importance of technology, focus control, various aspects management in relation to the built environment, job satisfaction and company's image. The users were also recognizing the significant role of

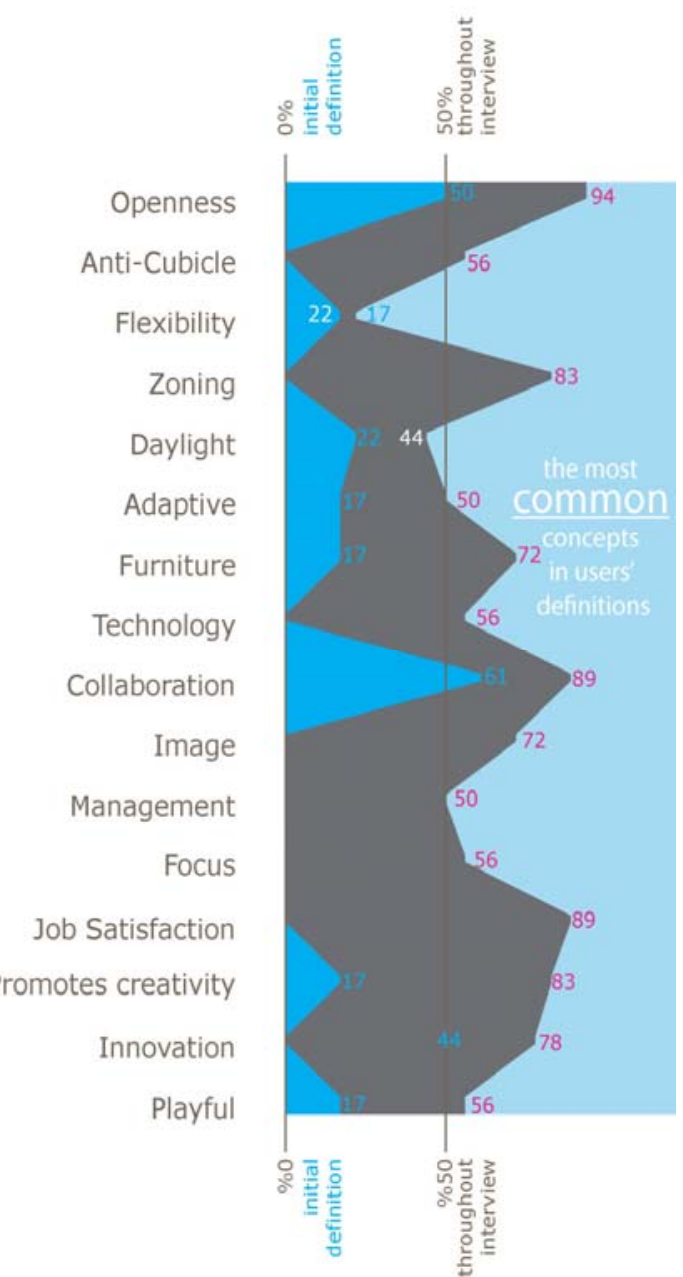

Figure 18: The most common concepts in users'definitions.

innovation in the work they were pursuing. Possibly due to the lack of architectural design background many of the users described "creative workspace" as the opposite of "cubicles" and used that example to showcase the advantages of the second in comparison with the first.

In describing the user of the "creative workspace" users mainly talked about 
the different work modes that requires to visualize data for more efficient communication and high level of mobility to change work environments depending on the work modes or types. The users also stressed the importance of independent work and often time interdisciplinary collaboration.

Creativity or the outcome of creative work was defined was heavily related to collaboration or "willingness to work together," self-discipline while working individually ("being able to be focused," "do research and puzzling," applying personal traits ("being your most individual self") and innovation ("or phasing things in a different way than we've ever done it before") and visualize the result through "experiment, learn and touch," "play, like in art classroom" and otherwise engaging "manually" in other than digital work modes.

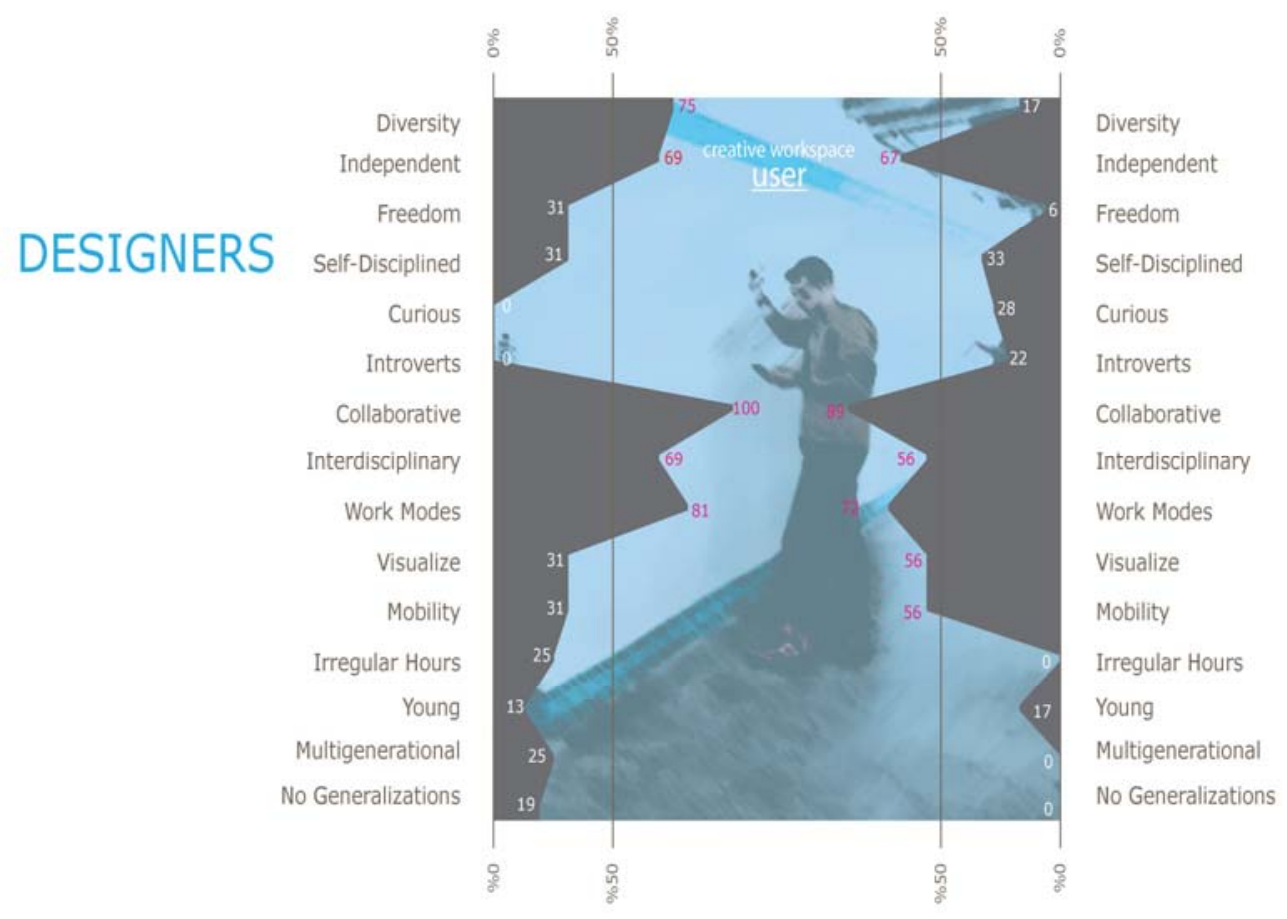

Figure 19: "Creative workspace" user definitions 


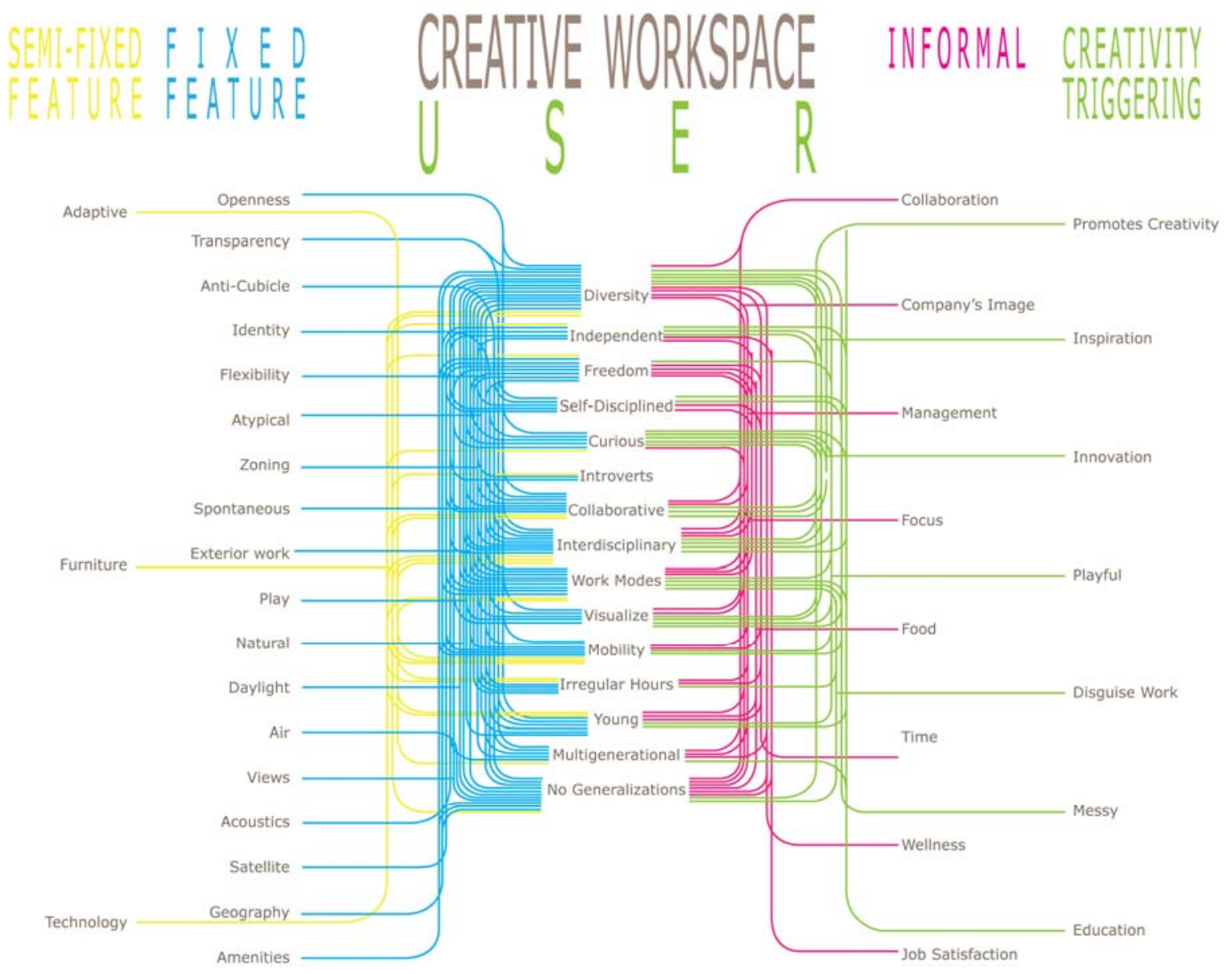

Figure 20: "Creative workspace" definitions in relation to identified activities 


\subsection{ElementS AND PRINCIPLES}

\subsubsection{Physical Settings. Fixed Feature Space Elements and Principles}

\subsubsection{Physical Settings. Fixed Feature Space Elements and Principles - Researchers}

Building Configuration. Open space offices are popular due to their dual positive influence: a more transparent, collaborative work atmosphere as well as a more cost effective space use (Myerson, Bichard, Erlich, 2010). As core and shell are the building

elements that have the longest life span, it is also important to consider spatial adaptability and reuse options. Simplified structural volumes provide more options for individual subdivisions for each repurpose of the building. It is important to consider depth of space as well as floor to floor height. These decisions will impact lighting, ventilation, engineering systems installation and optimal plan opportunities.

Building skin is a design element, providing options for natural ventilation and daylight strategies as well as central and individual control. Development of intelligent adaptive systems and vegetation adds on creative knowledge work office design possibilities.

Ever since office landscaping a configuration and building proportion has been shifting. The free shape plan transformed to a more efficient rectangular form with utilities placed in a building core. Novel approaches examine the most efficient ratios structurally and functionally with building segmentation, but this approach has a weakness in its limited repurpose options.

Zoning. For a long time, ever since office landscaping, open space was perceived as a solution to productivity and collaboration issues. However, with increasing implementation it was soon noticed that besides all the positive outcomes, open spaces might be "noisy, distracting, tiring and generally unhelpful to getting the real work done" (Myerson, Bichard, Erlich, 2010). Semi-private space transformed into semi-public one (Becker, 1981). People could not be made to work together through "enforced proximity." The issues with confidentiality also arose from a very flexible and open spatial and 
organizational arrangements.

As described in Gensler survey the most important issue for an office building zoning is to find a balance between different work modes and thus different physical settings for each of them. Gensler lists the need for Focus, Collaborate, Learn and Socialize. Duffy (Duffy et. al, 1998) describes similar spatial division by listing Cells, Hives, Dens and Clubs zones. Cells and Hives could be referred as two types of Gensler's Focus, while Dens and Clubs respectively as two types of Collaboration mode. Myerson (Myerson, Bichard, Erlich, 2010) suggest a different divide into Collaboration, Concentration and Contemplation (also referred to as Reflection) modes, identified in his research about graying knowledge workforce. Groves (2011) names the mane activities as Stimulate, Reflect, Play and Collaborate. The modes of Contemplation, Reflect and Learn are somewhat similar as they are not directly related to work tasks, but rather to long term mental preparation. Each of these zones have specific requirements such as isolating and silent for Focus, Concentration and Reflect zone or encouraging communication for creative hubs, labs, Collaboration, Den, Club zones and other team work spaces.

Creative activity was also structured with varying spatial need assumption. Wallas (Wallas, 1926) lists four stages of creative process: Preparation (problem investigation), Incubation (mental information processing), Illumination (the birth of the idea) and Verification (testing). Other authors claim that creative process besides problem solving also includes problem finding (Florida, 2012, Sawyer, 2003).

Another contemporary workspace design strategy is based on picking defining company's culture and basing workspace design off of it. Haworth research offers a framework of four main organizational types that every company should fall into based on the culture and workstyle. The categories consist of Collaborate ("do things together"), Create ("do things first"), Compete ("do things fast") and Control ("do things right") (Haworth, 2015).

Building Systems. Acoustics. As a BOSTI research (Brill et. al., 2001) revealed 
people spend about $25 \%$ of their work time making noise in or near their work place. As "noise is the most significant and consistent cause of distraction" (Myerson, Bichard, Erlich,2010), it is very important to have controls over it. Design options may include physical noise barriers (various types of walls that may or may not also isolate visual interventions), natural elements (divisions formed out of plants or water curtains) or novel sound transformations systems (eg. Future Acoustic that 'listens' to background noise and reduces its distracting qualities by overlaying more pleasant sounds) (Myerson, Bichard, Erlich,2010)). Acoustics could also be controlled by social conventions (eg. setting silent zones like in the library), partial or full enclosure of the workspace and appropriate zoning of work activities within the office.

Johnson (2015) summarizes 5 basic acoustic design strategies. First, it is important to distribute spaces by gradual acoustic sensitivity. Second, it the use of absorptive materials, to control the amount of reflected sound within a room, and absorptive surfaces on furniture is crucial. Third, design should incorporate sound blocking between the spaces. Fourth, intruding noises should be covered with background noise and specifically electronic sound masking. Lastly, a social factor driving new behavior in the workplace with design, protocols and group norms should encourage appropriate actions reducing the levels of noise (Johnson, 2015).

Building Systems. Lighting. Effective lighting is a very important factor for employee's productivity. A smart combination between the daylight and artificial lighting systems can not only improve workspace quality but also save energy, which adds up to general profitability and operations cost of the project. The light strategy should also vary depending on the zone it is used in. Individual control over the amounts, directions and sources of light helps to personalize the space and adjust to the varying needs of creative knowledge workers. The use of task lights and daylight are often defined as an optimum lighting design strategy (Myerson, Bichard, Erlich, 2010, Duffy, Laing, Crisp, 1993).

Natural Elements. Sustainable approaches also emphasize natural design elements. 
Plants or flowing water elements inside may provide a harmonious and relaxing work environment, while nice views through the windows and the feeling of connectedness with the environment can help to concentrate (Myerson, Bichard, Erlich,2010).

As sustainability becomes an important social, political and economic cause it is often used as one of the integrative strategies for contemporary office design. Companies consider life cycle cost instead of an initial one and require designers to take into consideration resources conservation and impact on workers' health. In addition the assessment of environmental features is proven to positively correlate with the performance factors (Feige et.al., 2013). Green design systems such as LEED or BREEAM set new office building design standards.

Geography of location. The physical location of an office depends on many factors: reliance on central urban resources, the need to be accessible for the customers, proximity of particular infrastructure and other location related amenities (Duffy, Laing, Crisp, 1993). However, creative knowledge workers are heavily involved with ICT which makes them more mobile on the inside as well as the outside of the building. Increased workers' mobility diminishes the importance of particular geographical setting, as they can work from almost anywhere as long as they get an adequate support from the physical environment for their professional activities.

Keeping an office in the city center, unless it is not absolutely necessary (eg. customers service office), is too expensive, so most of the creative knowledge offices move to suburban areas. There is an urban fabric tendency of knowledge sector clustering in particular regions such as California's Silicon Valley or London's Shoreditch(Myerson, Bichard, Erlich, 2010). 
7.2.1. 2. Physical Settings. Fixed Feature Space Elements and Principles - Designers

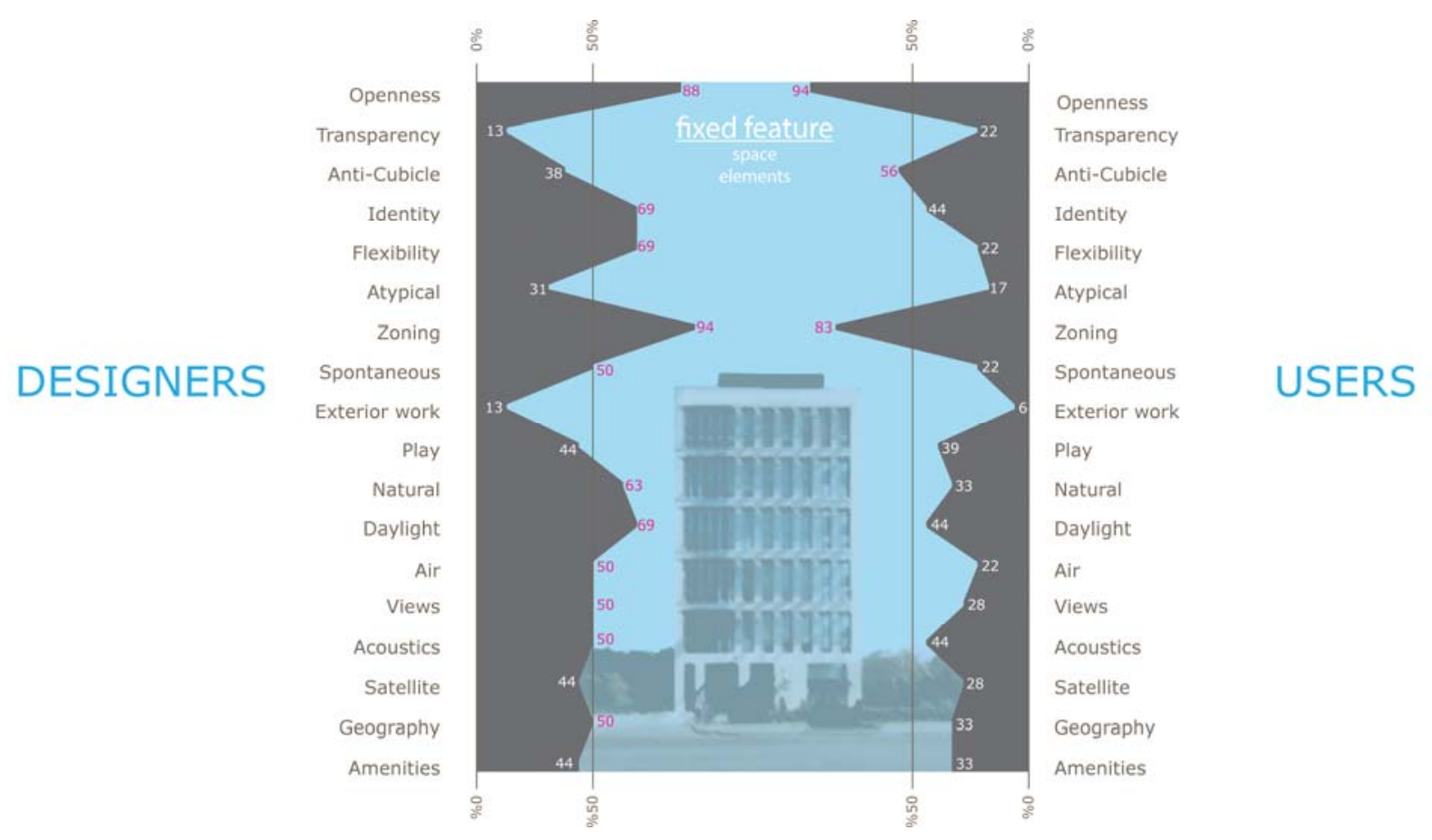

Figure 21: Fixed Feature Space elements' definitions.

Building Configuration. Openness. One of the most common concepts that appeared on designers' responses related to the building configuration was the open plan. Interviewees referred to it as an "open ended," "airy," "spacious," "large space" and "somewhat of a blank slate." The openness was mentioned as not only a planar characteristic as designers mentioned "higher volumes, higher spaces (not necessarily an indoor detail)," and "ceiling height (twice as tall as a typical height)" as "creative spaces should be big to contain big thoughts."

Some of the interviewees contrasted the openness of "creative workspace" to the private closed offices layout and referred to it as a "corporate," "hard wall offices, where you can't see who's in," "common office," "very traditional workplace ," "the old model," and "the workplace that supports work that was needed 20 or 50 years ago." Open layout in these cases is defined as a result of "breaking down the walls." Others, similarly, juxtaposed open layout to the "typical cubicle setup" that reminds of a "box" or "accounting department" and gives an impression of "repetitive, fixed individual spaces," 
"classic giant pool of office workers," and employees being "boxed in." Although, some interviewees agreed that "a 'cubicle' has various meanings" and the height of the wall can make a big difference in space division and perception. In most of the cases the openness was presented as an inevitable design solutions to promote collaboration.

However, as often times "creative workspace" design is a retrofit rather than new building project interviewees spoke about potentially frustrating limitations of existing structural and functional conditions. Sometimes the ideals of openness to all the three dimensions cannot be achieved due to the construction or budget restrictions.

Building Configuration. Transparency. Openness was also related to the idea of transparency, which can be present as a visual characteristic of the space showcasing the "choices in front of you," meeting "fire safety and security" requirements, but also as a statement about organizational values. "Transparency in your work environment" helps to show that you "stand for transparency as an organization."

Building Configuration. Flexibility. Open plan layout is also very flexible in accommodating "spatial devices through which different spatial arrangements can occur." Flexibility by some of the interviewees was defined as the transformative potential of the space, capability to easily rearrange the plan and its functions. "It can open up and be one big area" or it "can close and it becomes a conference room or a game room." The space "can transform in the variety of functions: game room, conference room, display room, presentation room, gathering place just by rolling a door, flipping a table, moving some chairs." The space should have "no hard walls, predicting rearrangements that might happen" "on a moment's notice."

Flexibility was also defined as having a potential for expansion or densification, which means the change in function or usage intensity "with the growth of the company." It was also related to quick development of the company when "they don't know all of their product brand services" by the time the space is being designed, so certain opportunities should be provided to refine the functional distributions in the future. In addition, some 
designers were using this term interchangeably with adaptability, which would mean the ability to adjust spatial elements to individual user's needs on Semi-Fixed Feature Space level.

Building Configuration. Other typologies. Designers' responses have also provided an interesting discussion about the way different building typologies can be adopted for "creative workspace" spatial configuration design. The given examples included the airport, residential, hospitality, storage, educational and restaurant building types. Designers mentioned particular spatial elements or principles that can be adopted such as "fluidity of movement and transparency," characteristics that fall somewhere "between the home and the hotel, trying to provide all the functions," "large space" from "warehouses, storage spaces and utility areas," "architecture studio" collaborative spirit and informal "third place" vibe translated into "lounge environment."

Zoning. Most of the designers have recognized the need to accommodate "different kind of moods," "all the work settings," "appropriate" or "wide range of spaces" and break up the open environment "in different areas and have distinct personalities," allowing the "individuals to make decisions over where they're getting their best work done."

The space types that came up in designers' in-depth interviews were "series of conference rooms around the open space," "social functions of the space," "individual space to break away and retreat," circulation, "food, recreation, showers, even dog parks." It was also emphasized that designing the space is not sufficient and users have to be trained to "understand that when I have this kind of work to do, I can go to this kind of place and it will really support this kind of work."

In addition, "the location of their performance shifts throughout the day" and it requires for higher level of mobility. The employee has to "move from one space to another depending on what kind of task you're trying to tackle." This requires for visual and physical connectivity between the different kinds of spaces, exterior and public/work environments. 
Zoning. Spontaneous Interactions. Higher rates of mobility results in higher importance of circulation paths. It becomes an ideal environment for unexpected interactions and spontaneous activities, which are seen to be as one of the main sources of innovation. Space should be "planned and almost require people to move around and bump into one another, interact" and "not staying stationary."

Unexpected interactions result from flexible treatment of time and space. Therefore, another kind of spaces that can facilitate such setting is a social gathering area "driven by art, landscape or media," with "some reference points" or "a range of opportunities engaging with noise and distraction."

Zoning. Play. Another peculiar type of zone or activity that came up in the indepth interviews was related to games and play. "Blending work and leisure spaces," having "game rooms and relaxing rooms" with "ping pong table or movie screening on Friday night" is part of the built environment as well as part of organizational structure. It is considered to be an amenity to reduce stress levels and encourage more spontaneous interactions.

However, designers expressed certain skepticism towards "a cliché image of creative office as a funhouse" and referred to it as an "infantilizing." Also, interviewees mentioned that "with high lease rates it is harder to justify area for playing" and as a result "the area needed for job might be minimized."

Zoning. Exterior Workspace. Most of the designer reflected on various restrictions related to exterior space design. They have mentioned regulations and codes, little to no access to the site from the designed property and uneven climatic conditions. However, exterior design and landscaping was seen as a desirable part of the project with a lot of potential to contribute to employees' wellness, retreat, social needs and quite work.

Zoning. Balance. The in-depth interviews with the designers have revealed a common concern related to "creative workspace" design. Interviewees noticed a pattern of prioritizing superficial design elements, such as furniture or finishing, to 
multifunctional planar layout. "It is very important not to let that concept to be so overbearing that it limits what the users can do ultimately with the space." Some of the designers were favoring "not looking in the aesthetics," but "concentrating on supporting the works processes." They stated that "that the creative intent of the workspace potentially became overwhelming" and "a little chaotic" with "too many different materials, too many different styles" and that the "design is not what we're trying to accomplish, it is a tool to help us accomplish creative workspace." Overall, the importance of meeting "operational goals of the client first, while adding design value along the way" should be based on a balanced design process.

Building systems. Lighting. The designers would mention light and ventilation strategies as a part of basic design. However, the fact that these elements were mentioned separately might mean that on regular basis there is not enough attention dedicated to them.

Building systems. Air. Specific comments related to the daylight in big open spaces were about structural limitations, building code requirements, use of skylights, glare and heat control.

Building systems. Acoustics. Acoustics related comments were two-fold. On one hand, interviewees were talking about the measure to achieve "acoustic privacy," isolate the sound and thus achieving these goals were perceived as design restriction. On the other hand, designers were discussing energetic sound qualities and how it can sparkle more creative work attitudes. Silence was described as the opposite of communication an essential part of creative work. "If we have a lot of silence it stops creativity along the way." Therefore, some of the interviewees suggested that "it shouldn't be quite," and the "a place where you can be loud and active" or "active acoustically" place creates "energy" embodied in "sounds (music, noise, and buzz)."

Natural Elements. As discussed in the section about "Exterior Workspace," designers recognize limitations related to the design that takes place outside of the 
building. However, they also recognize the importance of natural elements and the comments related to this topic could be divided into three distinct groups: exterior spaces, exterior circulation and exterior elements inside of the building.

Exterior space and landscape design can potentially provide social, recreational or work environments. The "natural amenities" can be as complex as a "a network of secret gardens" or as compact as a "vertical green wall [that] allows to create green open spaces without really having much space." Facing the trouble of finding space outside of the building the space can be "reclaimed" as an "inside courtyards and big balconies or terraces" or "park in parking space."

Exterior circulation was described as a "refreshing" experience, giving "a sense of fresh air," a way "to take breaks," providing "a sense of exercise," which "helps to get back in tune to what's happening in the world." It has been described as a physical and mental recreational measure.

Partially due to external design restrictions, partially due to the need of natural elements in urban environments designers expressed the need of "bringing the outside in." The "natural elements" were not discussed in a greater detail, but their importance was definitely stressed.

Geography of location. Geography of location was refereed by the interviewees as an important aspect when resolving transportation, providing views and amenities for the highest convenience of the users. Designers explained that there's a tendency of similar industries clustering in a single "zone of likeminded individuals or likeminded businesses." A potential negative outcome that may result out of that is that all of the companies are providing needed amenities internally, cutting down the need for the employees to go outside and creating "unhealthy urbanism" with no pedestrian circulation in the area.

Geography of location. Views. The "visual access to the outdoors" was described as an important asset, allowing "to daydream and escape" and "to give a break for a mind 
from what the mind is intensely focusing on." The "views to the trees" or other natural elements should be a result of picking the right location for the object and potentially landscape design on the exterior.

Geography of location. Satellite Work. "Work doesn't always happen within four walls of the office in the traditional setting we've been thinking of in the last 50 years." The increased "creative workspace" users' mobility may result not only in the internal movement within the workspace but also in "satellite work [that] might be managed through spatial systems." Satellite work option provides employee with more choice, flexibility and employer with a more efficient use of space and having more work done without paying for extra area to accommodate the process.

Satellite work can be done either from home, or from the "third places," which are neither work, nor home, such as "a café, a sandwich shop or coffee shop." There are work modes that require very minimal tools to be completed such as a place to sit, a drink and $\mathrm{Wi}-\mathrm{Fi}$. Some businesses noticed this opportunity and created alternative space uses for such workers. For example, a car exhibition space provides sitting area with cafe and Wi-Fi to accommodate satellite workers while peripherally promoting their product.

On the other hand satellite work is less managed and controlled. Therefore, some companies are trying to create fake "third places" internally within the company to keep higher accountability of their employees. For example, they can intentionally design company's canteen so that I would remind of a coffee shops or transform lobby into a less formal "lounge environment" that still promotes company's values.

Geography of location. Amenities. The geography of location is very important in terms of what amenities are being provided to the workers: "it must be convenient for the employee." The more chores and personal matters they can take care of during the lunch break the more dedicated for the work they will be for the rest of the day. Therefore transportation, recreation, food, relaxation, education, medical and other services should be either in a close proximity to the workplace or provided by the company internally to 
ensure undivided attention to the work tasks.

Some designers have even called "creative workspace" to be an "amenity driven" design. They claimed to get the lists of all the spaces that would not be directly related to work, but would have to be incorporated in the building plan. Because, "if there's no amenities in the area you got to be able to support a life-work balance, to allow people to get done with what they need to in their personal lives and then get back to work so they can be creative." Some of the amenities listed by interviewees included "from coffee shops to a gym to other places to work, to park spaces" and "food, coffee, basics, ability to take care of your personal matters during the lunch break: doctor appointment, dry cleaning." A cultural context was also seen as an amenity as seemingly an "area where the arts are peripheral" is supposed to spark creativity.

Identity. Over half of interviewees stated that "creative workspace" concept was related to the identity of the space. Designers stated to choose different strategies to achieve this design goal: from expressing the brand and the values of the company as a marketing tool for the public and "providing unique experiences" of the space to emphasizing organizational culture and management strategies.

Identity of the space "can translate emotion" through interaction with the space. "The memory in the space helps" "to feel more welcome the next time." "Every visual clue matters and makes every new visit more pleasant." "Space that facilitates the experience of being more thoughtful," "comfortable enough" and has "energy." In terms of attracting and retaining young talents the design of the space should spell "fun" and "cool."

One of the patterns in creating an identity for "creative workspace" was described as "a space that had a raw feeling" as a base for an "intervention based design," tried to translate "casual image" and be "minimalist, because it forces to imagine rather than see and apply."

Another pattern that showed up from in-depth interviews in relation to creating 
identity was atypical spatial elements and arrangements. Interviewees spelled it as "qualities of strangeness," "a bit non-traditional," "elements that are really bold" and "provoking thought, moods that would instigate people to think in a different way." Atypical elements can be achieved by displaying unexpected or out of place things, "making strange things familiar and familiar things strange" to "get brain working."

\subsubsection{Physical Settings. Fixed Feature Space Elements and Principles - Users}

Building Configuration. Openness. The concepts of openness showed up more often in the users' responses than in the designers' ones. Interviewees stated that "creative workspace should have a lot of space in it, it shouldn't be too cluttered," it should be "spacious," have "less walls," "architecturally there are no boundaries." Users

directly related openness to collaboration. "Having a big room where everyone can get together and collaborate" or "just go and talk to someone or see what they're doing from across the room." Although openness was also perceived by some as "a cluttered space" where "it's hard to manage who is responsible for what." Therefore, "open is great, but within a certain structure."

Users even more often than designers in lack of terms to define "creative workspace" would rather contrast it to "cubicle" settings and "stereotype of the box." They would negatively reflect to "mental and physical barrier," difficulties "to casually interact with colleagues," "gray walls and beige desks," "bureaucratic, government agency, boring" and "institutional hall" as a perfect opposite to their current "creative workspace" environment. An interesting thing to notice is that the mental barriers would not be necessarily attributed to physical cubicle layout. On one hand, "some places don't have physical cubicles, but you feel that you're designated to a specific spot and you're not able to do all of these great things where you may meet other people." On another hand, there're "modified open workspaces, where people still have their individual cubicles, but the wall is half as tall" and that helps to reduce the feeling of barrier.

Building Configuration. Transparency. Transparency in users' responses was seen 
as a managerial measure keeping employees "accountable," "not being able to hide," "open to the public at all times." The idea that you share the workspace with your supervisors and "the rest of the department could check" on what you do creates "no secrets environment" and encourages higher levels of performance. This "visibility to everything around you" also promotes cautiousness about your colleague, their work and being part of a bigger organization that relates to job satisfaction and engagement.

Building Configuration. Flexible. Flexibility as a concept was less common in users' responses compared to the designers' ones. The respondents indicated that "creative workspace" "must serve a number of needs at any moment," should be "versatile" and allow to "change the layout depending on how things are going." Users appreciate the simplicity of transformations ("couple of desks turning into table or single person's workspace turning into conference call") that would allow them to make changes quickly and concentrate on the work. The flexibility through mobility can be expressed in changing the work environment geographically rather than physically "experimenting unassigned seating."

Zoning. Just like designers, users emphasized the importance to "support different work modes: conference rooms, phone booths, writing rooms (quite spaces)," "having different ways to work" and "a special zone for craft."

Despite from all the praising of collaborative and open environments interviewees also stressed the importance of getting things done in quite private spaces and a lack of such settings. Users expresses the need for "more quite spaces, phone booths," a "quite room to balance the design out," a "place to do certain kind of work and not be distracted" and "options to go somewhere to think by yourself." The interviewees also spoke about quiet and focused work in small teams and a need of "smaller conference rooms" to "focus things when you only have couple people in the room that have a more refined purpose than just a general work."

Connections between the spaces were mentioned as an important thing for 
continuous information flows. Users were mostly talking about the importance of containing all workforce in near proximity for more efficient communication. "It really helps when everyone in a company is in the same building" or even better "in one space together" to make it "much easier" "to communicate."

Zoning. Spontaneous Interactions. Users described circulation areas as an important element contributing to employees' mobility and freedom of motion. It was important for the interviewees to "roam around without bumping into things," experience "diversity of the movement within the space" and to "move about freely."

On the other hand spontaneous interactions with other people are seen as a virtue. It may derive from "places with people traffic" but mostly is perceived to happen in the open and transparent work environments. Such settings enable users to "stand up from your desk walk to another place and see entirely different people and hear entirely different conversations" or "be exposed to something, which you didn't think of before or you didn't expect" and encounter an "unexpected collaboration."

Zoning. Play. In their interviews users have indicated "play" as one of the activities integral with their work and requiring for an addition space or zone. Throughout the responses there have been two patterns related to the activity of "play" showing up. Interviewees identified play as a way to distress, relax and "disconnect from whatever you're doing" or as a way to brainstorm with mock-ups and other tactile tools to visualize work-related ideas ("we get to play, like in art classroom").

Zoning. Exterior Workspace. In the discussion about exterior workspace users were skeptical. They acknowledged such intentionally designed "option to sit and work outside" in their work environment, but admitted that it did not become one of their common work spaces and they do not see too much of creative potential related to the work in the exterior.

Building systems. Lighting. Users have expressed the crucial importance of the daylight. They stated that "it should be bright, and there should be a lot of natural 
light," that is the "first thing" they look for in the workspace and that they could use more of it. One of the interviewees even compared himself to a "plant" to better illustrate the effect daylight has on him and his performance.

Building systems. Air. Some of the users have also mentioned the air conditioning, temperature and "feeling of air circulation." Having personal control over it was defined as an important measure in terms of workspace adaptability and cost efficiency.

Building systems. Acoustics. Different than the designers, users have named acoustics as solely problematic characteristic that should be controlled for better work results. The problem arises in open workspace where any kind of sound (from "three or more people having a conversation" to upset coworker "typing on his keyboard") travels with no physical barrier. Interviewees indicated strategies to cope with the issue such as additional insolation in perimeter walls to damp the sound, having quite rooms for really focused work or management solutions such as "quite hours" or special "focus" table sign indicating that a person should not be disturbed at a given moment

Natural Elements. The rate of mentioned natural elements was not very high in users' responses. However, they did recognize the importance of "getting out of the office," have an "ability to go for a walk" and that the "change in sceneries can be helpful." They have also mentioned a positive impact of having "a park behind our building" and an access to "natural living things."

Geography of location. "Creative workspace" users' responses related to the geography of location indicated the importance of site's energy while calling it "active and fun to be at," "dynamic" and "near a lot of inspiration." They have also mentioned the importance of amenities (either inside or near the building) which allows them to not leave the building or the area.

Geography of location. Satellite Work. Users mentioned the satellite work from either home or a "café" as a proof of trust and freedom provided by the employers. The interviewees mentioned that on one hand such an option provides a "retreat for one 
project for as long as they want without being interrupted," but also a satellite worker can get "a little cut off" "from what's going on" in the workplace.

Identity. "Creative workspace" users in their responses mainly related the identity of the space to the identity of the worker and levels of individual control over it. They described it as an incorporation of "your most individual self," "customization of the space" and that the "environment is reflective of the process." In that way "people hack every space into being creative" and "even in the most traditionally not creative space" can teach something.

The levels of modification were not indicated clearly in the responses, but interviewees stated that "there's a creative vibe" and "it doesn't seem like an office, but you're getting work done."

\subsubsection{Physical Settings. Semi-Fixed Feature Space Elements and Principles}

\subsubsection{Physical Settings. Semi-Fixed Feature Space Elements and Principles - Researchers}

Furniture. The evolution of the workstation was related to changing concepts on ergonomics, quality, materiality, transformability and styles of the furniture, while the advent of the paperless office dramatically reduced storage space requirements. Individual control of the workspace which may be achieved with adjustable furniture (also lighting or ventilation) provides

more self-confidence, psychological comfort and personalization options (Myerson, Bichard, Erlich, 2010).

Work posture, which is very important for employee's health condition in a long run, is also related to furniture. The office work is commonly seen as a seated one and "to get up from your seat signals a stop to doing serious work" (Myerson, Bichard, Erlich, 2010). Design solutions could provide options for work in various postures protecting workers from skeletal-muscular disorders.

Furniture may also serve as an element for isolation or division. Tim Parsons (Parsons, 2001), for instance, suggested experimental office furniture such as a chair with umbrella or a 'no door mat' instead of a physical partition with a door. His study 
concluded that such a simple mean may effectively reduce the amount of distractions.

Technology. Technology is being seen as synonymous with knowledge work and therefore a workspace must not only accommodate the needed appliances but also take into consideration a human factor and make the use of ICT effortless. 'Paperless office' or 'clean-desk' concepts represents novel ideas about knowledge work and integrates voice, data, video and images (Brill et.al., 2001). However, 'alternative' (physical) data representation sometimes is still more efficient and convenient to use as well as more engaging creative abilities (Myerson, Bichard, Erlich, 2010).

The fast pace of technological development might require additional training. While technological advancement goes hand in hand with the essence of knowledge worker's performance, the pace of change can be overwhelming even for them. "Some companies have introduced coaching and mentoring schemes," while "others rely on knowledge workers to work around the problem and find their own way through" (Myerson, Bichard, Erlich, 2010). It is important to understand that technology is just another tool to perform a task and not a workforce in itself.

As technology becomes integral within the building, additional systems are needed to control internal and external processes of the built environment. The rise of intelligent buildings proves a wider applicability of technological advancement (Duffy, Laing, Crisp, 1993). Additionally technology creates a parallel digital environment that becomes an alternative space to execute work tasks (Megill, 2004). 
7.2.2. 2. Physical Settings. Semi-Fixed Feature Space Elements and PrincirLes - Designers

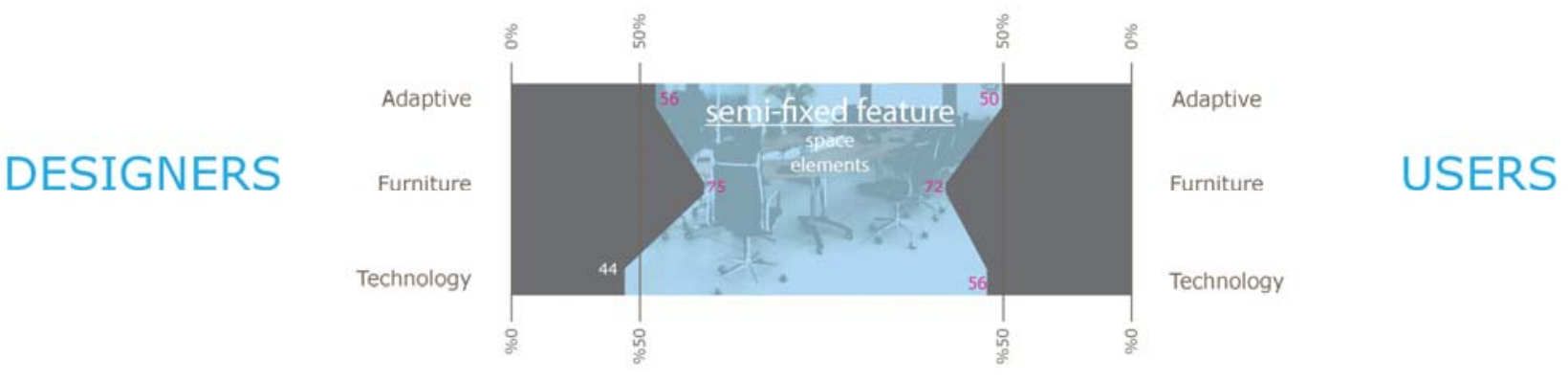

Figure 22: Semi-fixed Feature Space elements' definitions.

Adaptability. Designers expressed the importance of "the workspace that's able to respond to the needs of its users, adapt itself over the course of period of time, being it an hour, a day or a month or more." Interviewees have also defined adaptability as a form of interactions with the space. "Creative workspace" is "open for interpretation to as what each user defines as an appropriate workspace" and it is "the workspace that you would notice and interact" with. Adaptability also depends on different levels of control that the user has over it. So the more "choice of defining what your workspace needs to be for that task" employee has, the more efficient they will be.

The control over individual's environment also results in the feeling of "pride," "investment," "ownership" and in turn in higher job satisfaction. Employees "really recognize the connection between people being satisfied, feeling supported and even happy at work." The only controversy it may cause is that ownership contradicts mobility needed for easier communication between coworkers.

Furniture. In their interviews, respondents spoke about high level of customization in the field of furniture. Unique interior elements can be a part of the space identity, ergonomically adjusted to particular users' physique and help to create team spirit and reach higher levels of job satisfaction. One of the interviewees spoke about two neighboring teams that were competing as to which one will have a more extraordinary conference table and how that goal helped them to create part of their collective identity. 
Furniture or movable partitions in a very generic way were described as "work surfaces that come in a lot of different forms." In this sense the open space with movable and transformable parts should be ideal for individual to adjust to their needs.

Technology. Technology described by the designers was mainly related to either supporting individual work process or helping to have an easier communication with the coworkers. The interviewees spoke about the supportive environment with an "access to all the tools needed for work" and "the parts that support the need of user in that space" and how environment should reflect that. For example glare control is especially acute because "majority of work is done on computer screens."

From communication point of view "supporting technologies" were described as a way to visualize data and stay in touch with the team member working on satellite mode (be it another office division, home or a "third place"). "Almost every group spaces will have a technology in it that allows people to work together on things" and "make themselves accessible" and "being able to view what other have done."

\subsubsection{Physical Settings. Semi-Fixed Feature Space Elements and Principles - Users}

Adaptability. The users talked about the perks of being "given quite a bit of control over the space" and how that affects their relationship to the work environment and work itself. The choice and different options allowed for the users to "hack every space into being creative," be their "most individual self" and incorporate it in the workspace, "manage [the] environment to address the problem" and "feel like if there's something that really bugs" them, they "can fix it." The ability to change the environment according to the individual needs was also described as "very subjective" and "reassuring."

Furniture. Nearly two thirds of respondents have stressed the importance of furniture. Three major functional patterns could be traced from the responses: flexibility, ergonomics and visual display. All of these functions are related to each other in terms of how the current furniture systems function. However, certain improvements could be built into the future designs based on the research findings. 
The benefits of having transformable, flexible and mobile furniture result in a wider range of spatial arrangements, increased ways of using the same space and varying density capabilities based on the need. "Couple of desks turning into table or single person's workspace turning into conference call" allow resetting the space instead of having a rigid pre-assigned zoning. In addition, mobile furniture allows to easily try out "couple of combinations" or "move to different location to collaborate," while having the tools that may be a part of the furniture with you. In addition, multiple functions built in the furniture ("seating with a storage" or a "tall collaborative table" which serves as a quite work space in the times of no meetings) allow to save space in the workplace.

Half of the respondents mentioned the importance of ergonomics in the furniture design and how they appreciate the environment adjusted to their individual physiques and be able to change their working posture throughout the work day. Some of the respondents indicated having special staff within the company responsible for ergonomic standards, the others described the ease of convincing the employers to switch to the new type of furniture for workstations, and others described dedicated zones with standup desks as a different way to provide the variety in work posture.

Half of the respondents emphasized the importance of visualizing their work through drawing, writing or otherwise making their work process visual. The most common piece of furniture responding to this need was a "whiteboard," but interviewees have also mentioned certain exposition settings such as pinup boards, magnetic walls or other platforms to expose in-progress as well as finished projects.

Technology. Over half of the interviewees has mentioned the importance of the technology in their workspace. It was identified as a very important tool helping to visualize the work and communicate with distant team members and/or clientele. Commonly mentioned technology related aspects were related to a modern, easy to use communication and presentation tools as well as an appropriate distribution of outlets to ensure an undisruptive function. 


\subsubsection{Organizational Settings. Informal SPACE ElementS AND PRINCIPLES}

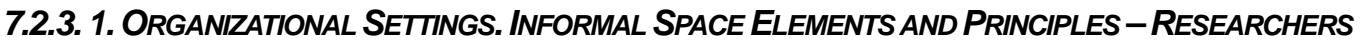

Collaboration. As researchers indicate 'creative knowledge' work is in big part about collaboration, interdisciplinary attitudes towards the problems and combination of force in search of excellence (Rasmus, 2010, Duffy et. al, 1998, Nedler, 2014). Working in team of mixed disciplines helps to change the perception towards the problem and hence, think

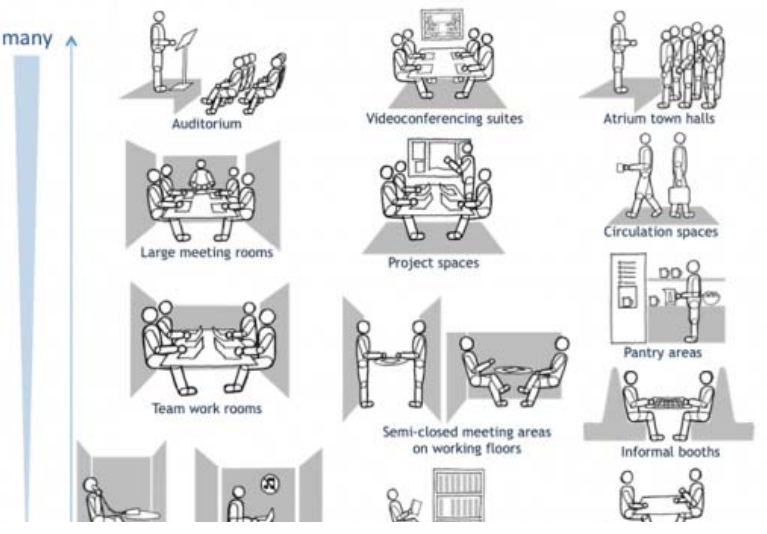

Figure 23: A range of different spaces for different levels of collaboration

differently and creatively. However, it is important to distinguish the difference between "coordination ('I'm handing this over to you')", "cooperation ('I'm helping you out')," "communication ('I'm keeping you up to date')" and collaboration, a process that creates new material through team work (Groves, 2011; Megill, 2004). This kind of work approach has to be nurtured spatially (no physical or visual boundaries in collaborative spaces), conceptually (technology allows to link different spaces through different times) and culturally (the management strategies and company's values have to support collaborative attitudes in the workplace) (Megill, 2004).

Collaboration is often times directly tied to the open plan strategy and enforced proximity of the workers that has been a common workspace design solution ever since office landscaping (Rasmus, 2010, Martens, 2011, On the Job: Design and the American Office, 2000). However, the Researchers recognize limiting factors of such layout as they can get "noisy, distracting, tiring and generally unhelpful to getting the real work done" (Myerson, Bichard, Erlich, 2010, Brill et.al., 2001). Moreover, Davenport, Thomas and Cantrell wrote a paper for the MIT Sloan Management Review in which they were discussing that not all the knowledge workers are the same and certain segmentation based on varying needs should be developed 
(Myerson, Bichard, Erlich, 2010). 'Creative knowledge' workforce grows to be increasingly diverse collaboration becomes more complex and requires to rethink the space that inhabit it (Rasmus, 2010). Therefore, Researchers recognize the need to have a designated collaboration space or even different kinds of space for kinds of collaboration (Groves, 2011, Gensler, 2013, Duffy et. al, 1998, Myerson, Bichard, Erlich, 2010, Wallas, 1926).

Management. Physical place has a social-psychological dimension related to individual experiences of the same setting so it is important to control basic activities. Management strategies regulate the work processes as well as control the quality of the final outcome. It is also important to promote collaboration, provide resources and stimulate a creative culture by expressing the organization's creative identity (Martens, 2011).

Management also plays a major part in the efficiency of physical environments. The employees have to be trained to make the best of innovative workspace solutions. Moreover, if the performance and behavior is continuously tracked, effective additional measures may be implemented. Tim Parsons in his study "Privacy in Open Plan Offices" (Parsons, 2001) discovered that the named open spaces disadvantages may not be solely related to the lack of territorial and physical elements. It turned out that intangible distractions as well as office culture and customs have just as much of effect on employee's ability to concentrate for the task as a spatial arrangement. Simple things such as office post-delivery or disrespectful personal space treatment may distract the workers and reduce productivity.

Part of management issues are resolved through changing work culture where an expected self-sufficiency of a worker should minimize the need of different positions. The need of secretaries is being cut down through reliance on each employee to plan his or her own time, meetings, print and copy and organize events. The need of technicians is minimized requiring a higher technological expertise from creative knowledge workers. It is especially true in design and IT related fields where each office may work with a 
different software program to achieve the same result.

Time. New managerial trends in time and space management emerged as a response to high real estate rent and maintenance costs as well as to improved ICT approaches. The need to use office space as efficiently as possible led to extreme occupancy enforcements and encouraged detachment from particular 'anchored' locations within the workspace.

Hot desking, hoteling, flextime and other space use efficiency augmentation measures did not always prove to improve the performance (Florida, R., 2012, On the Job: Design and the American Office, 2000, Brill et.al., 2001). Being free of location results in a diminished amount of supervision, which in turn despite from individual responsibility may result in decreased productivity (Myerson, Bichard, Erlich, 2010). Working from home also has a negative impact on employee's personal life since it is harder to manage transition from 'work' to 'live' mode without physical differentiation of the environment.

A concept of 'compressed work week' is also changing the patterns of workspace use. Two common forms of such time management involve 4/10 and 9/80, where respectively employers offer to work either 10 hour days for 4 days and then have an additional day off or 9 hours for 9 days and then enjoy additional free day. These measures not only improve the percentage of time dedicated to work tasks within a day but also helps to save operational costs on additional free days (GBES, 2014).

Wellness. A healthy worker is a happy worker and a happy worker is a productive worker. Taking measures such as a fitting lighting, screens adjusted for prolonged reading, reduced need for heavy weight lifting, the use of ergonomic adjustable furniture and the incorporation of fitness support facilities - all contribute to a better physical condition, positive mood, reduced fatigue and improved productivity. Therefore companies are developing special Health and Productivity (H\&P) programs or monitor work environment influence with Healthy Workspace 
Index (HWI) (Watson Wyatt Worldwide, 2010).

Restorative measures also contribute to the general performance. "Short periods of 'contemplation', 'meditation' or 'power napping' may boost workrelated mental activity and productivity among all employees" (Myerson, Bichard, Erlich, 2010).

Health issues are more acute with senior workers as their general physical condition is comparatively less positive. However, taking measures to ensure a healthier environment for all, might preserve positive physical shape of younger employees for a longer time and also boost their work satisfaction by letting them know that their supervisors care about their physical state.

Job Satisfaction. The study that Duffy fronted for the BCO (British Council for Offices) and CABE (Commission for Architecture and the Built Environment) identified that the satisfaction at work is a primary factor influencing knowledge workers' productivity. Moreover, it stated that 24 percent of total job satisfaction is related to the workplace design and can affect the performance by 5 percent for individuals and 11 percent for teams (Myerson, Bichard, Erlich, 2010). Other Researchers agree that workplace design directly affects "productivity, job satisfaction, quality of worklife and learning" (Martens, 2011, Brill et.al., 2001, Del et al., 2011)

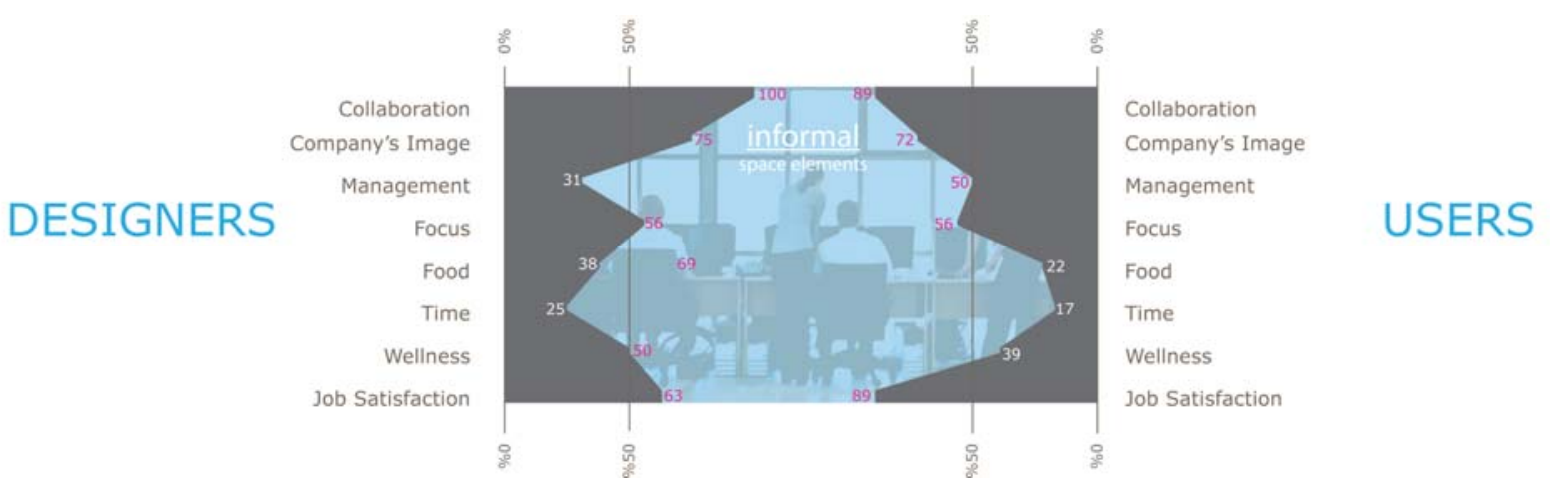

Figure 24: Informal Space elements' definitions. 


\subsubsection{Organizational Settings. Informal Space Elements and Principles - Designers}

Collaboration. Collaborations was mentioned in all of the interviews and designers distinguished different forms that arise in the work process and different spatial arrangements needed to accommodate these forms.

First, the designers were talking about designated collaboration zones such as conference or meeting rooms. They expressed the importance to "respond to the needs for collaboration" by providing "tools for communicating" and allowing to easily bounce "ideas off of each other" and enabling "people to work to together to create output." The main goal of local or distant team work spaces should be increasing the "speed of communication."

Besides the planned meetings and other collaborative activities, designers in their responses have recognized the need for informal social spaces as well as making common workspaces more open for interaction. According to the respondent, the social informal environments create opportunities "to talk to people from different departments" and generally "facilitates easy communication." This may result in unplanned new or strengthened connection and higher willingness to collaborate on work projects.

On the other hand, respondents have also identified the goal of making common workspace more interactive by creating easily approachable settings. Interviewees described the space "where everybody can hear each other, can see what's going on and everybody ways in even when they're not asked to." They were also talking about the "space that encourages you to see what other people are doing and for that to encourage what you do." In addition, there designers expressed an idea of merging social and work environments and/or functions through encouraged circulation through "the space that is planned and almost require people to move around and bump into one another, interact."

Company's image. In their interviews designers were talking about different ways company's image can be expressed and used in the built environment. Respondents pointed out that the organizations seek for consistency in the work they do and the place they work at. The task is to design a workspace that "is culturally part of the brand promise" 
that organization is willing to deliver to its customer. "Workplace is a 24/7 manifestation of the mission, values, and brand of an organization" and "creative" becoming a recent buzz words is perceived as a singularly positive definition. Therefore, as respondents have shared, organizations are "extremely conscious of how they're perceived as a creative workspace."

The other image related design issue is related to translating company's values to the current and prospective employees through visual communication. Such visual elements can convey the company's values, achievements, create a sense of pride, rise motivation to work as well as help to attract and retain key talents of the industry. "Perception is critical in talent recruitment" and "external perception of an active and exciting work environment adds value to the tenant and increases desire to work there." The space should convey that "this is a cool, fun place to work." Designers have mentioned the ways to achieve such impressions with "spatial ideas" (for example, conveying company's transparent policy with an open floor plan layout and high levels of visibility), placing an "image that's very strong with the culture of the company" as a decorative graphics or choosing a "representation of company's work" in a physical or digital way (special stands or screens showcasing highest creative achievements).

A physical environment can also help to achieve cultural or managerial goals and instead of presenting the way company is, present the way "it wants to be." Playful environments or certain layout representing flattened company's hierarchical structure may not represent position of all of the members, but help to attract the desirable workforce and improve the performance.

Management. With open plan and flattened hierarchy commonly described by the interviewees, organization faces certain managerial challenges. Designers named higher need for self-management, self-discipline to overcome distractions, non-conventional work hours ("some people may show up at 6am in the morning and some people are 
gonna stay there until the midnight, but it's not the same person") as well as reduced sense of privacy and comfort.

All of these factors place more trust on the employee and provide more freedom. Employees are "empowered [...] to come up with their own ideas" with less supervision and a little bit of education on "how to use certain practices in design" and "how to use best this kind of space." This kind of training that helps to adopt to contemporary work environments is called "change management." It "describes a process of engaging the people to illustrate how research and understanding have helped to develop recommendations and solutions on a workplace." Organization needs to employ "training or other programs" after severe spatial changes resulting in "using of the space in a different way."

Food. Although food is just one of the amenities that are usually provided in "creative workspaces," designers in their in-depth interviews emphasized the importance of eating as a social act. Interviewees shared experience of designing "central space for food as a gathering point" or "exterior gathering space" and providing "high end kitchens and dining areas." The space to get a meal is considered to be perfect for big company's meetings and casual potentially unexpected interaction on daily basis.

Wellness. Interviewees in their responses recognized the importance of wellness elements being incorporated in the "creative workspace." Besides the ergonomic furniture, already discussed previously, designers were also talking about "gym or meditations room, or yoga studios," "bike path outside," "a sense of exercise and connection to the outside" or designing the showers and an appropriate amount of bike racks, so that the employees could bike to work. Passive measure to improve wellness at work mentioned by the interviewees were "having natural ventilation, daylighting, access to landscape having workspace outside" and making employees "feel comfortable and relaxed, not confined to the office."

Job Satisfaction. More than a half of research respondents admitted actively 
considering a job satisfaction of the future tenants. As "firms are competing for the best employees" in the "creative knowledge" sector, the best way to attract and retain the key talent is to make them "feel comfortable and motivated in their work environment." According to the interviewees "people really recognize the connection between people being satisfied, feeling supported and even happy at work." Some of the designers named "a distinction between satisfaction and engagement" to emphasize the connection between the two. If employees "are more productive they're more happy and satisfied, because they're getting their work done."

According to the interviewed designers, job satisfaction is also highly related to the sense of ownership over the workspace. The sense of ownership can be achieved with "individual space [that] makes it easier to connect." However, open plan or even unassigned seating workspaces face challenges of old ownership patterns "show me my chair, where is my computer," and the organization has to initiate "the change management," described previously.

\subsubsection{Organizational Settings. Informal Space Elements and Principles - Users}

Collaboration. The users in their in-depth interviews agreed on the importance of collaboration but their reasoning was more practical than the one offered by the designers. The users of "creative workspace" emphasized the speed of communication, access to the spaces that allow intense interaction and how that translates to the speed of the work process holistically. An option to "turn around and ask the question rather than call," "get up at any time and talk to [the] coworkers" or "go to another room in order to collaborate." Not feeling "restriction physically or in your mind of where you can go and who you can talk to" provides "willingness to work together."

Another practical elements of collaboration the interviewees have mentioned was the variety of spaces and media helping to quickly exchange the ideas. Having an access to "shared collaborative space in close proximity where other people work and having them coming in and out," "a lot of different options for conference rooms," "overhead projectors, 
conferencing technology," "having a big room," "amenities that allow the staff to jump on an idea when it comes up" or other "elements that can support different kinds of conversation" can improve the rates of successfully communicated and refined ideas.

Research respondents have also talked about being "comfortable to approach someone they may not work in a day to day capacity," "collaborating across different industries, different disciplines, sharing ideas, brainstorming together" and design solutions that can facilitate that. Interviewees have mentioned the spaces that imply a more informal contact, public visual communication with the exhibition of the company's work ("celebrate a finished piece where more people be able to see it") or special events where employees gather socially for non-work related team building activities ("people would put on the workshops on the skills their good at").

Company's image. "Creative workspace" users in their interviews have mainly spoken about company's image reflecting in the space providing a certain positive emotion. "Open space reflects transparency," "it spells 'cool' and affects people's impression," "it's an inviting space" and that "the company is alive" and "fun." Some of the interviewees have mentioned the ways to represent company's identity with graphics or exterior elements, but most of the comment were generally about emotions that the environment is triggering for the employees and visitors.

Management. From management point of view users have emphasized the importance of flattened hierarchy through open space design and distraction management. The same physical setting from their perspective results in seemingly contradictory outcomes.

"The ability to talk to the boss at the same table" and even the ideas that the "boss has the same workspace" that they do or that "nobody has their own office, maybe even CEOS" helps to create a "very family oriented" company culture and make people feel more equal and comfortable.

However, "being in an open space like this can be really distracting" and "at times 
there might be a lot of noise going on." One third of the respondents admitted either having trouble concentrating or being in a need of additional measures (headphones with music, special "focus" signs or "areas to let people their mind wonder") to "zone out," "get rid of distractions and be more creative."

Food. Although, users have indicated food as one of important amenities, but it was not too common among the responses and was reflected more as a service than part of a social life or physical environment.

Wellness. Most of the users emphasized the importance of ergonomic and/or exercisable furniture as a big part of their wellness at work. Some of the users spoke about wellness initiatives provided by the employee such as "a workout program" with a trainer come in and do workouts twice a week. They also have recognized the higher need for recreation because they "don't need to leave the building." However, even if the respondents had more recreational amenities provided at work, they did not reflect on them in their interviews.

Job satisfaction. The respondents of the in-depth interviews were mainly talking about two elements related to the job satisfaction. They were describing a supportive environment that responds to their needs and the ways they can feel a part of "something bigger."

The workspace according to the respondents has the power to make them "happy," "improve employee morale," show "that company cares," "celebrate the work" and simply be "cool." All of these factors, according to interviewees makes them "want to work harder."

The other important thing related to the job satisfaction according to the users was "to see everybody else working on everything else." This realization helps to be more appreciative, build "a relationship between the person and the company" and "feeling part of one big thing instead of just doing my stuff on my own." Both of these elements make employees "invested in proud of" the work they do. 


\subsubsection{CREATIVITY TRIgGERING DESIGN}

\subsubsection{CREATIVITY TRIGgERING DESIGN - RESEARCHERS}

In order to understand how to support creative activities it is important to define what creativity is. Following R.Florida's thorough analysis of creative work it is an ability to "create a meaningful new forms" (Florida, 2012). "New means unusual, unique, new point of view, varied, original, breaking from existing patterns and contributing something to the field which was not there before. Valuable indicates that the product meets a need or solves a problem; it is useful, effective, efficient, serves a purpose and contributes to society" (Martens, 2011).

Beside from different creative work modes listed previously, creative thinking may also have certain features assigned. Sternberg (Sternberg, 1999) lists three intellectual abilities that are especially important to trigger creativity: the ability to see problems in new ways escaping the bounds of conventional thinking, analytic ability to recognize the worthiness of ability to pursue and ability to persuade others of the value of one's ideas. Creativity is also encouraged by divergent (towards insight) as opposed to convergent (analytical) processes as well as tolerant and challenging environments (Martens, 2011).

Mihaly Csikszentmihalyi has defined the efficient creative knowledge workers' performance as a 'state of flow' or an 'optimal experience' (Csikszentmihalyi, 1996). It was described as a complete and unconditional involvement in a task. After the interruption of 'flow' it might take 20 to 30 minutes for an employee to refocus (Florida, 2012).

Myerson et. al talks about importance of satisfying all physical and mental workers' needs, to allow him to concentrate on work (Myerson, Bichard, Erlich, 2010). Creative thinking is negatively affected by noise, anxiety and hunger and positively affected moderately raised temperatures and the absence of noise (Martens, 2011). Beautiful environments and physical activity (such as a walk) may also help to find new connections among ideas and new perspectives on issues (Csikszentmihalyi, 1996). A survey by the Lemelson-MIT Programme (Lemelson-MIT Programme (2005)) of 1,003 adults in the 
USA, showed that most respondents did their creative thinking in the car, when they are alone and when it is quiet with no interruptions. The researchers explained that the car may be one of the last environments in which one can escape a busy life and just be alone with their thoughts.

Experimental studies show positive correlation between certain features of the physical workplace and creative task performance. Presence of plants, colors, a noncrowded workspace, direct window view or combination of various physical features (adequate light, furniture, space, and ventilation) can stimulate creativity. It is also important to use physical environment to stimulate positive worker's perceptions towards his or her work (Dul, Ceylan, Jaspers, 2011).

Megill (2004) talks about importance of play in 'creative knowledge' work and relationships between play and creativity. If you look at the structure and principles of creative work it looks like a game: "to take risks, to create new toys, to put together things in unique new ways, to make up rules as they go along, to be inventive" (Megill, 2004).

Allison Arieff in her exploration of contemporary workplace tendencies notes the importance of family involvement. In her article "Beyond the Cubicle" (Arieff, A. 2011) she examines parenting in the workplace tendencies, their impact on creativity and the way workplace design responds to it. The examples cover instance of nurseries at work, livework environments and social frameworks such as "co-op babysitting arrangement among working parents"(Arieff, A. 2011).

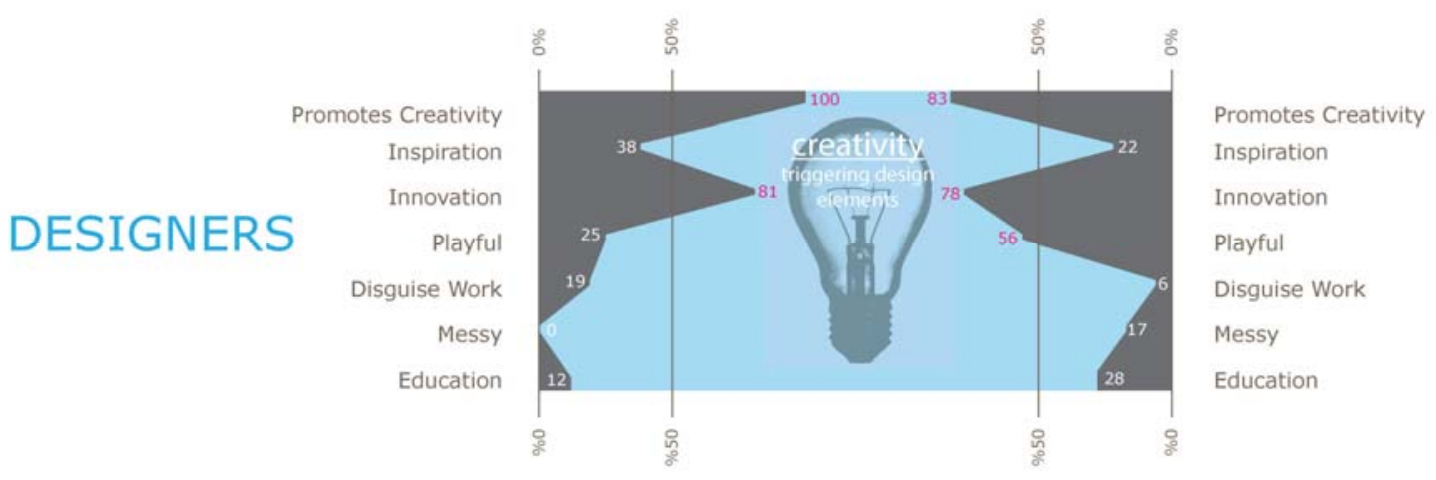

Figure 25: Creativity triggering design definitions 


\subsubsection{CREATIVITY TRIGgering DeSign - Designers}

When talking about creativity triggering workspace design interviewees from the design field were firstly referring to the work attitudes and their relation to the spatial design. The respondents tend to emphasize the need for the workspace to adjust to the

worker and allow them to be fully comfortable and free. According to the "creative workspace" designers the workspace should" "empower people to do their best work," help "maintaining creative mode," promote "a lifestyle or freedom that induces more of a creative atmosphere," support "natural habits, natural tendencies, human nature" and allow "to be [their] individual self." Another way to keep employees fully engaged with their work according to the interviewees is "a disguise of the workspace where people actually work hardly 60-70 hours/week."

The discussion of creativity was tightly related to the ideas of innovation. "Creative knowledge" companies are "constantly looking for new ideas, growing and redefining" themselves, "promote out of the box thinking," and seek for "something different than what has always been." Therefore, besides passively supporting the employee, the workspace according to the interviewees should also challenge the user. It should inspire "an individual to work and think differently," "examine habits that are engraved" in the nature of work, foster "creativity just by letting you see someone else doing something completely different than what you do" and/or be "minimalist, because it forces to imagine rather than see and apply."

The "inspiring" environment is also commonly described by the interviewees as a "collaborative" one. According to the designers "innovation really does happen when people get together" and "pulling people in the open office automatically" boosts their creativity levels.

Another way to challenge a "creative workspace" user, according to the designers, could be making them switch the environments between interior and exterior. Some of the interviewees stated that "exterior can help to promote sense of innovation and cre- 
ativity," "surroundings add value to [the] work" and that "the spaces that are not designed in a formal walls of organization" may also help to shift the focus and be more creative. Such spaces could be inside or around the workspace, but also, if the work allows enough mobility, it can happen in the "third places."

On the general level designers have also expressed certain level of prejudice that they have to deal while communicating with the clients. According to the interviewees, there are certain not strictly defined but still common stereotypes among wider public about how the "creative workspace" should look and function like. The main concern among the interviewees related to this issue was that in some cases the general function might get in conflict with these preconceived design notions. According to the designers "creative workspace" in the clients minds is related to the "useless elements and kitsch quality," "office as a funhouse," "image of industrial space with exposed structure and reclaimed wood finishing" and "the infamous slides."

Despite certain resistance to these common ideas about the "creative workspace" interviewees admitted that they provoke a certain level of playfulness in their design. Since that is expected by the users and the competition for talent in "creative knowledge work" sector is very tough, the design besides providing the function has also to please the worker. Therefore, one of the design criteria mentioned by the interviewees was to create "desirable and exciting places to work," "innovative, inspiring work environments" and help companies to "stay young, relevant and attractive" through their workspace design.

\subsubsection{CREATIVITY TRIGgering DESIGN - USERS}

"Creative workspace" users that participated in the research stated that the workspace "stimulates your energy" and "makes the user more creative, more comfortable, and more efficient." Some of the elements that the interviewees named were "erase boards," "earthwork" and "living things," "environment that is open," "colorful," "a lot of different surfaces, materials: woods, metal," graphics ("quotes to inspire us to give us 
perspective on what we're doing") and a platform to "appreciate [the work] internally and celebrate it."

Collaboration and any settings that support it were also mentioned and praised by the respondents: "the space where you can overhear what other people are working on, you can see what they're doing and that sparkles creativity directly." Interviewees perceived creative part of the work process as highly collaborative: "everyone that works in your team brings ideas to final product."

More than half of the users named the importance of playful elements in their work environments. They called it "exciting," "with different shapes and colors," with "a lot of eye candy stretched through the process or design," "having messy desk, things to hold and play with," "cool unique" elements and quite literally games to play with. According to the interviewees it helps to "disconnect from whatever you're doing and then go back to whatever it is that you do" and expresses the idea that "yes, we're here to work, but let's make it fun, while we're working."

Another important aspect related to creativity and innovation, according to the respondents, was the ability to experiment and try things out. This kind of need related to the earlier described visual characteristic of a "creative workspace" user. "The ability to prototype and mock up things," "use your hands to build and make it real and see if it works" or "having a lot of tactile tools" seemed to be an integral part of creative process for some of the interviewees. This kind of need definitely depends on a final product that the users are working on, but it is still important to consider and respond to.

"Creative workspace" users have also recognized the importance of continuous education. As developing new skills and updating the old ones is an inevitable part of their work, certain physical settings should be dedicated for this particular aspect. Interviewees have discussed that in their work they have to "witness trends ahead of time and take the creativity and elements I see on platform organically, use them and marry it with the brand and their style," "understand different skills, methodologies, making a person 
more well-rounded," "experiment, learn and touch, figure out how to fix things." As a response to these needs companies either organize workshops to bring in the external expertise, or encourage the employees to share their expertise internally on special events. Having an archive or exposition platform of existing company's works is also perceived as an educational element.

Despite different elements listed, some of the respondent were skeptical towards the connection between the built environment and inspiration. Some respondents were not convinced the particular location could induce creativity: "we get inspired in place that you can't really predict." Others were not fully sure about the effectiveness of playful elements and saw them as rather distracting: "not everything that's cool and fun is necessarily positive." 


\subsection{SUMMARY}

The research findings described in more detail previously in Chapter 5.1 and 5.2 are summarized and sorted into three main groups. The first group is called 'Perceptual Consistencies' and represents the parallels between the findings from all three stakeholder groups in regards to the same parts of the research. The second group is called 'Perceptual Inconsistencies' and shows mismatching perceptions from two or more stakeholder groups towards the certain parts of the research. The last group is called 'Findings Beyond the Existing Literature' and represents the elements or tendencies regarding research topic from the interviewing part that was not specifically stated in the literature.

\subsubsection{Perceptual Consistencies}

Table 1: Perceptual consistencies

\begin{tabular}{|c|c|c|c|}
\hline & researchers & designers & users \\
\hline & Openness & Openness (88 \%) & Openness (94 \%) \\
\hline Feature & Zoning & Zoning (94 \%) & Zoning (83 \%) \\
\hline Space & Natural Features & Natural Features (63\%) & Natural Features (33\%) \\
\hline & Daylight & Daylight (69 \%) & Daylight (44 \%) \\
\hline Semi-Fixed & Adaptability & Adaptability (56 \%) & Adaptability (50 \%) \\
\hline & Furniture & Furniture (75\%) & Furniture (72 \%) \\
\hline & Collaboration & Collaboration (100 \%) & Collaboration (89 \%) \\
\hline & Management & Management (31 \%) & Management (50 \%) \\
\hline Informal & Focus control & Focus control (56 \%) & Focus control (56 \%) \\
\hline space & Job Satisfaction & Job Satisfaction (63\%) & Job Satisfaction (89\%) \\
\hline & Wellness & Wellness (56 \%) & Wellness (39 \%) \\
\hline
\end{tabular}

A portion of the coded data from the interviews was positively correlating with the findings from literature. Elements from all of the three spatial categories were mentioned 
in a high percentage of the interview responses. From the Fixed Feature Space category Openness and Zoning were equally important for both interviewee groups and commonly found in the literature. Natural Features and Daylight was found more often in Researchers and Designers positions, but also appeared in Users interviews. From the Semi-Fixed Feature Space category Adaptability of the space and the Furniture were commonly mentioned in written sources and important for at least half of the respondents. From the Informal Space Collaboration, Management (especially Focus control), Job Satisfaction and Wellness (ergonomics and restoration) were commonly found in the literature and in the interview responses.

Another consistency pattern that showed up in the research was that the distinction between different stakeholder groups is becoming more ambiguous. Researchers sometimes are also Designer or Users, Designers perform extended researches that are being published in non-academic context and Users read design related literatures and journals to better understand their own needs and general tendencies in the field. These overlaps show the relevancy of the topic and additional information needed by all of the stakeholder groups.

\subsubsection{PeRCeptual InCONSISTENCIES}

Table 2: Perceptual inconsistencies

\begin{tabular}{l|l|l|l} 
& researchers & designers & users \\
Spontaneous & Playfulness, \\
Definitions & 'Contemporary work- & Technology, \\
'creative & interactions, & Geographic location, & Management, \\
workspace' & & Views, & Furniture, \\
& Connectivity & Daylight \\
Definitions & Process abstract ideas, & Diversity, & Visualization, \\
'creative & Self-sufficient, Lifelong & Age, & Mobility \\
workspace' user & learner, Self-managed & Freedom &
\end{tabular}




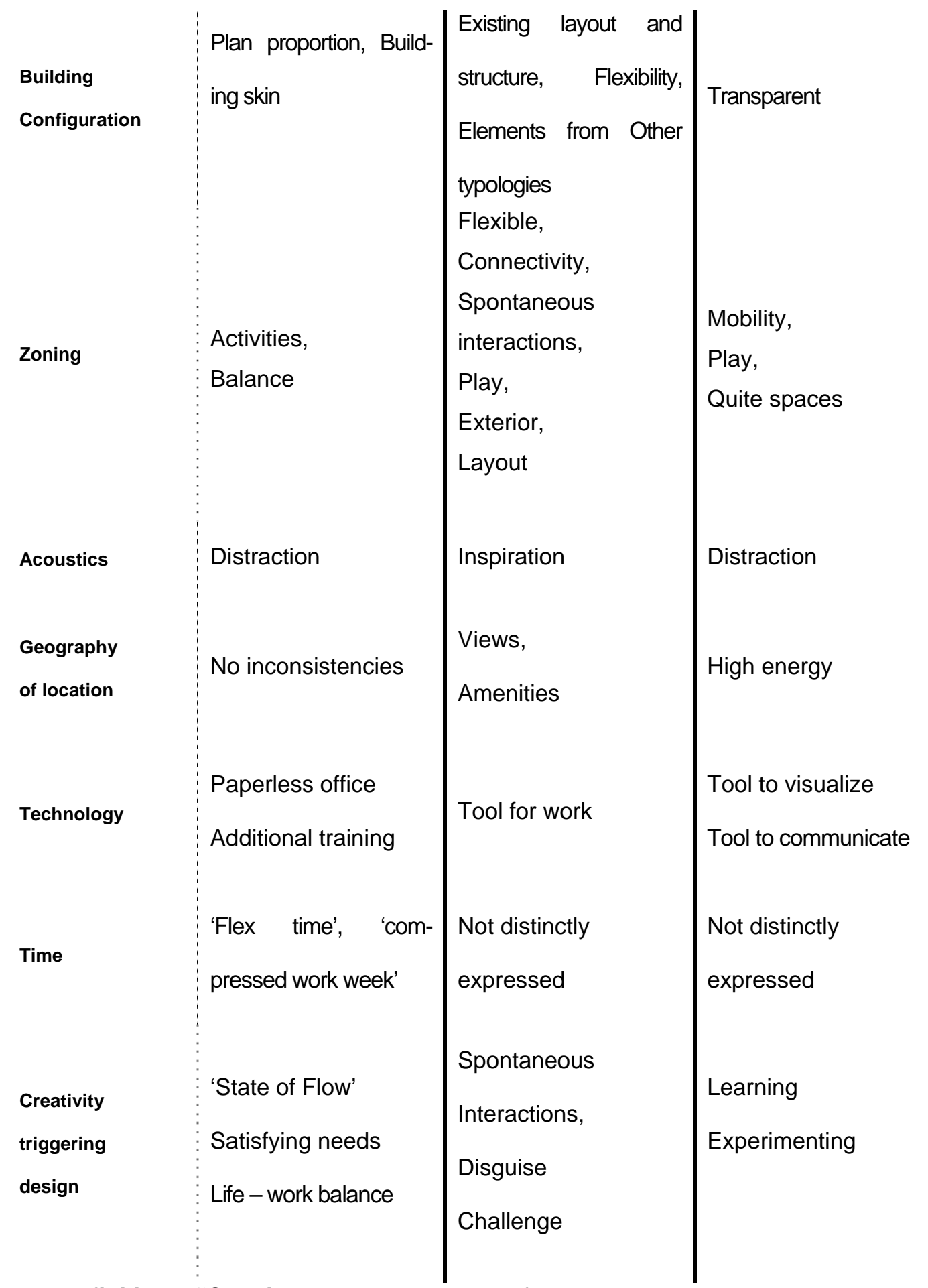

Definitions. "Creative Workspace." The definitions between all the three sources were not matching and the content was processed with coding for a more accurate comparison. Proposed definitions are not very common among the Researchers, but Designers and Users were highly responsive to them which signals about their current relevance. 
As the topic of "creative workspace" is still fairly new there is not too many academic written sources on it. The researchers are exploring the changes in work patterns, employees' characteristics and needs for contemporary workspace. Although, there are similarities in content, it does not always fall under the name of "creative workspace". On the other hand, designers and users seemed to have very peculiar images of what "creative workspace" is, but their descriptions were not always matching. The responses from both groups showed the importance of openness, adaptability/flexibility, focus, company's image and job satisfaction and collaboration, having different zones for different activities, support of needed activities and promotion of creativity. Designers have also stressed on encouraging spontaneous interactions, geographic location, views and connectivity of different spaces, while Users thought that the term "creative workspace" is more related to playfulness, technology, management strategies responding to built environment, furniture, daylight and glare control.

Definitions. "Creative Workspace User." Definitions of "creative workspace" user have also had certain inconsistencies. While all three sources agreed on the importance of working in the different modes which include collaboration and independent work, interdisciplinary nature of work process and creation of "meaningful new forms," there were also characteristics perceived as of different importance. The researchers talked about the mental abilities including processing of abstract ideas, self-sufficiency, lifelong learning and self-management in flattened hierarchical structure. Designers, emphasized the diversity of the workforce including the age of the employees and freedom trusted for an individual, while Users were stressing the need to visualize work related materials and be mobile within the workspace. Users have also described "creative workspace" users as curious and often times introverted individuals.

Building Configuration. While all three sources agreed on the importance of openness in 'create workspace' plan, there were certain inconsistencies on methods in achieving it and expected functions. The Researchers were focusing 
on ground up building and explored different proportions, layout configurations and skin selection to achieve the highest levels of performance efficiency. The Designers, based on their practice, saw "creative workspace" as more of an adaptive reuse or interior projects and emphasized limitations related to the existing layout and structure. Additionally, Designers expressed the importance of flexibility achieved through the open floor plan and potential of employing elements or design strategies from other types of the buildings. Users, saw openness mainly as an ultimate expression of transparency as part of the company image, space identity and managerial/control tool.

Zoning. All three sources agreed on importance to have different zone in "creative workspace" for different kinds of activities. However, the researchers were mainly concerned about the exact naming and definitions of the activities as well as balance between the zones. Designers were mostly talking about encouraging spontaneous interactions in circulation or gathering spaces, exterior elements including exterior workspaces, the efficient layout of all of the zones, visual and physical connectivity between the spaces and flexibility in rearranging the preassigned layout and function. They have also expressed certain skepticism towards the designated games areas that are highly regarded by clients. In addition, Designers mentioned a potential need for additional training so that the Users would be informed about the intention and uses of the zoned space. Most of the Users expressed the need for more quite spaces, their affection towards the zones meant for play and prioritized mobility of the employees over the flexibility of the space.

Acoustics. While all three respondent groups talk about the importance of acoustic privacy, Researchers and Designers explain various methods to achieve it. However, some of the Designers also perceive background noise or the 'buzz' as a potential source of inspiration.

Geography of location. Responses from all three sources correlated on the importance of "creative workspace" location in terms of existing infrastructure, amenities 
and potential to extend the office work to the 'third places' employing ITC. Designers were more concerned about the new amenities that should be provided with building design and the views in regards to geographic proximity to either natural or cultural focal points. Most of the Users mentioned the importance high energy in the surrounding area that might be achieved through natural, cultural and social zones easily accessible from the "creative workspace".

Technology. All three stakeholder groups agreed on the importance of technology in "creative workspace" design, but emphasized different features and ways to employ it. Researchers were taking a historic perspective towards the evolution of technology, which resulted in 'paperless office' and thus in different needs for the storage space and furniture. They also noted a potential need for additional training as the evolution of technology used in creative knowledge work is very fast. Designers perceived technology as a tool for work and acknowledged the need to incorporate it in the workspace design, but did not provide details on this cause. Users were very particular about the ways they employ technology in their "creative workspace". This group stated that besides using it for work tasks it is a crucial tool to visualize work related materials for colleagues and clients as well as an important way of communication both: inside and outside of the office.

Time. Researchers were describing the importance of time management strategies such as 'flex time' and 'compressed work week' in relation to 'creative knowledge work'. However, neither Designers, nor Users spoke much about it in their in-depth interviews.

Creativity triggering design. All of the stakeholders' positions were correlating in terms that natural elements, high levels of daylight, different materials and colors and highly encouraged collaboration results in a more creative work environment. Researchers spoke about maintaining rather than instigating creative activities by supporting the 'state of flow', satisfying all employees' physical and metal needs and helping them to balance life and work. Designers were very methodical about creating 
opportunities for spontaneous interaction and disguising the work or the initial function of the space through built environment design. Users expressed the need related to their creative work to have an access to continuous learning materials and experimenting or try-out space, where they could work on ideas in tangible form.

\subsubsection{FINDINGS BEYOND THE EXISTING LITERATURE}

Table 3: Findings beyond the existing literature.

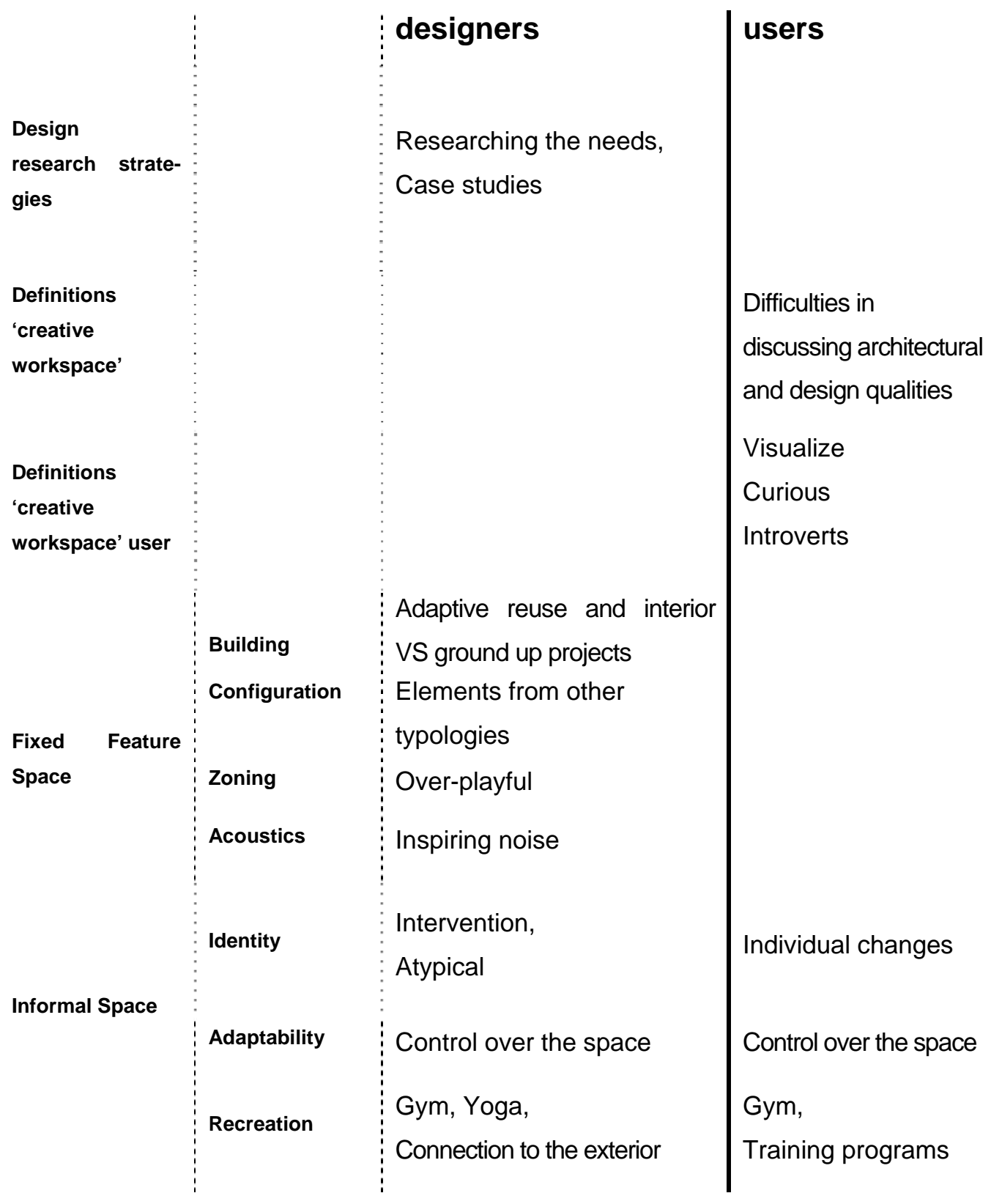




\begin{tabular}{ll|l} 
Company's & Brand & Emotion \\
image & Values & \\
$\vdots$ & Future path & \\
Food & Social life, & Service \\
& Physical environment &
\end{tabular}

Design research strategies. The interviews with Designers have revealed main research strategies that are currently being employed to inform "creative workspace" design decisions. Two main research directions included different ways to understand Users' needs to transform them into design solutions and case studies to set the context, generate ideas and find best practices.

Definitions. "Creative Workspace." The general tendency in the Users' responses showed that most of them did not have an architectural background and it made it difficult for them to effectively communicate their needs to the Designers. This tendency was most obvious in their attempts to define "creative workspace" and potential improvements of an existing "creative workspace" conditions. This finding signals about the need for more abstract ways for Users to express their needs that could be translated into architectural design solutions.

Definitions. "Creative Workspace User." While definitions varied between all the free sources of the research, the Users group provided additional qualities while describing "creative workspace" user. They emphasized the importance to visualize work process and outcome, which should have direct implication for workspace design. Users also have mentioned the curious nature of people working creatively. This quality should be accommodated by allowing people to try things out, experiment and continuously learn. Lastly, according to the interviewees, "creative workspace" users often times are introverted and in response to this characteristic there should be a higher percentage of quite work spaces to help them keep the inner balance.

Building Configuration. From building configuration portion of the interviews Designers responding based on their professional experiences stated that "creative 
workspace" projects are most often adaptive reuse or interior in the existing building design. This adds another dimension to the literature, that either does not specifically mention the context for the design or talks about ground up projects and thus different issues related to it.

Also, interviewees mentioned the design strategy of taking characteristics from other typologies of the buildings and applying it to "creative workspace" design. Examples included airport, residential, hospitality, storage, educational and restaurant building types.

Zoning. In their interviews Designers critically examined common needs and stereotypes related to "creative workspace" zoning. The tendency of negative perception towards 'over-playful' design was a new finding beyond existing literature. Designers, saw the stereotypically playful design style with designated game zones as a "funhouse," having a "kitsch quality" and "infantilizing" the function of work.

Acoustics. Another finding from the Designers' interviews was that some of the respondents perceived background noise or 'buzz' as a positive contributor to the creative process. It was seen as a tool to create atmosphere and mood and make the space less formal.

Identity. While the importance for "creative workspace" to have a unique identity is not clearly expressed in the reviewed literature, both interviewee groups perceived it as an important part of the design. Designers formulated strategies to achieve the uniqueness such as employing a raw, intervention based elements or atypical, bold, non-traditional spatial design solutions. The Users valued the option to modify and adopt "creative workspace" on a personal scale and make it uniquely matching to their physical, mental and cultural needs.

Adaptability. While not explicitly distinguished by Researchers, adaptability of the space or individual control over it was mentioned by both: Designers and Users. Both interviewee groups agreed that the ability to change the environment or interact with the space provides reassurance and creates a sense of investment and pride not only with 
the space but also with the company.

Recreation. Although the topic of wellness appeared quite a lot in the existing literature it was mainly related to making the workspace less damaging during the process of work with ergonomic design of the furniture, encouraging people to take stairs and choosing alternative transportation to the office. During the interviews both respondent groups expressed the need and design practice of additional recreational facilities that exist within the workplace and help "creative workspace" users to stay fit, manage their time more efficiently and control their work related stress levels. Designers mentioned gym and yoga rooms inside of the workplace as well as connection to the exterior and potential work or recreational activities outside, next to the workplace. Users have also expressed the need to work out either in the gym facilities or with a scheduled work out programs potentially on the exterior of the workplace.

Company's image. Although it might be evident, but the way company's image reflect in the "creative workspace" design is not explained in the reviewed literature. However, both respondent groups stressed the importance of this design strategy. Designers stated that workspace design should speak about company's values and express 'brand promise'. It can also be a tool to shift company's image by representing the intended direction that organization plans to take in the future. Users, on the other hand, saw company's image related "creative workspace" design strategies as a way to stimulate positive emotions for the employees: being inviting, reflecting transparency, 'cool' and 'fun' to stay at.

Food. The importance of food for "creative workspace" was evident from the in-depth interview responses. Designers described food facilities as an integral part of physical environment and as a tool to stimulate social interactions among the wider co-workers group. Users saw food as more of a service but expressed high levels of appreciation and confirmed the need of such facilities within the workspace. 


\section{CONCLUSIONS}

Research findings revealed strong consistencies between the perceptual qualities for "creative workspace" design. Researchers, Designers and Users groups' responses matched on many aspects of selected research framework. These consistencies can be treated as additional results control measure, proving consistency of the research topic, formulated question, literature selection and interview framework. It also represents the most important issues for the two stakeholder groups: Designers and Users. In addition, it potentially showcases the successful communication between Designers and Users on these particular aspects of "creative workspace" design, as designers based their responses on professional experience.

Moreover, research findings revealed that the lines between the knowledge of different stakeholders are becoming ambiguous leading towards more informed decisions and choices. The overlapping roles have also confirmed the need for a more in-depth research and additional data that all of the stakeholder groups are interested in.

However, the research has also revealed certain gaps in the existing literature as well as some disconnects between the perceptions of Designers and Users. This means that more research on "creative workspace" design topic should be conducted in regards of perceptual comparisons or "creative workspace" design in general. That would enrich the existing knowledge base for Designers and Users.

Additionally, the research revealed Users' low ability to clearly communicate their needs in terms of architectural concepts and design. The interviews have also revealed the most common strategies in design research employed by the Designers consisting of Researching the Users' needs and Case studies. However, if Users are restricted qualification wise in expressing their needs clearly it might pose limitations on Designers' research effectiveness. This signals that a more abstract way of communication in addition to the regular research methods currently employed by the Designers should be created. 


\section{DESIGN GAME}

In response to the research finding and conclusions this thesis will incorporate a proposal of Design Game. This abstract communication tool could be used as an additional measure in "creative workspace" design research for more detailed and accurate information on Users' needs. Instead of asking Users about potential final design outcomes, the game will fragmentize architectural ideas and concepts into activities and spatial qualities.

\subsection{PARTICIPATORY DESIGN AND EXPLORATORY DESIGN GAMES}

Design is perceived as "a social process which involves communication, negotiation and entering compromises" (Brandt, 2006, Habraken, Gross, 1988). Exploratory design games is a type of participatory design or co-design tool that helps to get answers to design questions using more than one method and thus increasing the accuracy of the answers through triangulation. In addition the outcome of such games is not supposed to be a final design, but rather "a co-constructed understanding about the context, people's experiences, potential designs and dreams" (Vaajakallio, Mattelmaki, 2014), which reduces the potential pressure for the participants to be wrong or silly and allows them to free their thoughts from the existing situation to the near as well as speculative future (Vaajakallio, Mattelmaki, 2014). Design games also allow for "direct involvement of people in the shaping of future artefacts" (Brandt, 2006).

Exploratory design games are "purposefully emphasize play-qualities" and are "supported by tangible game materials and rules" to "to deliberately trigger participants' imaginations as a source of design ideas" (Vaajakallio, Mattelmaki, 2014, Brandt, 2006). They are usually "staging participation," are seldom incorporating "competition over who wins the game," and has the "rules and tangible game pieces that guide the design moves" (Vaajakallio, Mattelmaki, 2014, Brandt, 2006). 
The most common uses of design games are for the research, for building design competence, for empowering users that are not traditionally part of design processes but are influenced by design and for engaging multiple stakeholders (Vaajakallio, Mattelmaki, 2014).

Design games differ in their form, appearance and function. From the architectural or planning design practice it can also vary in scale (city planning to district planning to research community needs to single building design). Exploratory design games can also be used for the areas beyond architectural or urban design. Usually the function dictates form and appearance choice.

The function of the design game can be "to conceptualize design," "to exchange perspectives," "to understand the work context and practice through negotiation and workflow orientation" or "to create scenarios that describe intended use situations" (Vaajakallio, Mattelmaki, 2014, Brandt, 2006). It can also help to create "a common design language," promote "a creative and explorative attitude," facilitate "the players in envisioning and enacting "what could be"' and help "to define the roles of participants in the interaction during a session" (Vaajakallio, Mattelmaki, 2014).

Design game usually have clear rules and structure, as the tangible pieces would not purposefully exist in isolation. It is very important that the users of game would understand the rules before starting to use the game for the most accurate outcome. However, the game framework is open for reinterpretation during the game process as questioning the base of the game can produce more design options (Vaajakallio, Mattelmaki, 2014, Brandt, 2006, Sanders, Stappers 2008).

"With new technologies and digital media currently transforming production and social communication, urban and architectural design is being redefined in a new context" (Sikiaridi, Vogelaar, 2012). Exploratory design games have also gone into digital environments and do not necessarily need tangible pieces to perform the intended function. The digital space allows for more complex structures and ideas that can played. Howev- 
er, the level of complexity might also im'act users' ability to freely and effectively perform in the game while expressing their position (Sikiaridi, Vogelaar, 2012).

The play framework is being perceived differently by different stakeholder groups. For designers design games are the "tools to organize dialogues among different stakeholders" to get information for the design. For players it facilitates a "mindset that creates an experience of being in a game world" and frees them from prejudice or restrictions in expressing their positions. For design game designer, design games offer "a structure" to conduct a research and gain information with tangible pieces and predefined rules that are open for reinterpretation (Vaajakallio, Mattelmaki, 2014, Brandt, 2006, Sanders, Stappers 2008). 


\subsection{EXPLORATORY DESIGN GAME EXAMPLES}

To better understand the existing exploratory design games context, the research is proving a few examples showcasing different scales, mediums and platforms that can be employed to perform a game.

\subsubsection{Concept DESIGn GaMe}

Concept games are tools for research in design theory and methods. These games take certain aspects of design to analyze them separately from the full conditions thus they do not resemble reality as simulation games do. The action oriented approach stresses the role of the artifact that varies in shape, size and color (Habraken, Gross, 1988).

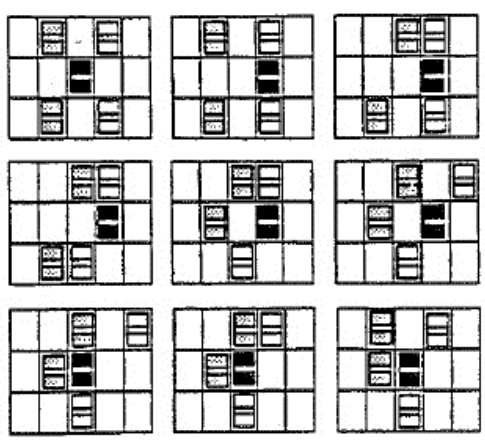

Figure 26: Concept design game.

\subsubsection{NURSES' AND PATIENTS' PARTICIPATORY WORKSHOPS}

Liz Sanders a president of design research firm MakeTools together with the architectural design firm NBBJ performed a nurse and patient participatory workshop to set the size and proportion of patient room and define the most efficient furniture layout. To assess

these factors two groups of users: nurses and patients are asked to play the exploratory design game with two dimensional and three dimensional pieces (Sanders,

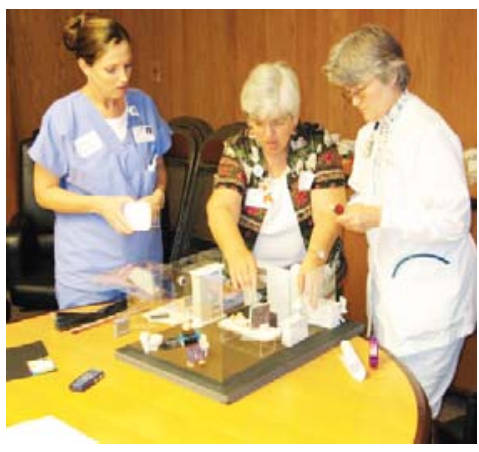

Figure 27: Nurses' and patients' participatory workshop

E.B.-N., 2006). 


\subsubsection{SIMPLE CITY}

Simple City installation is a participatory design game meant to develop urban projects by professionals and laymen. A modular segments of the game correspond to the "serially produced, global, generic city" and helps to accurately represent city layouts in the industrial age. The game was developed by Hybrid Space Lab (Sikiaridi, Vogelaar, 2012).

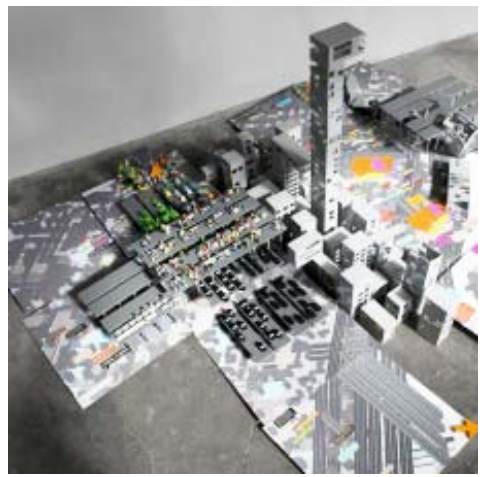

Figure 28: Simple City

\subsubsection{CITY KIT}

City Kit is a combined urban planning program and computer game meant for the residents and communities to think about potential upgrades of the neighborhoods. The project was developed for the Hong Kong Social Housing Authority and was supposed to primarily target young people to encourage them to re-engage with their built environment rather than virtual ones. The

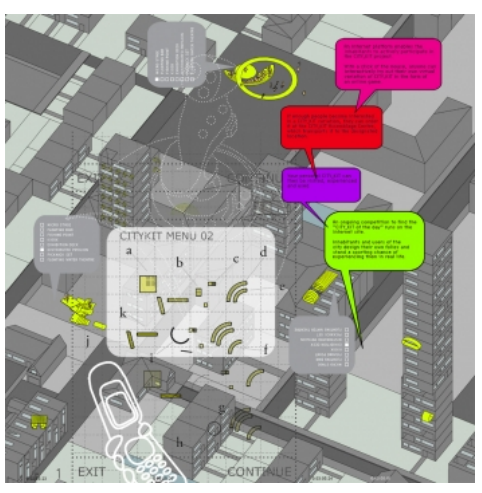

Figure 29: City Kit

game offers options of placing different objects within the set or adding new ones to improve the existing environment (Sikiaridi, Vogelaar, 2012).

\subsection{MAIN CONSIDERATIONS AND ASSUMPTIONS}

The main consideration related to this game were to conceptualize the ideas related to "creative workspace" design in a way that people (Users) without architectural background could easily understand them and use to express their needs for the Designers to translate into the functional schemes. 
To achieve this goal the following assumptions were made for the design of exploratory game as an additional communication tool between the Designers and Users:

a) The existing "creative workspace" design research techniques would benefit from additional conceptual communication tools between the User and the Designer.

b) The Users are experts of their daily activities and spatial quality needs and therefore are able to represent it in a tangible form.

c) It is easier for Users to relate to the names of activities they perform on daily basis rather than pre-assigned names of spaces.

d) It is easier for Users to relate to the names of physical and perceptual qualities of the space they need on daily basis rather than pre-assigned names of spaces.

e) It is easier for Users to thinks about close working relationships between different activities they perform on daily basis than about the circulation paths between the spaces with pre-assigned names.

f) The game provides more freedom and more options for the Users if all the activity and quality elements are broken down to singular values instead of preassigned combinations.

g) The game provides more freedom and more options for the Users if all assemblage of the pieces will not be restricted by the board or other boarders.

h) The game helps to eliminate mental connections to architectural representation of the design ideas (eg. plan, levels) that Users are not necessarily familiar with.

i) The ease of connection between different pieces should eliminate prejudice towards potential combinations.

The activities, spatial qualities and their relationship to "creative workspace" user derived from the research findings. These elements were translated into game pieces that can be connected to represent combination of activity support and spatial quality needs. 


\subsection{DESIGN}

\subsubsection{PIECES}

The game design based on previously discussed assumptions consists of three types of pieces: Activity pieces, Quality pieces and Connections pieces.

- Activity - represent the activities employed by the Users on daily basis. The pieces are triangular shape and comes in two sizes to distinguish the ration between levels of importance and space needed. The pieces are divided in two subgroups of 'Work' (performance activities directly related to work) and 'Retreat' (supporting activities indirectly related to work).

\section{\# Work}

- Concentrate - a focused work, performed individually.

- Collaborate - a team work on the same project combining mental sources by sharing ideas through an extensive communication.

- Spontaneous - an unplanned informal collaboration or consultation providing additional share of expertise.

- Create - a process to develop an original and innovative solution to a design problem either individually or in a team.

- Experiment - an iterative work with physical mock ups to develop design options for a certain concept either individually or in a team.

\section{\# Retreat}

- Sports - a physical activity, supported by indoor or outdoor facilities.

- Relax - a mental and/or spiritual practice, supported by indoor or outdoor facilities

- Eat - an activity involving buying food, warming up the food and eating.

- Learn - an activity involving browsing through archival data, live and online trainings and study groups for certificates and licenses directly or indirectly related to the immediate work.

- Socialize - an informal communication directly or indirectly related to the projects, enhancing team building, productivity and efficiency.

- Play - a game activity, involving two or more people, enhancing creative thinking, efficient communication and team building. 
- Quality - represents spatial qualities that can be attributed to the activities in relation to Users' need. The meaning of pieces is absolute and therefore these pieces come in a single size. The pieces are divided in two subgroups of 'Physical' (physically reflecting in the space) and 'Perceptual' (visually reflecting in the space) pieces. The 'Physical' pieces come in a rectangular shape and 'Perceptual' pieces come in a circular shape.

\# Physical

- Outdoors - a space that is outside of the building or has one or more open surfaces instead of the wall, window or ceiling.

- Flexible - a space that can be easily rearranged to meet different team needs.

- Open - a space that has little to no partitions and is shared by multiple users.

- Daylight - a space that has an access to the daylight.

- Acoustically Private - a space that is acoustically isolated to keep acoustic focus.

- Visually Private - a space that is visually isolated to keep visual focus.

- Personalized - a space that can adopt to individual user's needs.

- Wired - a space supported by specific technological appliances needed to perform the work tasks and/or communication.

- Atypical - a space having a unique identity directly or indirectly related to the activity performed in the space.

- Branded - a space representing company's image, values and brand.

- Managed - a space requiring additional management resources to be used most efficiently.

- Views - a space that has an access to the views over the focal point on the exterior or interior

- Playful - a space with vivid, original and attractive elements incorporated in finishing, furniture, light fixtures and art pieces.

- Natural - a space that has natural elements to improve aesthetic and air conditions.

- Disguised - a space that misrepresents its direct function. 
- Connections - represents close working relationships between activity and quality combinations to better understand functionally beneficial proximity of the pieces. The pieces come in hexagonal shapes of different colors, so that a system of more than one connection paths could be marked on the structure.

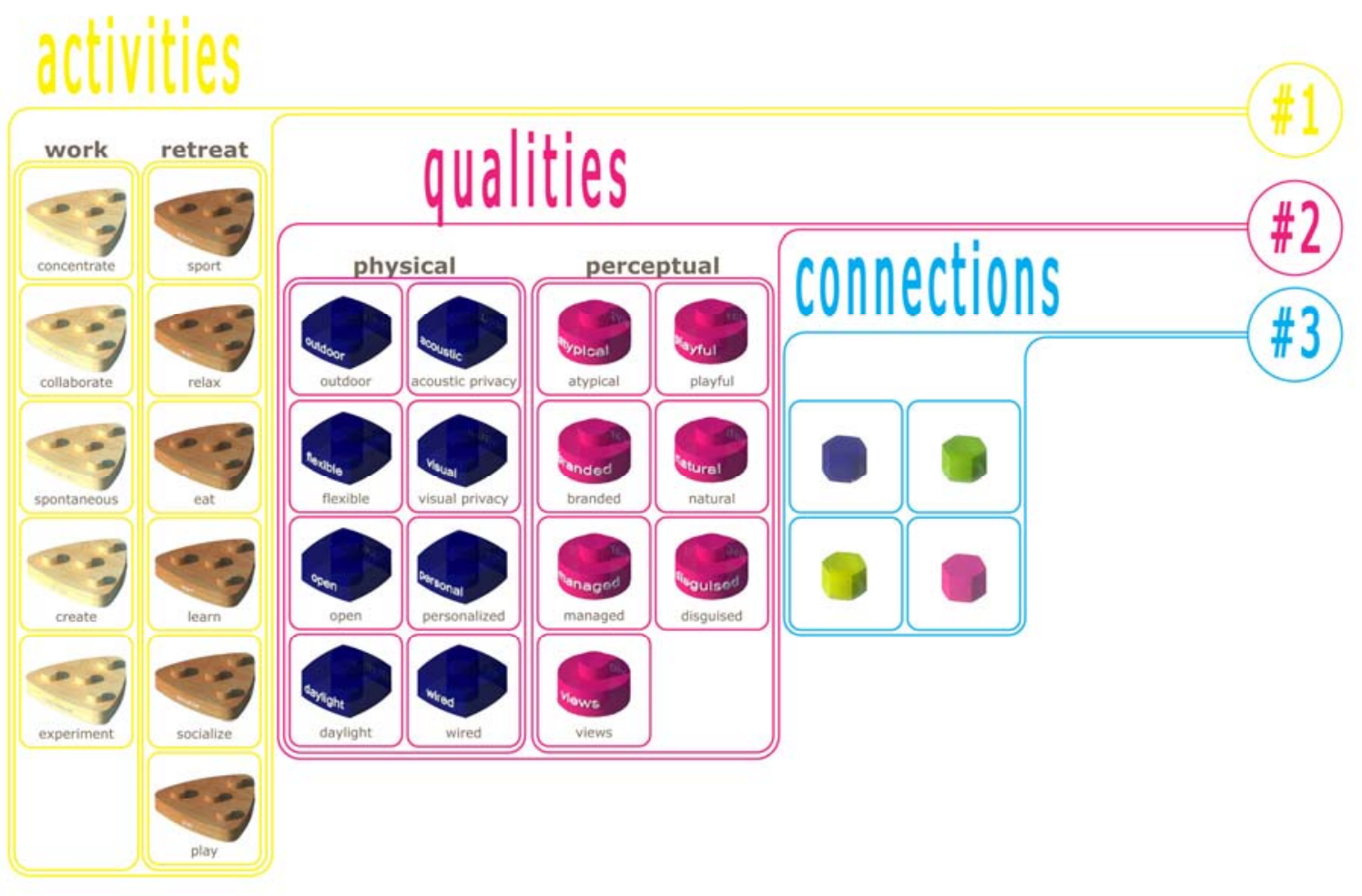

Figure 30: Exploratory design game: piece types

\subsubsection{RULES}

Players: The game can be played in teams of 4 to 8 Users.

Each move should be reasoned vocally, recorded in a chosen form of media and observed by the designer. The exact sequence and discussion arising between the players during the game provide additional information and should be interpreted together with the final combination by the designer. 
Moves: The players can employ these kind of moves:

a. Place a new connection piece.

b. Move a connection piece from one combination to another.

c. Remove a connection piece.

d. Replace a connection piece.

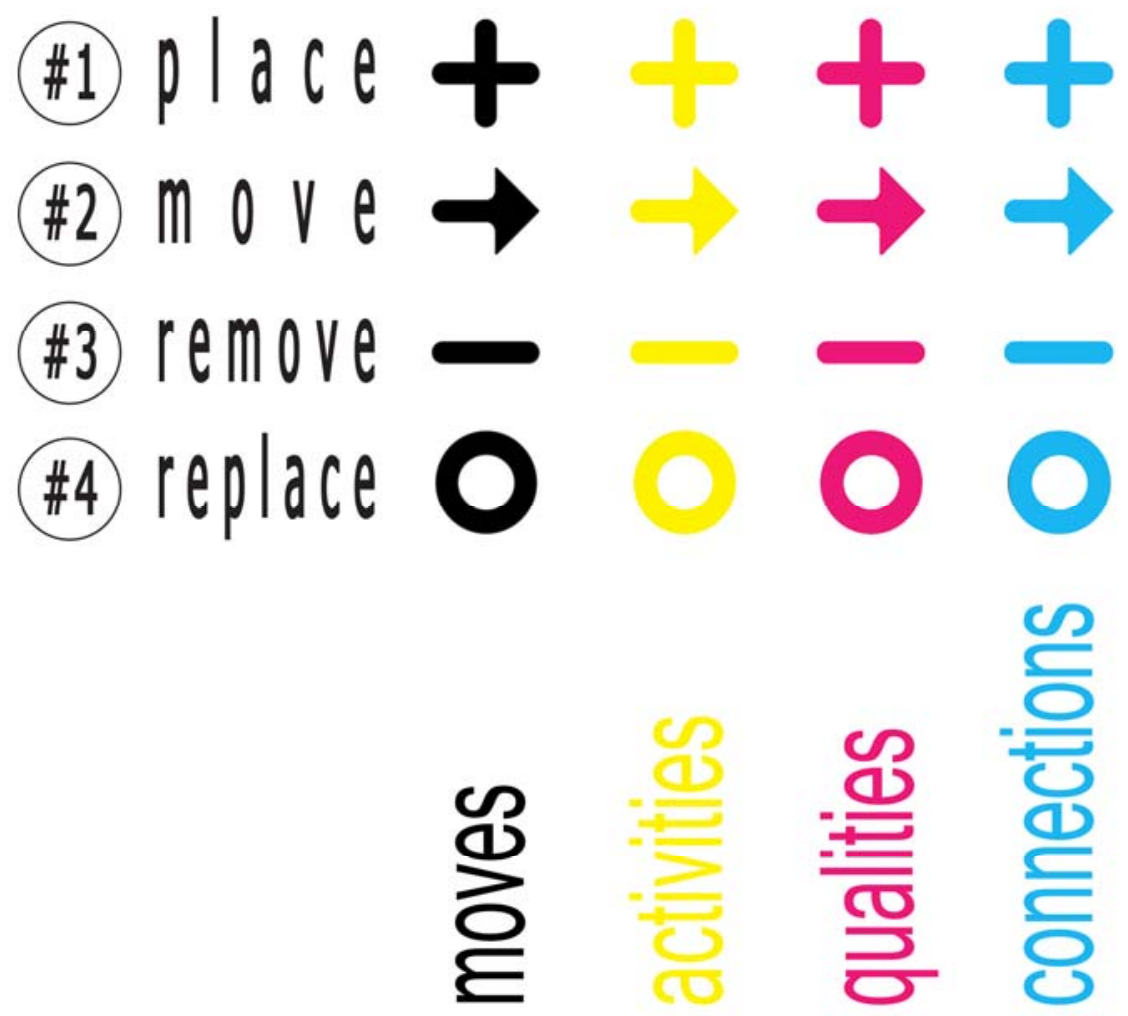

Figure 31: Exploratory design game: move types

\section{Game process:}

Phase \# 1. Activity and quality pieces are laid out on the desk and players pick them one by one on their turn. The players get to make a move in a clockwise circular fashion. On their turn they have one activity and one quality move. The players have to vocally reason their move. This phases continues until the players do not want to make any more changes in the amount and content of activity and quality 
combinations.

a) Activity moves. On their turn players can employ up to three activity pieces.

b) Quality moves. On their turn players can employ up to three quality pieces.

Phase \# 2. Once the, they move to the second phase of the game. Connection pieces are added on the desk. Each move the player has one connection and one rearrangement move. The players have to vocally reason their move.

c) Connection moves. On their turn players can employ up to two connection pieces.

d) Rearrangement moves. On their turn players can make up to two rearrangements. Rearrangement move allows the player to move the whole cluster of activities and qualities based on connection to other clusters or other reasons that have to be expressed vocally.

\subsubsection{OUTCOME}

The outcome of this exploratory design game is the structure representing "creative workspace" Users needs in a form of activities performed, spatial qualities needed and connections between the different combinations.

In addition, the record of the moves and reasons made during the game in a sequence should supplement data informing design.

Designers could translate all the collected data into the functional diagram where spaces would have assigned activity and quality combinations. Connections pieces could be translated into circulation paths or visual corridors. Designer may develop additional qualities, activities or connections, based on the sequence of moves and vocal reasoning during the game. 


\subsubsection{SAMPLE Game SCENARIO}

To better explain the game a sample sequence of game scenario is rendered, where imaginary four players build a combination.

\section{Phase \# 1}

\section{Player 1. Move 1. Activity moves:}

+ place: activity: work: collaborate

+ place: activity work: create

+ place: activity: work: concentrate
Quality moves:

+ place: quality: physical: visual privacy

+ place: quality: perceptual: playful

+ place: quality: physical: flexible

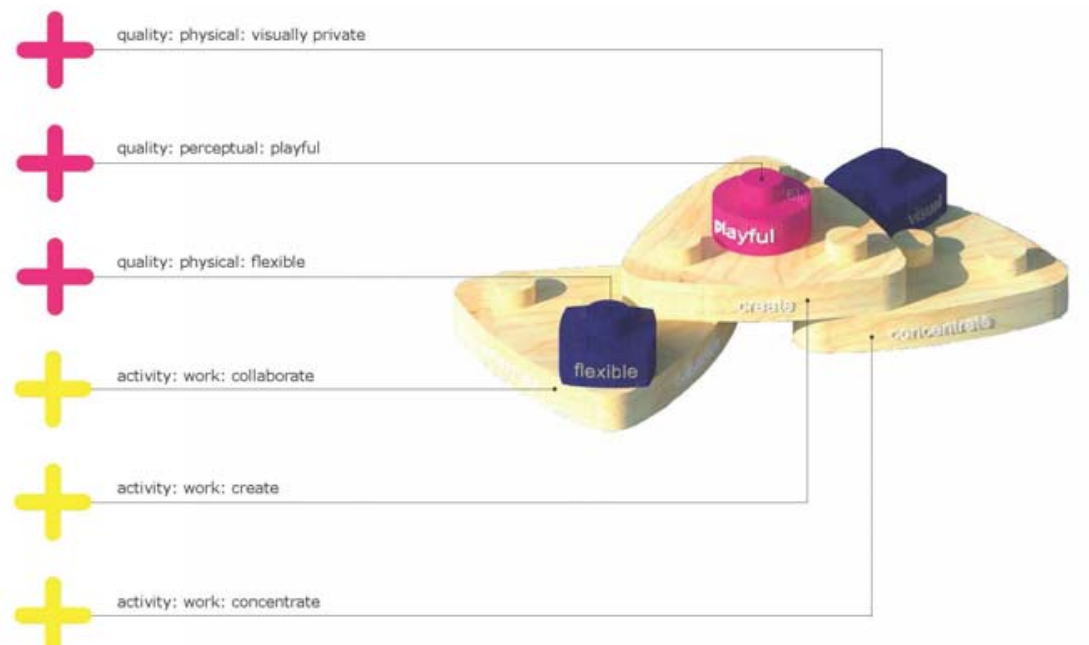

Figure 32: Sample game scenario. Player 1. Move 1.

\section{Player 2. Move 2. Activity moves: $\quad$ Quality moves:}

+ place: activity: work: concentrate + move: quality: physical: flexible

+ place: activity work: concentrate + place: quality: physical: acoustic privacy

+ place: activity: work: create + + move: quality: physical: visual privacy

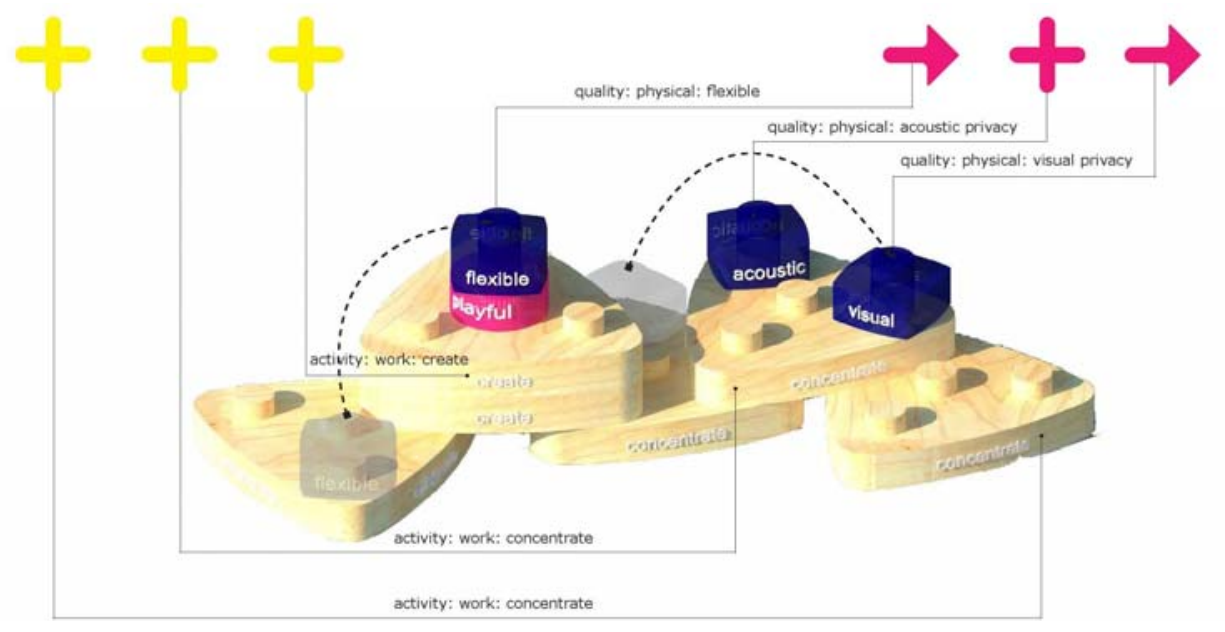

Fiqure 33: Sample qame scenario. Plaver 2. Move 2. 


\section{Player 3. Move 3. Activity moves: $\quad$ Quality moves:}

+ place: activity: work: collaborate + place: quality: perceptual: branded

+ place: activity work: experiment + place: quality: perceptual: natural

+ move: quality: physical: flexible

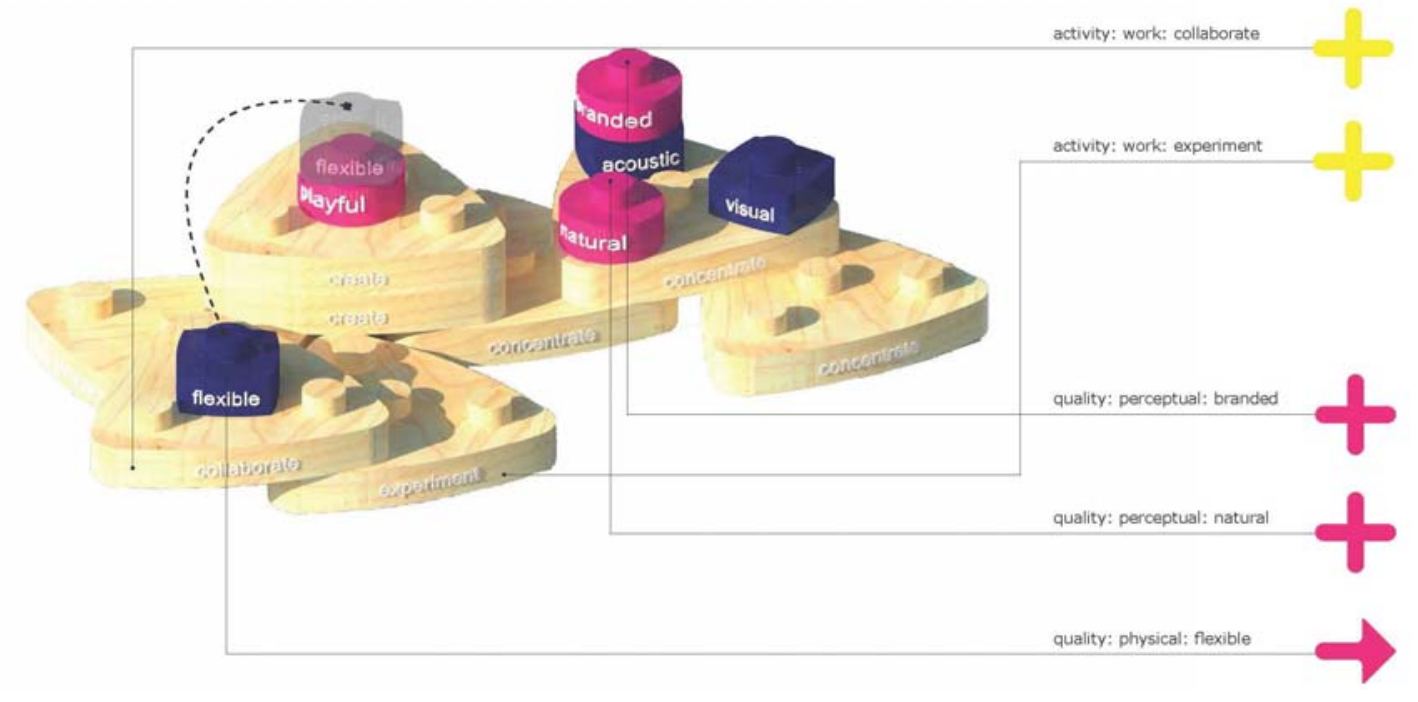

Fiqure 34: Sample qame scenario. Plaver 3. Move 3.

Player 4. Move 4. Activity moves: $\quad$ Quality moves:

+ place: activity: work: collaborate + place: quality: physical: daylight

+ place: activity: retreat: play + place: quality: perceptual: natural

+ place: activity: retreat: socialize

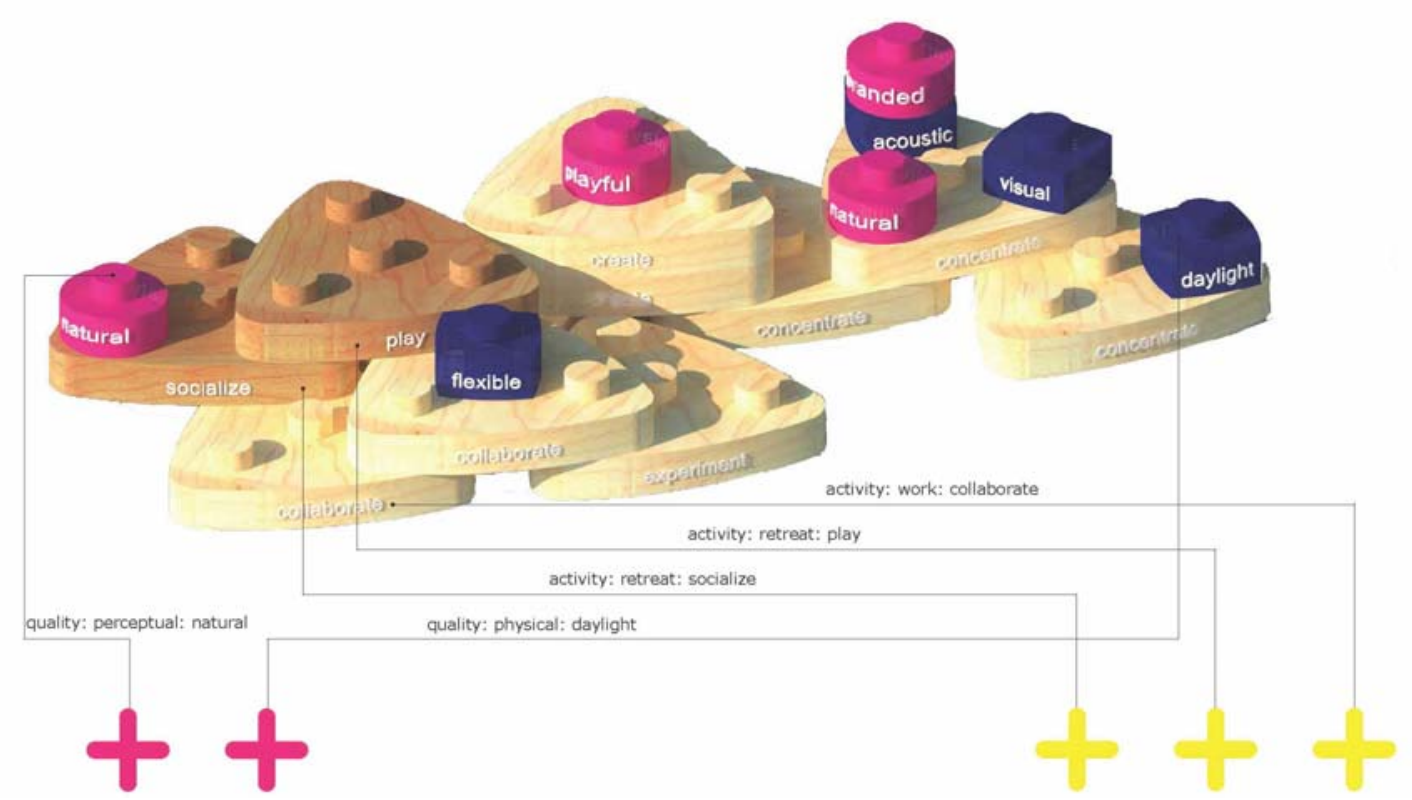

Fiaure 35: Samble aame scenario. Plaver 4. Move 4. 
Player 1. Move 5. Activity moves: $\quad$ Quality moves:

+ replace: activity: work: spontaneous + place: quality: perceptual: atypical

+ place: activity: retreat: play

+ place: quality: perceptual: playful

+ place: activity: retreat: eat

+ place: quality: perceptual: atypical

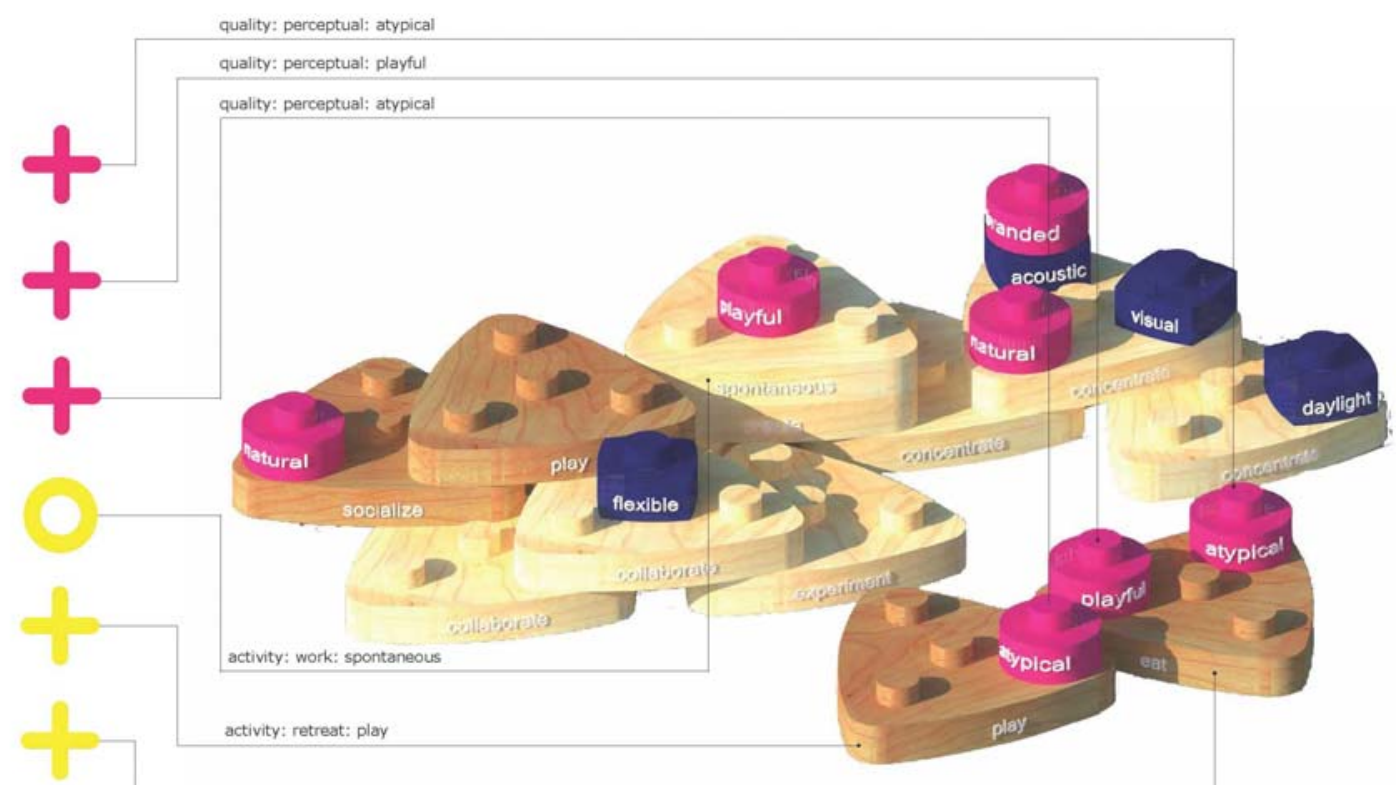

Figure 36: Sample game scenario. Player 1. Move 5.

Phase \# 2

Player 2. Move 6. Connection moves:

+ place: connection: green (play/ collaborate/ spontaneous-create-concentrate)

+ place: connection: pink (eat/ concentrate)

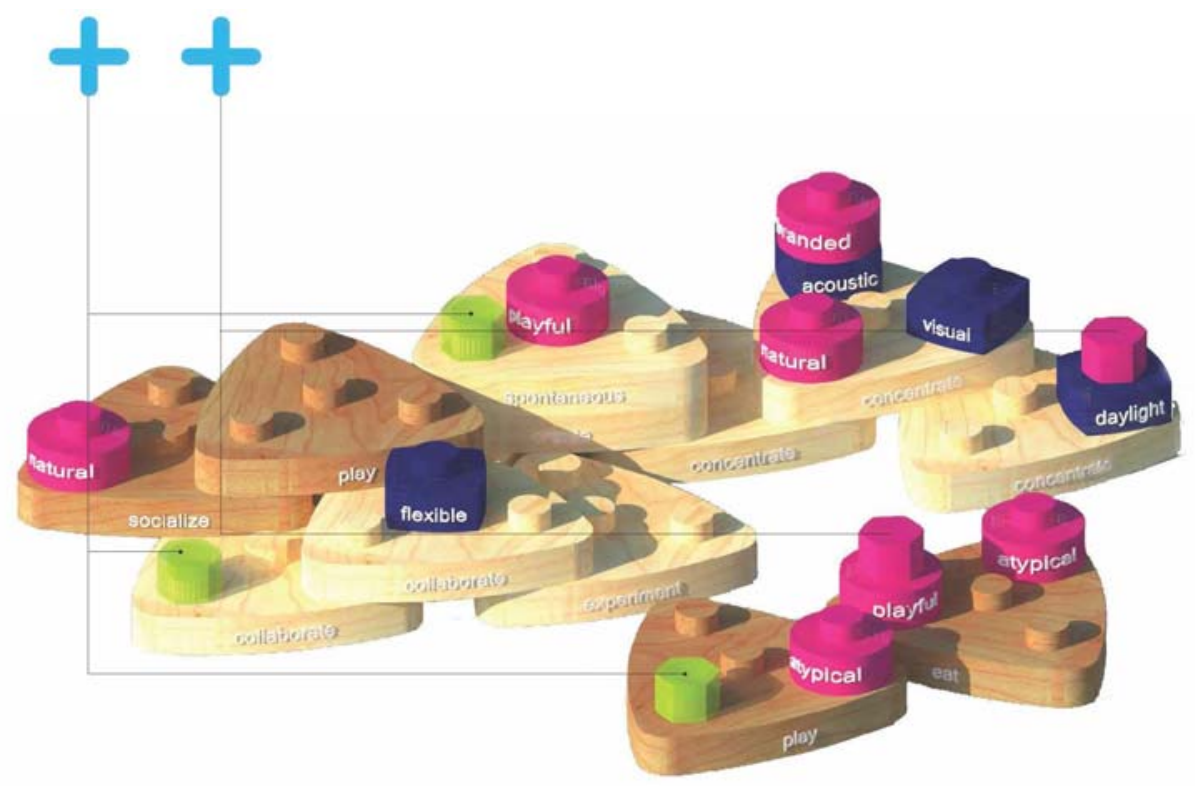

Fiaure 37: Samnle aame scenario. Plaver 2. Move 6. 
Player 3. Move 7. Connection moves: redundancies.

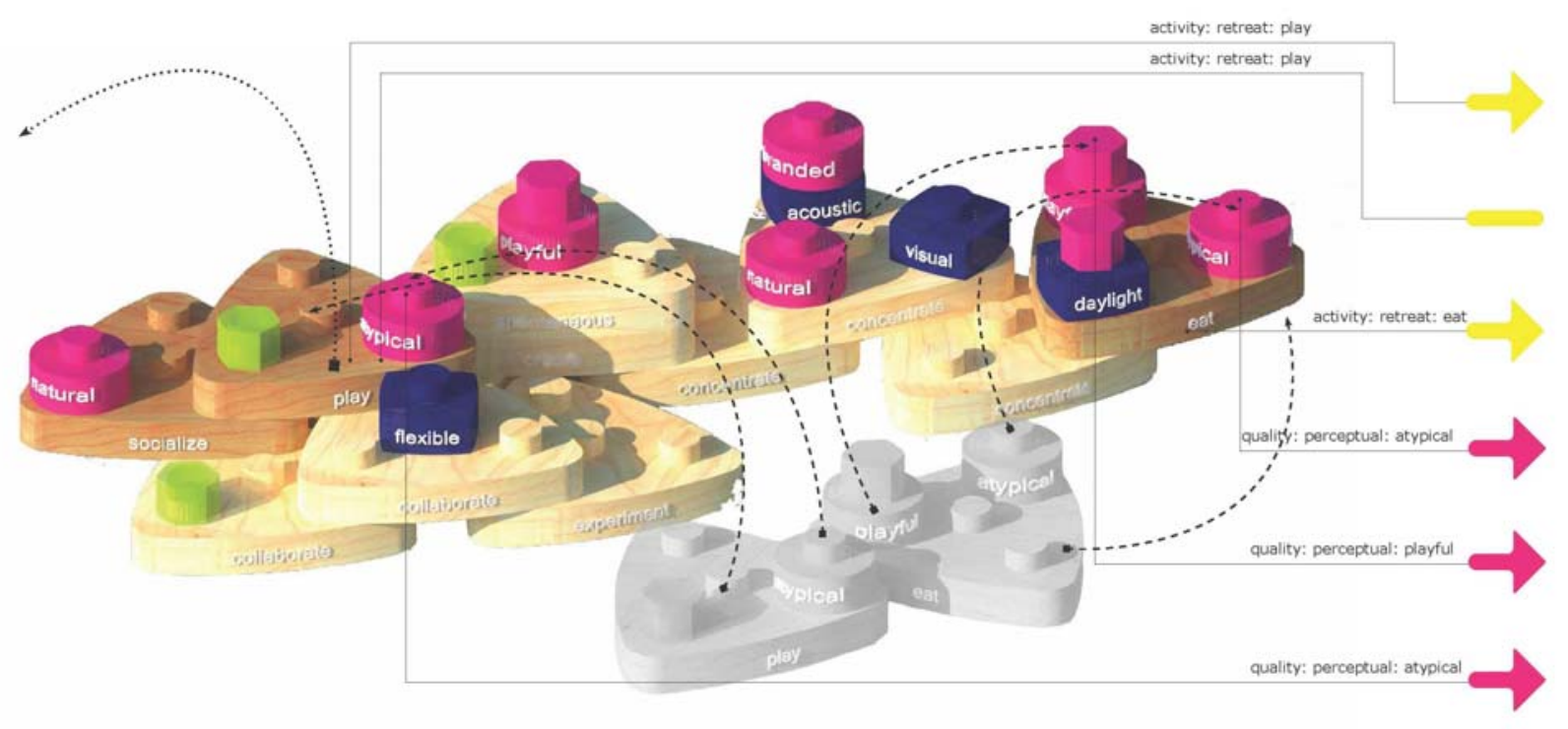

Figure 38: Sample game scenario. Player 3. Move 7. 


\section{DISCUSSION}

\subsection{OBJECTIVE}

The initial objective of this research was to compare the perceptions towards "creative workspace" design from three stakeholder groups: Researchers, Designers and Users. The research analyzed commonly employed definitions and design elements attributed to the concept of "creative workspace". For easier comparison and processing of the data all the findings were organized in three category spatial framework (Fixe Feature Space, Semi-Fixed Feature Space and Informal Space) borrowed from Edward T. Hall and additional category of 'creativity triggering' design elements.

After the conclusions indicated certain inconsistencies between the perceptions of all the three groups, the research formulated a design objective to create a tool for better communications practices resulting in more accurately expressed Users' needs. This communications tool was primarily targeted toward Designers group of stakeholders for the direct impact on future designs. However, the exploratory design game can also be used for the research purposes to enrich existing knowledge base.

\subsection{UNIQUENESS}

The research is unique in a way that it is questioning a commonly used "creative workspace" term and its definitions. The researcher was not able to find written sources explicitly analyzing this terminology.

The research also employs a perceptual comparison between three stakeholder groups. Most of the written sources that the researcher came across showcase either researchers perception based on other written sources or research that may or may not directly involve Users. Users' perception can partially reflect in some of the existing researches. However, researcher did not come across another research that would be comparing perceptions of all three stakeholder groups in regards of the same research question. 
The research concludes with a conceptual exploratory design game. Exploratory design games are not new and there is a wide typology of them employed depending on particular $r$ research goals. However, usually these games can be very abstract and applicable to any kind of a problem, but not specific enough to provide results with high level of detail. In other cases, they can be applicable only to a particular project as they are constructed for very specific context and thus not applicable for other situations. This thesis summarizes the design qualities of emerging typology and makes it applicable as an additional research tool for any project within that typology.

\subsection{APPROACH}

In order to compare the perceptions of different stakeholder groups the research employed two main methods. The researchers' position was formulated by analyzing and searching for particular points in nearly 60 written sources including workspace design related books and academic articles, design tendency reports from design and research companies and statistics on economics tendencies in relation the research topic. Designers' and Users' positions were analyzed with 32 in-depth interviews. The data from the interviews was coded to make it comparable to the data from the written sources. The coding also helped to extract the rate at which certain concepts were mentioned during the interviews to compare how important they were for Designers and Users.

After comparing the perceptions of all three stakeholder groups, research found certain inconsistencies and gaps. To improve the efficiency of communication between the different stakeholder groups research developed an exploratory design game, that can be used for "creative workspace" related design or further research. 


\subsection{AdVANTAgES}

The main positive attributes of the research:

- Offers new ways to define ambiguous concept of "creative workspace" by comparing three stakeholder groups involved in the design process.

- Showcases knowledge gaps related to "creative workspace" design in the existing literature.

- Provides high level of perceptual detail from Deisgners' and Users' indepth interviews.

- Provides a quantitative data coded from the interviews enabling to compare the levels of importance for different 'creative design' aspects.

- Enables single level comparison between all three stakeholder groups' perceptions.

- Formulates findings in a clear research framework sorting spatial elements into four groups.

The main positive attributes of the exploratory design game:

- Offers a conceptual framework that empowers Users without the architectural design background to express their needs for "creative workspace" design.

- Offers an opportunity to express the needs by activity and quality combinations rather than predefined space names and thus expanding pre-conceived design options.

- Can be employed for multiple projects within the same "creative workspace" typology.

- Can be easily reproduced for wider use. 


\subsection{LIMITATIONS}

The main limitations of the research:

As this was a Master of Sciences thesis research with a limit of two years the interviews were conducted within the period of four month which restricted the amount of people to reach out and the number of respondents agreeing to participate. A higher volume of interviewees, potentially sorted by geographic regions, could have provided more accurate results.

The sample of "creative workspace" Users could have been divided based on the major activities performed at work for higher accuracy of work and workspace related needs.

Although coding of the data helped to compare the positions of all three stakeholder groups, written sources could not be comparably translated in regards to time limitations into quantifiable graphs showing the importance of certain "creative workspace" design aspects.

The main limitations of the exploratory design game:

The time constraints did not allow for the testing of the exploratory design game. 


\section{FUTURE RESEARCH}

Potential improvements and extensions for the research:

- The sample of the interviewees could be bigger for a higher level of accuracy.

- The sample of the interviewees could be geographical region specific for higher level of accuracy.

- The sample of the Users could be segmented within "creative knowledge workers" into groups based on major activities for higher level of accuracy.

- The system to code written sources to translate them into quantitatively comparable results could be developed.

Potential improvements and extensions for the exploratory design game:

- The game should be testes with "creative workspace" design Users to evaluate the full potential of this additional communication tool.

- The game could be translated for other types of building designs as an additional communication tools between the Users and Designers.

- The game can be employed in extended research on "creative workspace" design.

- The game can be modified for research on other types of buildings. 


\section{REFERENCES}

1. Arieff, $\quad$ A., $\quad$ Beyond The 2011 , http://opinionator.blogs.nytimes.com/2011/07/18/beyond-the-cubicle/

2. Becker, F.D. (1981), Workspace. Creating Environment In Organizations, New York, N.Y.: Praeger

3. Brill, M., Weidemann, S. and the Bosti Associates (2001), Disproving Widespread Myths About Workplace Design, Kimbal International, Jasper

4. Brandt, E. (2006). Designing exploratory design games: A framework for participation in participatory design?. Proceedings of the Ninth Conference on Participatory Design, 1, 57-66.

5. Bureau of Labor Statistics from United States Department of Labor, (2014), Time Use Survey, http://www.bls.gov/tus/charts/

6. Cagnol, R. A Brief History Of The Office, 2013, Deskmag, Coworking Spaces, http://www.deskmag.com/en/a-brief-history-of-the-workspace-coworkingChicago-Architecture

7. Calabrese, F. (2010). Evolution of twenty-first century knowledge workers. On the Horizon,18(3), 160-170.

8. Castells, M. (1996), The Rise of the Network Society, The Information Age: Economy, Society and Culture, Vol. I, Blackwell, Oxford

9. Castells, M. (2004). The Power of Identity. Malden, MA: Blackwell

10. Centraal Beheer office building by Hermann Hertzberger, at Apeldoorn, The Netherlands, 1967 to 1972 , Modular scheme, https://www.pinterest.com/pin/162551867776403505/

11. Centraal Beheer office building by Hermann Hertzberger, at Apeldoorn, The Netherlands, 1967 to 1972 , Interior, http://www.earchitect.co.uk/holland/apeldoorn-buildings

12. Centraal Beheer office building by Hermann Hertzberger, at Apeldoorn, The 
Netherlands, 1967 to 1972, Section http://www.greatbuildings.com/cgi-bin/gbcdrawing.cgi/Central_Beheer.html/Central_Beheer_Axon.html

13. Chicago Architectural Photographing Company, 1884, The Home Insurance Building by William Le Baron Jenney, in Chicago, IL, US, https://en.wikipedia.org/wiki/Home_Insurance_Building\#/media/File:Home_Insura nce_Building.JPG

14. Cornell University, INSEAD, and WIPO (2014): The Global Innovation Index 2014: The Human Factor In innovation, Fontainebleau, Ithaca, and Geneva.

15. Cornell University, INSEAD, and WIPO (2015): The Global Innovation Index 2015: Effective Innovation Policies for Development, Fontainebleau, Ithaca, and Geneva

16. Coy, P. (2015) The Bloomberg Innovation Index, http://www.bloomberg.com/graphics/2015-innovative-countries/

17. Cuvillier, R. (1974), Intellectual workers and their work in social theory and practice, International Labour Review, Vol. 109 No. 4, pp. 291-317.

18. Csikszentmihalyi, M. (1996), Creativity: Flow and the Psychology of Discovery and Invention, Harper Perennial, New York, NY.

19. Davenport, T.H., Thomas R.J., and Cantrell, S. (2002) 'The Mysterious Art and Science of Knowledge-Worker Performance' MIT Sloan Management Review Fall, pp. 23-30.

20. DCMS (2001), Creative Industries Mapping Documents 2001, London: DCMS (Department of Culture, Media, and Sport)

21. Duffy, F. , Laing, A. , Crisp, V. (1993). The Responsible Workplace : The Redesign of Work and Offices. Oxford [England]; Boston: Butterworth Architecture in association with Estates Gazette.

22. Duffy, F., Jaunzens, D., Laing, A. and Willis, S. (1998), New environments for working: the re-design of offices and environmental systems for new ways of working, Construction Research Communication, London. 
23. Dul, J. , Ceylan, C. , \& Jaspers, F. (2011). Knowledge workers' creativity and the role of the physical work environment. Human Resource Management, 50(6), 715-734

24. Edward T. Hall, https://en.wikipedia.org/wiki/Edward T. Hall\#/media/File:Edward T. Hall 1966.j pg

25. European Commission (2010). European Competitiveness Report 2010 Commission Staff Working Document. Brussels: European Commission.

26. European Commission (2014 a). European Competitiveness Report 2014 Commission Staff Working Document. Brussels: European Commission.

27. European Commission (2014 b). The EU ICT Sector and its R\&D Performance 2014. Brussels: European Commission.

28. European Concerted Action (1989) Report No. 4, Sick Building Syndrome, A Practical Guide, Commisions Of The European Communities

29. Eurostat, 2015, Innovation Statistics, http://ec.europa.eu/eurostat/statisticsexplained/index.php/Innovation_statistics

30. Evolution of work timeline from D. Pink "A Whole New Mind" http://enviableworkplace.com/creating-collaboration-in-the-workplace/

31. Feige, A. , Wallbaum, H. , Janser, M. , \& Windlinger, L. (2013). Impact of sustainable office buildings on occupant's comfort and productivity. Journal of Corporate Real Estate,15(1), 7-34.

32. Florida, R. (2012). The Rise of the Creative Class, Revisited. New York: Basic Books.

33. GBES (Green Building Education Services) (2014), LEED Exam Preparation Study Guide LEED v4 Edition, GBES

34. Gensler, (2013), 2013 U.S. Workplace Survey, Gensler

35. Greene, C., \& Myerson, J. (2011). Space for thought: Designing for knowledge workers.Facilities, 29(1/2), 19-30. 
36. Groves, K. (2011), Creating Collaboration in the Workplace, http://enviableworkplace.com/creating-collaboration-in-the-workplace/

37. Hall, E. (1966). The Hidden Dimension. Garden City, N.Y: Doubleday.

38. Habraken N. J., Gross M. D. (1988) Concept Design Games, School of Architecture and Planning, MIT, Cambridge, Mass. 02139 US, Design Studies 9/3, 150-158

39. Haworth, (2015) How to Create a Successful Organizational Culture: Build ItLiterally, Haworth

40. Herman Miller, Cube Farm, http://www.wired.com/2014/04/how-officesaccidentally-became-hellish-cubicle-farms/\#slide-4

41. Herman Miller, Action Office I, http://www.wired.com/2014/04/how-officesaccidentally-became-hellish-cubicle-farms/\#slide-1

42. Herman Miller, Action Office II, http://www.wired.com/2014/04/how-officesaccidentally-became-hellish-cubicle-farms/\#slide-3

43. Jacobs, S. (2013) Offices designed as fun palaces are fundamentally sinister, http://www.dezeen.com/2013/02/28/opinion-samjacob-fun-office-design-sinister/

44. Lemelson-MIT Programme (2005), 2005 Invention Indexe: Daily Commute Could Lead to the Next Great Invention, Lemelson-MIT Programme, School of Engineering, MIT, Cambridge, MA.

45. Leslie, D. (2005). Creative cities?. Geoforum,36(4), 403-405

46. Lynch, P. (2016), This Kickstarter Campaign Hopes to Fund a Coworking Space Specifically for Architects, ArchDaily, http://www.archdaily.com/782697/this-bigoakland-kickstarter-campaign-hopes-to-fund-a-coworking-space-specifically-forarchitects

47. Martens, Y. (2011), Creative workplace: instrumental and symbolic support for creativity, Facilities, Vol. 29 Iss 1/2 pp. 63 - 79

48. Martin, R. , \& Moldoveanu, M. (2003). Capital versus talent - the battle that's 
reshaping business. Harvard Business Review, 81(7), 36

49. Megill, Kenneth A. (2005) Thinking for a Living: The Coming Age of Knowledge Work. Berlin, DEU: K. G. Saur

50. Mobile Communication and Society: A Global Perspective : A Project of the Annenberg Research Network on International Communication. (2007). Cambridge, Mass.: MIT Press.

51. Myerson, J., Bichard, J. , Erlich, A. (2010).New Demographics, New Workspace: Office Design for the Changing Workforce. Farnham, Surrey, England ; Burlington, Vt.: Gower.

52. Nadler, R. (2014). Plug\&Play Places: Lifeworlds of Multilocal Creative Knowledge Workers. Warsaw, [Poland] ; Berlin, [Germany]: De Gruyter Open

53. OECD (2007), Innovation And Growth. Rationale For An Innovation Strategy, OECD

54. OECD (2013) (a) New Sources Of Growth: Knowledge-Based Capital - Key Analyses And Policy Conclusions - Synthesis Report, OECD

55. OECD (2013) (b) Science, Technology and Industry Scoreboard 2013, OECD

56. OECD (2015), Research And Development Statistics (RDS), OECD, http://www.oecd.org/innovation/inno/researchanddevelopmentstatisticsrds.htm

57. On the Job: Design and the American Office. (2000). New York: Princeton Architectural Press

58. Parsons, T. (2001) 'Headspace: Privacy in Open Plan Offices', Royal College of Art. http://www.hhc.rca.ac.uk/archive/hhrc/programmes/ra/2001/tim.html, accessed August 2009.

59. Pink, D.H. (2005) A Whole New Mind, Riverhead Books

60. Pyöriä, P. (2005). The concept of knowledge work revisited. Journal of Knowledge Management, 9(3), 116-127.

61. Rasmus, D.W, Salkowitz, R. (2008), Listening To The Future, Hoboken, NJ: John Wiley \& Sons. 
62. Rasmus, D. (2010). Management by Design: Applying Design Principles to the Work Experience. Hoboken, N.J.: Wiley

63. Richard Florida, http://www.mckinsey.com/global-themes/urbanization/buildingthe-creative-economy-an-interview-with-richard-florida

64. Ross, A. (2008). The new geography of work: Power to the precarious? Theory, Culture \& Society, 25(7-8), 31-49.

65. Sanders, E.B.-N., 2006. Nurse and patient participatory workshops for the NBBJ project. Inpatient tower expansion for $\mathrm{H}$. Lee Moffitt Cancer Center and Research Institute, Tampa, FL, USA.

66. Sanders E. B.-N., Stappers P. J. (2008) Co-creation and the new landscapes of design, CoDesign, 4:1, 5-18, DOI: 10.1080/15710880701875068

67. Sassen, S. (2007). Sociology of Globalization. New York: W.W. Norton.

68. Saval, N. (2014), Cubed: A Secret History of the Workplace, Knopf Doubleday Publishing Group.

69. Sawyer, R.K. (2003), Creativity and Development, Oxford University Press, New York, NY.

70. Sikiaridi, E., Vogelaar, F. (2012), Hybrid Space Lab and Networked Participatory Design Systems, world-architects e Magazine, http://www.worldarchitects.com/en/pages/hybrid-space-lab

71. Steinbicker, J. (2001). Zur Theorie der Informationsgesellschaft: Ein Vergleich der Ansätze von Peter Drucker, Daniel Bell und Manuel Castells. Opladen: Leske+Budrich.

72. Sternberg, R.J. (Ed.) (1999), Handbook of Creativity, Cambridge University Press, New York, NY.

73. The World Bank, 2014, Research And Development Expenditures (\% of GDP), http://data.worldbank.org/indicator/GB.XPD.RSDV.GD.ZS

74. Towers, W. (2012), The 2011/2012 Talent Management and Rewards Study, North America, http://www.towerswatson.com/en-US/Insights/IC-Types/Survey- 
Research-Results/2011/10/2011-Global-Talent-Management-and-Rewards-Study

75. United Nations (2013), Creative Economy Report, United Nations Development Programme (UNDP), One United Nations Plaza, New York, NY 10017, USA

76. Vaajakallio, K. , \& Mattelmaki, T. (2014). Design games in codesign: As a tool, a mindset and a structure. Codesign-international Journal of Cocreation in Design and the Arts, 10(1), 63-77.

77. Wallas, G. (1926), The art of thought, in Vernon P.E. (Ed.) (1970), Creativity, Penguin Books, Harmondsworth.

78. Watson Wyatt Worldwide, 2010, Staying@Work Report, Watson Wyatt Worldwide

79. Wikimedia Commons/National Park Service, Jason Wax Building by Frank Lloyd Wright, at S. C. Johnson \& Son in Racine, Wisconsin, US, 1936 to 1939

80. Whyte, W. (1956). The Organization Man. Philadelphia: University of Pennsylvania Press.

81. Zukin, S. (1995). The Cultures of Cities. Cambridge, MA: Blackwell. 